\title{
PLASMA DESTRUCTION OF NORTH CAROLINA'S HAZARDOUS WASTE BASED OF HAZARDOUS WASTE GENERATED BETWEEN THE YEARS OF 1989 AND 1992
}

by

DWIGHT LeROI WILLIAMS

A thesis submitted to the Graduate Faculty of

North Carolina State University

in partial Fulfillment of the

requirements for the Degree of

Master of Science

NUCLEAR ENGINEERING

Raleigh

1994

\section{APPROVED BY:}
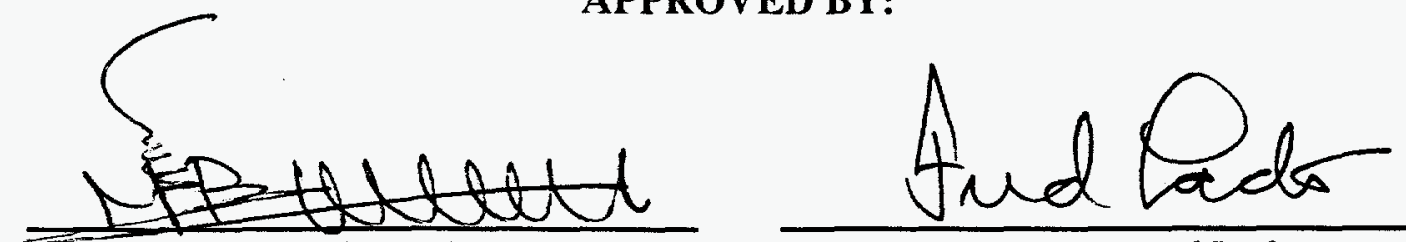

Dr. Mohamad Bourham

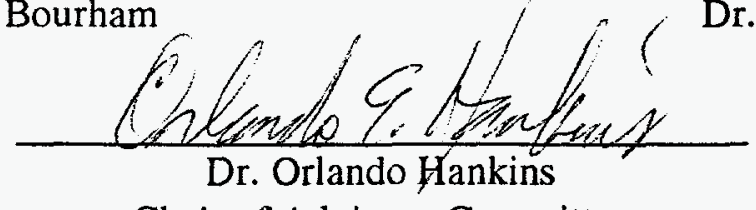

Dr. Orlando Hankins

Chair of Advisory Committee 


\section{DISCLAIMER}

Portions of this document may be illegible electronic image products. Images are produced from the best available original document. 


\begin{abstract}
WILLIAMS, DWIGHT LeROI. Plasma Destruction of North Carolina's Hazardous Waste Based on Hazardous Waste Generated Between the Years of 1989 and 1992. (Under the direction of Dr. Orlando Hankins.)
\end{abstract}

The purpose of this research is to analyze the applicablilty of the plasma waste destruction technology to North Carolina hazardous waste streams. This study outlines the current regulations, existing technologies, and innovative technologies being considered as hazardous waste treatment alternatives. From this foundation, the study proceeds to identify the superiority of the plasma waste destruction technology. Specific areas of discussion include: temperature capabilities, waste residence time requirements, destruction removal efficiencies, operational efficiencies, economic issues, safety, and maintenance. This study finds the plasma destruction technology to be fully effective and superior to conventional facilities. The technology completely destroys hydrocarbons and can reduce the volume of many other hazardous wastes on the order of one part per million. The required residence time of waste in a plasma facility for effective destruction is a fraction of a second, while the rotary kiln incinerator maintains an average residence time of approximately 5 seconds. Also mass and heat balance calculations are performed to quantify the effectiveness and efficiency of this technology. It is found that one day's average amount of hazardous waste generated in the state of North Carolina can be destroyed in approximately thirty seconds using a standard one megawatt power source. Yet, before this technology is adopted as North Carolina's primary hazardous waste destruction technology, further study is needed so that all issues considered in this research can be conducted in great detail.

\title{
DISCLAIMER
}


I dedicate this thesis to my Lord, Jesus Christ, whose continued encouragement and guidance facilitated my completion of my Master of Science Degree. 


\section{BIOGRAPHY}

Dwight LeRoi Williams is originally from Washington, DC and currently resides in Silver Spring, Maryland. Dwight has attended North Carolina State University for the past six years where he earned his Bachelor of Science Degree in Nuclear Engineering in 1992 and expects to receive his Master of Science Degree in Nuclear Engineering in 1994.

Dwight is a recognized academian -- the recipient of a U.S. Department of Energy Environmental Restoration and Waste Management Graduate Employment Program Fellowship in 1992. Also, Dwight has been recognized by the North Carolina Board of Surveyors as an Engineer in Training.

While at North Carolina State, Dwight has participated in numerous extra curricular activities. He was a dynamic leader as he served as a squad leader in the Navy Reserve Officers Training Corps (ROTC), and as he served in his local church as a Sunday school teacher, an Executive Board Member, a Bible study leader, and a counselor. Also, Dwight was an active athlete. He participated on North Carolina State University's varsity track team as a decathlete. In addition, he played intramural sports including swimming and basketball. Moreover, Dwight enjoyed serving others. This trait was manifested through his participation in the Peer Mentor Program, and his assistance of fellow students as a volunteer tutor.

Dwight considers himself to be a deeply religious man and believes that the verse 1 Corinthians 15:10 in the Bible, applies to him. The verse reads: By God's grace I am what I am, and His grace toward me was not in vain because I worked harder than everyone else; yet it was not me doing the work, but it was God's grace which was with me. 


\section{ACKNOWLEDGMENTS}

Many persons contributed to my successful completion of my Master of Science Degree and I shall recognize the efforts of those most supportive to me. I thank the U. S. Department of Energy (DOE) for their sponsorship of this research through the Environmental Restoration and Waste Management Undergraduate/Graduate Employment Program which is administered by the Oak Ridge Institute for Science and Education (ORISE) for DOE. I appreciate the numerous hours of effort put forth by Bridget Jones and Tom Richmond of ORISE as they advised me regarding my ORISE fellowship. Next, I acknowledge my advisors: Dr. Orlando Hankins, Dr. Mohamed Bourham, and Dr. Fred Lado. I especially recognize the patience and effort of Dr. Hankins who implemented many innovative methods to motivate me to speedily complete my research. I thank the Plasma Energy Corporation (PEC) for making their equipment available to me and for their valuable information which greatly assisted me in my research. Also, I offer my sincere gratitude to my entire family for their consistent support. A very special thanks goes to my father, Leroy Williams, and my grandmothers, Emily Bullock and Elzado Williams, for their effective prayers; and to my mother, Sharon Musa, who's labor, financial support, concern, and faithfulness have been greatly valued. In addition, I recognize the efforts of all persons who contributed in any way to my success. To all persons, I say thank you and I do appreciate the support you have generously given me. 


\section{TABLE OF CONTENTS}

LIST OF TABLES vii

LIST OF FIGURES viii

1.0. Introduction and Problem Statement 1

2.0. Hazardous Waste Definition 2

3.0. Hazardous Waste Regulations 3

4.0. North Carolina Hazardous Waste Description 5

$\begin{array}{ll}\text { 5.0. Thermal Destruction Requirements } & 7\end{array}$

6.0. Conventional Technologies for North Carolina Waste Disposal 10

6.1. Rotary Kiln Incinerator 10

6.2. Commercial Package Boiler $\quad \cdot 11$

7.0. Competing Innovative Technologies for North Carolina Waste Disposal 13

7.1. Liquid Injection Incinerator $\quad 13$

7.2. Fluidized Bed Incinerator $\quad 14$

7.3. Molten Salt Incinerator 16

8.0. Plasma Destruction of North Carolina Hazardous Waste 17

8.1. Introduction to Plasma Destruction 17

8.2. Plasma Torches 18

8.3. Plasma Confinement 22

8.4. Heat Transfer 24

8.5. Plasma Gases 27 


\section{TABLE OF CONTENTS (continued)}

Page

9.0. Evaluation and Discussion $\quad 30$

9.1. Mass Balance and Heat Balance 30

9.1.1. D002 Analysis 31

9.1.1.1. Mass Balance for D002 31

9.1.1.2. Heat Balance for D002 34

9.1.1.3. Practical Applications of D002 Findings 39

9.1.2. K083 Analysis $\quad 42$

9.1.2.1. Mass Balance for K083 $\quad 42$

9.1.2.2. Heat Balance for K083 43

9.1.2.3. Practical Applications of K083 Findings 45

9.2. Trends Observed Varying Destruction Temperature with Respect to Time 46

9.3. Radicals Generated 48

9.4. Comparison of Plasma Destruction with Conventional Destruction . $\quad 52$

9.4.1. Residence Times and Waste Throughput 52

9.4.2. DRE

9.4.3. Effiencies $\quad 55$

9.4.4. Maintenance 56

9.4.5. Costs $\quad 58$

9.4.6. Safety 60

9.5. Regulations Met $\quad 61$

10.0. Additional Considerations 63

10.1. Future Considerations $\quad 63$

10.1.1. Medical Wastes $\quad 63$

10.1.2. Mixed Wastes 66

10.1.2.1. General Considerations 66

10.1.2.2. Uranium Hexaflouride Considerations 68

$\begin{array}{ll}\text { 10.2. Needs } & 69\end{array}$

$\begin{array}{ll}\text { 11.0. Conclusions } & 71\end{array}$

$\begin{array}{ll}\text { 12.0. Appendices } & 73\end{array}$

12.1. Appendix 1: Chemical Constituent Selection for Analysis 73

12.2. Appendix 2: Volume Calculations $\quad 77$

12.4. Appendix 4: Plots of Temperature vs. Time Data 88

$\begin{array}{ll}\text { REFERENCES } & 116\end{array}$ 


\section{LIST OF TABLES}

Page

Table 4.1 . Average Volumes of North Carolina Waste (1989 - 1992)

6

Table 9.1 Formula Weights of Compounds Studied in Mass and Energy

Balances

Table 9.2 Energy Balance Constants

Table 9.3 Temperature Required for Set DRE at Two Seconds

Table A1.1 Chemicals Investigated

Table A1.2 Metals Eliminated from Study

Table A2.1 Average Masses of North Carolina Wastes

Table A2.2 Compounds within EPA Code Groups Analyzed In Study

Table A2.3 Physical Properties of Compounds Considered

Table A2.4 Itemized List of Fractional Volumes within Each EPA Code Group 


\section{LIST OF FIGURES}

Page

Figure 8.1 Plasma Torch in Transferred and Non-transferred Arc Mode

Figure 8.2 Axial View of Cusp Confinement of Plasma Discharge

24

Figure 8.3a Cylindrical Approximation

27

Figure 8.3b Jet Impingement Approximation

27 


\subsection{INTRODUCTION}

North Carolina generates thousands of tons of hazardous waste every year as defined by the North Carolina Department of Environment, Health, and Natural Resources (Cobey, Howes). The hazardous waste is treated, disposed, or stored depending on its qualities and amounts. Some hazardous waste disposal solutions are wiser than others because of their efficiencies or their overall effectivenesses. One of the consistently effective mechanisms for hazardous waste disposal is thermal destruction.

Thermal destruction, also called thermal treatment, requires that the hazardous waste be subjected to very high heat for a period of time. The heat causes the waste to be reduced to its atomic and ionic constituents from the original molecular composition. Under correct conditions, the recombination of the resulting atoms and ions can be biased to produce generally innocuous compositions.

There exist many thermal destruction techniques and many innovative technologies are currently being developed. One of the more technologically advanced methods for hazardous waste treatment is plasma destruction. Plasma thermal destruction utilizes the extremely high temperature of a plasma to destroy wastes.

This study accomplishes the following objectives:

- It outlines the hazardous waste disposal needs of North Carolina based on four years of North Carolina hazardous waste data.

- It addresses the applicability of plasma thermal destruction as a mechanism to meet the waste disposal needs of North Carolina's hazardous waste.

- It discusses the feasibility of the plasma incineration technology as North Carolina's chief hazardous waste disposal mechanism. This requires a detailed study of the thermal treatment facility's temperatures, waste residence times, and destruction removal efficiencies (DREs). Also considered are the regulations met, cost of operation, resultant 
wastes and their volumes, and safety along with a comparison between a plasma thermal treatment facility and other waste destruction technologies.

- It investigates the future potential applications of a plasma waste destruction facility concerning North Carolina's waste disposal needs.

\subsection{HAZARDOUS WASTE DEFINITION}

North Carolina statute defines hazardous waste as "a solid waste or combination of solid wastes which, because of its quantity, concentration, or physical/chemical characteristics may:

- cause or significantly contribute to an increase in mortality, irreversible or incapacitating illness; or

- pose a substantial present or potential hazard to human health or the environment when improperly treated, stored, transported, or disposed of, or otherwise managed." (Cobey, Howes)

Although the definition specifies solid waste, the label "hazardous waste" may be accurately applied to include solids, sludges, liquids, or contained gases that are ignitable, corrosive, toxic, or reactive. The two ways a waste may enter the hazardous waste regulatory system is by identification through characteristics and by listing.

Characteristic Wastes:

A waste is hazardous if it exhibits at least one of the following characteristics: ignitablilty, corrosivity, toxicity, or reactivity. Ignitable wastes are flammable under certain conditions. Examples include wastes that readily catch fire and friction sensitive substances such as acetone and industrial alcohols. Corrosive wastes are those that can corrode metal and burn the skin. Examples include battery acid, rust removers and 
acid cleaners. Toxic wastes are either harmful or fatal when absorbed or ingested. A laboratory procedure called the Toxicity Characteristics Leaching Procedure (TCLP) identifies toxicity. Examples are wastes containing high concentrations of heavy metals. Wastes such as lead-based paint, mercury batteries, and specific pesticides are all toxic. Reactive wastes are not stable under normal conditions. They may create explosions and, or toxic vapors, fumes, and gases when mixed with water. Cyanide plating wastes and bleaches are examples of toxic wastes.

Listed hazardous wastes exhibit at least one of the qualities of characteristic wastes or contain toxic portions that have been shown to be harmful to the environment and, or human health. More than 400 hazardous wastes are "listed". These wastes include manufacturing process by-products and discarded commercial chemical products. Listed wastes are considered to have a greater inherent danger that characteristic wastes and are presumed hazardous independent of their concentrations and must be handled according to hazardous waste regulations.

Not all wastes potentially harmful to the ènvironment and, or humans are regulated as hazardous wastes. One example is polychlorinated biphenyls (PCBs) which are regulated under the Toxic Substance Control Act (TSCA). Infectious medical wastes and asbestos wastes are regulated as non-hazardous solid wastes (Briggum, HMIC).

\subsection{HAZARDOUS WASTE REGULATIONS}

Hazardous waste is primarily regulated by the federal government although state governments may impose stricter regulations if they desire. The two main regulatory mechanisms for the identification and control of hazardous wastes are the Resource Conservation and Recovery Act (RCRA) and the Toxic Substances Control Act (TSCA). 
RCRA both defines hazardous wastes and describes the methods for the control of these wastes; while TSCA governs the amounts of PCBs in the environment, as stated previously.

Both RCRA and TSCA regulations require that all individuals involved in the hazardous waste process (generators, transporters, depositories, treatment facilities, and ultimate repositories) obtain permits. The RCRA permit is more universal than the one required by TSCA and may be issued by either the federal or state governments. The only agency with authority to issue a TSCA permit is the federal Environmental Protection Agency (EPA). In the future, the TSCA requirements and permitting authority will be included within RCRA requirements. Currently, however, TSCA requirements must be met when a waste contains at least a $50 \mathrm{ppm}$ by weight of PCB component. All other hazardous wastes must meet RCRA requirements (Briggum, HMIC, Wagner). 


\subsection{NORTH CAROLINA HAZARDOUS WASTE DESCRIPTION}

An average of 71.0 thousand metric tons of hazardous waste was generated in North Carolina between 1989 and 1992. This waste was produced by the state's 702 generators within the state's 82 counties. A general description of the hazardous wastes produced in North Carolina is presented below. A more specific description of North Carolina's hazardous waste is given in Appendix 2.

The various types of hazardous wastes are identified by four character EPA waste numbers that correspond to a hazardous characteristic or a reason for listing. Wastes exhibiting one of the four hazardous characteristics have numbers beginning with the letter " $\mathrm{D}$ " and followed by three numbers to identify which characteristic is present. For example, corrosive wastes have the code "D002".

Listed wastes are classified according to their sources. The "F" series of waste numbers correspond to wastes from non-specific sources. The "K" series represents wastes from specific sources. The "P" and " $U$ " series identify wastes from discarded commercial and chemical products. In the case when wastes have a variety of potential classifications, they are generally recorded as identified by the first generator.

The percentages of each EPA classification of hazardous waste generated in North Carolina are as follows. The largest quantity of waste generated was in the D category, totaling twenty thousand cubic meters (41 percent) of waste. The F series was next with seventeen thousand cubic meters (30 percent) generated. The $\mathrm{K}$ series followed with ten thousand cubic meters (23 percent); while the $P, U$, and Lab Pack series generated two thousand cubic meters ( 6 percent). Table 4.1 lists the average waste volumes of wastes generated in North Carolina by EPA code numbers (Cobey, Howes). 
Table 4.1: Average Volumes of North Carolina Waste (1989-1992)

EPA Code Description

Volume $\left(\mathrm{m}^{3}\right)$

D001 Ignitable

15133.96

D002 Corrosive

2 514. 19

D003 Reactive

1728.74

D018 Benzene

555. 21

TOTAL D

19 932. 10

F001 Spent Halogenated Degreasing Solvents

1231.67

F002

Halogenated Solvents

1271.60

F003

Spent Non-halogenated and Toxic Solvents

5 459. 42

F005

Spent Non-halogenated Solvents

9 432. 09

TOTAL F

$17 \quad 394.78$

K001 Wastewater Treatment Sludge from Wood

Preserving Processes

8 037. 87

K083 Distillation Bottoms from Aniline Production

2216.26

TOTAL K

$10 \quad 254 . \quad 13$

U060

1-1-(2,2-Dichloroethylidene)bis[4-Chlorobenzene]; "DDD" 945. 79

U061 1-1-(2,2,2-Trichloroethylidene)bis[4-Chlorobenzene]; "DDT" 495. 28

U159

Methyl Ethyl Ketone; "Butanone"

960. 64

TOTAL $P, U, L A B$ PACK

2401.71

TOTAL WASTE

$49 \quad 982.72$ 


\subsection{THERMAL DESTRUCTION REQUIREMENTS}

There exist specific requirements that a thermal destruction facility must meet before it is capable of commercially treating hazardous wastes. These requirements involve the designed residence times of waste in the facility, the burn temperatures of the facility, etc. The requirements are crucial for consistently safe and effective waste destruction. For most hazardous wastes, incomplete destruction results in materials of equal or greater hazard than the original wastes. PCBs (polychlorinated biphenyls), for example, are converted to PCDDs (polychlorodibenzo-p-dioxins) and PCDFs (polychlorinated dibenzofurans) upon incomplete destruction. Both PCDDs and PCDFs are as hazardous as PCBs; moreover, both are more difficult to destroy than PCBs. Therefore, the materials that are generated as a result of improper thermal treatment are likely to nullify or decrease the benefit of having been thermally treated at all. The established thermal destruction facility requirements minimize the possibility of such improper thermal destruction occurring.

If a hazardous waste is classified as such specifically because it has characteristics of corrosivity or ignitability, or if the waste will be recycled or used for heat recovery, its incineration need not comply with hazardous waste incineration criteria. Also, certain waste which are hazardous only because they are reactive may not have to comply with the criteria.

The regulatory criteria require that a trial burn be conducted on the principal organic hazardous constituent (POHC). An extensive list of POHCs exist. If multiple compounds from the POHC list are present in the waste stream, the selection of the POHC is a matter of judgment according to the difficulty of incineration and the amount of the compound present. More than one compound within a waste stream may be designated as POHCs. Ultimately, the permit writer, which is the EPA or designated state 
agency, makes the final determination of the compounds designated as POHCs. One possible method for determining the $\mathrm{POHC}(\mathrm{s})$ is described later in this section.

The trial burn is one of four phases in the permit process. Permitting provides for a one month preparatory phase prior to the test burn. The trial burn is the second step of the permitting process. The third permitting phase allows for limited operation while the results of the trial burn are being analyzed. The fourth phase is the permanent operation phase. The permit requirements include the following:

- The generator must identify all of the listed POHCs present so the regulatory agency will be able to select the POHCs to be considered.

- The incinerator must achieve a destruction and removal efficiency (DRE) of at least 99.99 percent (four nines destruction). The DRE is defined using $W_{\text {in }}$ and $W_{\text {out }}$ (the inlet and outlet mass flow rates, respectively) as follows:

$$
\mathrm{DRE}=\left(\mathrm{W}_{\mathrm{in}}-\mathrm{W}_{\text {out }}\right) * 100 / \mathrm{W}_{\text {in }}
$$

- Continuous monitoring of the combustion temperature, combustion gas flow rate, and waste feed rate are required.

If no test data exists for a particular waste, the initial design may assume the following criteria as a reasonable estimate of combustion:

- For a non-halogenated hazardous waste, the combustion chamber temperature must be $1000{ }^{\circ} \mathrm{C}$ and the residence time must be at least two seconds.

- For a halogenated waste, one which contains more than 0.5 percent chlorine, the combustion chamber temperature must be $1200{ }^{\circ} \mathrm{C}$ with a residence time of at least two seconds.

These criteria are not stated in RCRA nor in any other federal statutory requirements. They are only offered as recommended criteria that can be used when no other data is available. 
TSCA, the PCBs regulator, does not require that wastes containing less the 50 ppm PCBs be controlled. Wastes containing over 50 ppm PCBs must be handled, stored, treated, and disposed of in compliance with TSCA. All wastes with a more than $500 \mathrm{ppm}$ PCB content must be thermally treated according to TCSA. For wastes containing between 50 and $500 \mathrm{ppm}$ PCBs, thermal destruction or other methods of disposal may be applied. PCB thermal destruction must meet the following criteria:

- The destruction temperature must be $1200{ }^{\circ} \mathrm{C}$, with a retention time of two seconds in a destruction environment of 3 percent oxygen. Otherwise, a temperature of $1600{ }^{\circ} \mathrm{C}$ coupled with a one and one-half second retention time is required in a 2 percent oxygen environment.

- The PCB feed rate must be monitored at least every fifteen minutes.

- The destruction temperature must be continuously monitored.

- PCB flow shall automatically cease if there is a temperature drop below the required thermal treatment temperature, an oxygen content drop below the specified value, or a failure in any monitoring system.

- If the PCBs to be destroyed are nonliquid, then a DRE of six nines (1 ppm, or 99.9999\%) is required (Brunner, HMIC, Wagner) 


\subsection{CONVENTIONAL TECHNOLOGIES FOR NORTH CAROLINA WASTE DIS- POSAL}

Between the years of 1989 and 1992, twenty-two percent of North Carolina's hazardous waste was thermally treated. The main established waste destruction technologies include the rotary kiln incinerator and the commercial package boiler. These thermal destruction facilities are discussed below.

\subsection{Rotary Kiln Incinerator:}

The rotary kiln incinerator can be used to destroy a wide variety of solid, sludge, liquid, and gaseous wastes, making it the most nearly universal waste disposal technology. This incinerator is a refractory lined cylinder situated such that its central axis is at a slight incline from the horizontal. The rotary kiln incinerator has a length to diameter ratio which ranges between two and ten; a rotational speed ranging between one and five feet per minute (measured along the kiln's outer edge); a maximum operating temperature of $1650^{\circ} \mathrm{C}$ although typical operating temperatures are lower; and a residence time that varies from on the order of seconds to the order of hours. The average residence time if a rotary kiln is approximately 5 seconds. The kiln controls the waste residence time and the mixing of wastes with combustor air through its speed of rotation. The system is designed to maintain a negative pressure in the kiln to ensure that emissions at the end seals of the rotating section are minimized (Brunner).

Rotary kiln incinerators are unique because they are designed to allow a portion of their waste load to be charged in batch rather than continuous mode. In the batch mode operation, solid wastes and contained liquid wastes are introduced through entrance chutes, typically concurrent with the gas flow. Bed motion resulting from kiln angle and speed of rotation continuously exposes fresh surface for oxidation, determines 
the residence times of non-combustible materials, and provides for continuous ash removal. When the liquid waste container (typically a cardboard, plastic, or steel drum) enters the incinerator, it ruptures or burns, exposing the contents to the hot kiln environment. The liquid then quickly vaporizes and reacts with the excess oxygen present in the combustion gases from the continuous primary flame. A possible kiln failure may occur when the evolution of waste gases from the ruptured container is more rapid than the rate at which the stoichiometric amount of oxygen can be supplied by the combustion gases from the primary flame. This overcharging condition, unique to batch mode systems, can lead to a volume of incompletely destroyed organic material which must subsequently be destroyed in the afterburner. Under circumstances when the afterburner is unable to destroy the quantity of the organic material being released, this volume leads to a system failure.

Typically, the kiln and the afterburner are equipped with an auxiliary fuel firing system which bring the units to the required operating temperatures. The auxiliary system may consist of two sets of burners - one for the fuel and the other for liquid wastes, or dual-liquid burners designed to accommodate combined fuel and waste firing. Once the desired operating temperature is reached, the fuel flow is gradually turned off so that only the liquid waste is burned by the auxiliary firing system. The firing of liquid wastes may be designed to occur at either the feed or the discharge end of the rotary kiln (Freeman, Hall, Palmark).

\subsection{Commercial Package Boiler:}

At one time, co-firing or co-combustion of hazardous waste with conventional fuels in industrial boilers was widely practiced in the U.S. Because of the use of 
waste with a high heating value as a fuel represented an attractive energy recovery option, it had historically been exempted from RCRA controls. This situation changed in 1991 when new regulations for burning hazardous waste in boilers and industrial furnaces (BIFs) became effective.

Environmentally, thermal destruction of hazardous waste is preferable to landfilling of these compounds if the destruction is effective. But a sufficient data base indicating successful destruction is necessary. Also, hazardous materials may be destroyed on site thus eliminating the major problems of transportation and storage. These hazardous waste compounds must be destroyed in the furnace or boiler with the same effectiveness as required for a standard thermal destruction facility. Therefore, the thermal destruction requirement of $99.99 \%$ DRE becomes a standard of comparison for boilers and furnaces. The boiler's burner can fire gas or any type of fuel oil, singly of in combination.

Many conclusions may be drawn from the system's performance. The system's performance shows that when the liquid fuel is not fully atomized then the hazardous waste DRE drops to $99.9 \%$, even in excess air. Also, as the DRE increases, the level of $\mathrm{NO}_{\mathrm{X}}$ emissions increases and the $\mathrm{CO}$ emissions decrease. A discussion of $\mathrm{NO}_{\mathrm{X}}$ is included in section 7.2. Thirdly, transient waste flow rates are found to lower the DRE to less than $99.99 \%$. Moreover, numerous PIDs are found in the destroyed waste, indicating that $99.99 \%$ DRE may be an incomplete criterion for adequate waste destruction. On the other hand, a benefit of this system is that transient firing conditions does not affect the $99.99 \%$ DRE.

Therefore, although this system is currently operational, the concept proves to be a poor technology. The excessive monitors that are necessary coupled with the consistent down time for maintenance make this technology both expensive and ineffi- 
cient. Also because of $i$ ts numerous possibilities for shortcomings, this system is generally not as safe than other technologies (Hall).

\subsection{COMPETING INNOVATIVE TECHNOLOGIES FOR NORTH CAROLINA WASTE DISPOSAL}

Plasma thermal treatment is one of the most promising novel waste destruction technologies. It must be realized that it is only one of many available innovative waste destruction technologies. Some of the innovative waste destruction technologies in addition to plasma thermal treatment facilities include the liquid injection incinerators, the fluidized bed incinerators, and the molten salt incinerators. These incinerators are discussed below.

\subsection{Liquid Injection Incinerator:}

The liquid injection incinerator utilizes at least one refractory lined combustion chamber in addition to numerous atomizing nozzles. This incinerator is able to destroy nearly all pumpable wastes. The wastes are typically blended in tanks before the atomization process to stimulate their combustibility or pumpability. Afterwards, the wastes are atomized in this blended condition. The usual combustion chamber residence times range between one-half to two seconds, and the residence temperatures vary be-

tween 700 and $1650^{\circ} \mathrm{C}$. Although this incinerator is often used as a primary combustion mechanism, it may also be used as an afterburner to complete the combustion of waste emissions from other thermal destruction facilities.

The liquid injection incinerator is popular because it has the capacity to thermally treat a wide variety of hazardous wastes. In addition, its few moving parts aids in minimizing maintenance costs. However, this incinerator only burns fluids and may ex- 
perience interruptions in operation because of clogged nozzles. Also, the liquid injection incinerator is usually purposed to destroy specific types of waste; therefore, it is not readily used as a multipurpose facility.

This incinerator has successfully demonstrated the ability to incinerate numerous hazardous wastes. Some of the wastes destroyed include PCBs, phenols, solvents, polymer wastes, still bottoms, and pesticides. On the other hand, the incinerator is less capable of effectively burning inorganics, heavy metals, or wastes with a high moisture content (Lee).

\subsection{Fluidized Bed Incinerator:}

The fluidized bed incinerator utilizes fluidized bed combustion (FBC). For over a decade, FBC has been used for municipal sludge incineration and coal combustion. The fluidized bed incinerator offers unique capabilities concerning hazardous waste destruction. One of these features is that it simultaneously combusts and scrubs the materials in the bed.

The incinerator's major components include a bed for combustion, a plenum chamber or "windbox", and an air distributor. The bed is usually composed of sand or limestone.

A description of the incinerator operation follows. A chemical waste is injected into a fluidized bed combustor operating at $750{ }^{\circ} \mathrm{C}$. If necessary, a fuel oil is added as well. Air is forced up through the bed material. Its velocity is so high that the bed mixture behaves like a boiling liquid. Limestone is regularly added to the bed to replenish the limestone expended through reactions with combustion products. In addition, during the incinerator operation, fluidized bed material is systematically drained from the vessel to maintain the necessary fluidity and bed depth. 
The fluidized bed incinerator offers benefits in addition to the one listed above. Wastes can be combusted at lower temperatures because they are in direct contact with the heated bed particles. Also, the vessel temperatures are high enough to sufficiently destroy hazardous waste but low enough to prevent $\mathrm{NO}_{\mathbf{x}}$ formation.

Nitric oxide, NO, appears to be the dominant catalyst for smog generation. At high temperatures, $\mathrm{N}_{2}$ and $\mathrm{O}_{2}$ react to form a small quantity of $\mathrm{NO}$. The NO is oxidized in air generating $\mathrm{NO}_{2}$ which in turn absorbs electromagnetic energy and decomposes to nitric oxide and free oxygen atoms:

$$
\mathrm{NO}_{2}(\mathrm{~g})+\text { Energy ---------> } \mathrm{NO}(\mathrm{g})+\mathrm{O}(\mathrm{g})
$$

Oxygen atoms are very reactive and recombine with $\mathrm{O} 2$ to form ozone:

$$
\mathrm{O}(\mathrm{g})+\mathrm{O}_{2}(\mathrm{~g})
$$

Ozone is very reactive and will produce other pollutants It can react with unburned hydrocarbons to produce chemicals which are harmful to the human respiratory system and eyes. Therefore, the generation of of $\mathrm{NO}_{\mathrm{x}}$ compounds is not desired because of their unfavorable effects on humans.

Although the incinerator offers pleasant benefits, drawbacks exist also. The disposal of the sand and limestone is generally problematic because they are often considered to be hazardous materials by the time their removal and replacement is necessary. As the hazardous waste combustion proceeds, noncombustable ash accumulates in the fluidized bed. Removal of this noncombustable material poses a problem. If the bed's ash content is greater than twenty percent by weight, then defluidization may occur. Because of the large amounts of fine particulate matter captured within the exhaust gases, extensive pollution control devices are necessary. Accurate control of the combustion environment is necessary. This primarily ensures that the residence time in the bed will allow for complete combustion. The analysis of hazardous residues in the fluid 
bed required complex analytical models. The analysis is generally necessary to determine the quantity of unburned waste remaining in the residues (Dorin, Lee).

\subsection{Molten Salt Incinerator:}

Molten salt incineration is a method of destroying organic material while, at the same time scrubbing in-situ any objectional by-products of the destruction and thus preventing their emission in the effluent gas stream. The process of stimulating combustion and scrubbing is achieved by injecting the waste to be burned with air or oxygenenriched air under the surface of a pool of molten carbonate salts. The melt is maintained at temperatures near $900{ }^{\circ} \mathrm{C}$ which promotes the rapid oxidation of organic wastes. Halogen species, glass, and ash in the hazardous waste form halide and oxygenated salts. These by-products are retained in the melt as inorganic salts and are not released into the atmosphere as volatile gases.

The main advantage to the molten salt incinerator is that the molten material acts as a scrubber to capture the halogens released during the incineration of the waste material. This incinerator possesses the same general disadvantages as the fluidized bed incinerator. Also the molten salt incinerator will not incinerate dilute acidic wastes because rapid contact between the water and the salt may cause an explosion (Lee). 


\subsection{PLASMA DESTRUCTION OF NORTH CAROLINA'S HAZARDOUS WASTE}

\subsection{Introduction to plasma destruction:}

A plasma is defined as a collection of charged and neutral particles in which the particle's collective behavior is governed by the charged particle properties. The usual method of plasma generation is electrical discharge through a gas. Although the specific gas used is relatively unimportant in creating the discharge, it will ultimately affect the products formed. When the electrical energy passes through the gas, it is converted to thermal energy and is absorbed by gas molecules. The gas molecules are activated into ionized atomic states, losing electrons in the process. Arc temperatures above $10,000{ }^{\circ} \mathrm{C}$ may be achieved along the centerline of the recirculation vortex. Radiation is emitted when atoms or molecules relax from the highly activated states to lower energy levels.

When applied to waste disposal, the plasma can be best understood by thinking of it as an energy conversion and energy transfer device. As the energized components of the plasma decay, their energy is transferred to waste materials exposed to the plasma. Thus, this process atomizes, ionizes, pyrolizes, and finally destroys the wastes as they interact with the plasma species. The destruction of wastes will result in simple molecules or atoms such as hydrogen, carbon dioxide, and hydrochloric acid.

A plasma arc thermal treatment unit uses a DC-arc generated in a flowing gas between two electrodes. The torch may operate in one of two modes: transferred arc mode and non-transferred arc mode. The transferred arc mode requires that the slag be utilized as the positive electrode. Whereas, the non-transferred arc mode requires that both the negative and positive electrode be contained within the plasma generating device. Figure 8.1 (PEC) illustrates the transferred and non-transferred discharge modes. 
Energy is resistively dissipated in the arc in the form of light and heat as the electrical current travels through the gas between the electrodes.

The plasma destruction process effectively destroys organics and transforms them into a glassy waste form as a final product of the process. Plasma arc thermal treatment technology is characterized by high efficiency destruction of organics, maximum reduction of waste volumes, low off gas rates, and the capacity to process many waste types in a single process (Chen, Guyer).

\subsection{Plasma Torches:}

Various plasma torches offer applicability concerning the destruction of North Carolina's various hazardous wastes. Plasma destruction torches are constructed in different ways depending upon the desired application of the torch. Although many elements and alloys would serve as functional constituents of plasma electrodes, some materials are exceptionally less favorable than others. Steel is expensive and has poor heat transfer qualities. Refractories, highly temperature resistant elements and alloys, are expensive, are reactive with oxygen, and demonstrate poor material properties. Therefore, neither class of materials is commonly used as torch electrodes. The most commonly used materials for plasma torch electrodes are copper and graphite.

Both copper and graphite offer distinct advantages as plasma torch electrode materials. The main benefit of copper electrodes is their inexpensive cost. Copper is one of the least expensive metals on the market, is easily machineable, has good thermal and electrical conductivities, and exists in an abundance. Although the material properties of copper are not favorable for electrode requirements, adjustments within the incineration system can be made to enhance copper's usefulness. Two of copper's unsatisfactory properties are its softness and its low melting point. Both of these drawbacks can be 
quite detrimental if they are not addressed; but the simple adjustment of water cooling the electrodes minimizes both of the problems.

Graphite electrodes appear to have the greatest potential as plasma destruction electrodes. Graphite has the unique quality of sublimating at high temperatures instead of melting. This quality is outstanding for the purposes of thermal treatment technology because graphite's sublimation causes it to remain a sound solid material until its vaporization point. Therefore, waste destruction temperatures much higher than those achieved by conventional technologies may be safely attained and no cooling of the graphite electrodes is necessary. Also, as the sublimated graphite cools, it settles and solidifies onto surfaces. This means that the electrode deformation caused by sublimation can be remedied with no maintenance utilizing a temperature adjustment. The chief disadvantage of graphite electrodes is their reactivity with oxygen. Oxygen is acutely necessary for waste combustion. Since graphite reacts well with oxygen waste destruction must be accomplished in an oxygen starved environment which requires higher temperatures; however, necessary temperatures are safely achievable using graphite electrodes. In addition, oxygen starved waste destruction generates more free radicals which may improperly recombine.

The two main types of plasma thermal destruction torches are the reverse polarity plasma torch and the straight polarity plasma torch. Both torches possess the same external shell and similar configurations. The only physical difference between the torches is their material composition. A diagrammed cross section of a typical plasma torch is shown in Figure 8.1.

The reverse polarity plasma torch operates in both transferred arc and nontransferred arc modes. In the transferred arc mode the torch is operational between the range of $50 \mathrm{~kW}$ to $2000 \mathrm{~kW}$. The principal arc gases that are used are nitrogen, helium, 
argon, hydrogen, air, methane, and propane. The torch's functional nature utilizing methane and propane makes it especially suitable for meeting the North Carolina hazardous waste needs. Methane is a hazardous waste generated in North Carolina and propane is a by-product of propylene oxide destruction. Therefore, as these wastes are burned, they can support the plasma gas needs as well. Typically, this torch is used for waste pyrolysis but it appears that oxygen could be used as a plasma gas to allow combustion to occur.

The non-transferred operation of the reverse polarity torch possesses a power range of $50 \mathrm{~kW}$ to $1500 \mathrm{~kW}$. In general the arc gases used in this mode of operation are air, nitrogen, and oxygen. The use of oxygen as a plasma gas makes this torch suitable for waste combustion. This is necessary because otherwise this mode would be of little value to the incineration industry because combustion temperatures are lower than pyrolysis temperatures. This is why this mode is considered even with the abbreviated power range. One reason no inert gases are used as plasma gases is because of the ionization energies associated with them.

The straight polarity plasma torch operates between the range of $200 \mathrm{~kW}$ and $2000 \mathrm{~kW}$. The primary arc gases used with this torch are argon and nitrogen. Therefore, this system is useful for hazardous waste pyrolysis. Pyrolysis is waste destruction in the absence of oxygen; whereas, combustion specifically refers to waste destruction in an oxygen rich environment (PEC, Reynolds). 


\section{PLASMA ARC TORCH}

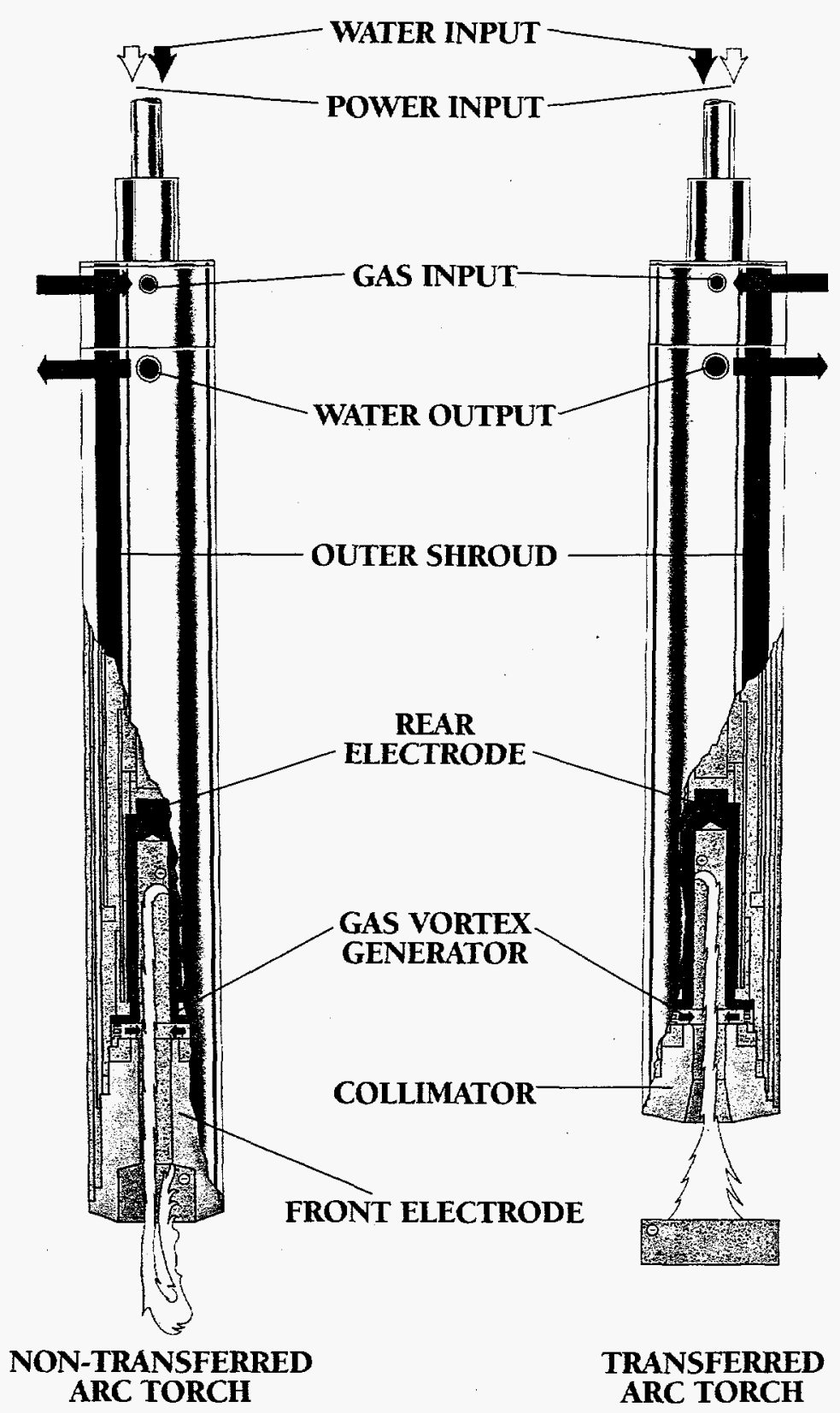

Figure 8.1. Plasma Torch in Transferred and Non-transferred Arc Mode 


\subsection{Plasma Confinement:}

Because a plasma is an electrical phenomenon, it is important to ensure that it remains fully under control while the plasma destruction system is in operation. As is common with electrical flow, a plasma arc desires to utilize the least resistive path from its origin to its destination. Since a plasma is a manipulation of an ionized gas, many extraneous ionized molecules and atoms exist that may provide a path of less resistance than the one desired. One mechanism available to increase the controllability of the plasma while minimizing the possibility for it to follow a less resistive path to the one expected is the use of a plasma nozzle.

The purpose of a plasma nozzle, also called a collimator, is to confine the plasma into a beam instead of allowing it to operate unrestricted as a spray. This objective presents an interesting paradox for a plasma destruction facility. While it is desirable to have the plasma arc focused for the purpose of control, it is also favorable to have the plasma operate as a spray to provide for a more even temperature distribution in the hearth and in the slag. The harm of either mission upon its counterpart is significant and must be addressed.

When plasma control is preferred over an even temperature distribution, the detrimental results are twofold. First, the intense, small volume heat source promotes extensive heat losses due to radiation into the furnace atmosphere, so less plasma energy is imparted to the slag than is desired. In addition, the small, superheated heat source is only able to heat a small volume of the slag because it contacts such a small cross sectional area of the slag. This leads to superheating of some portions of the slag while underheating others. To compensate for this occurrence, the slag residence times must increase to allow the underheated slag to be heated to a suitable temperature. Both of these effects result in a significant loss in system efficiency. 
However, when the even temperature distribution is valued above plasma control, harmful effects are still realized. An unrestricted plasma will combat the inefficiencies of a restricted plasma, but the uncontrolled arc will be free to attach to any place on the electrode that will provide a low resistance for the arc. This means that the expensive electrode external components may be severely damaged due to plasma erosion. History has proven that that external components are the most damaged by the unrestricted plasma arc. The main reason for the extensive and costly damage to these components is that they are not designed to withstand the intense localized heat of a direct arc attachment. The damages to the electrode externals are far more costly than the inefficiencies resulting from a nozzled plasma. Therefore plasma destruction facilities are designed with a plasma arc which is confined.

The two leading plasma confinement concepts are mechanically nozzling the plasma with machined hardware and magnetically confining the plasma through the use of external magnetic fields. To mechanically confine a plasma, a collimator is used. A collimator is a heavily machined piece of copper alloy that is placed at the lower end of the upper electrode. Thus it serves as a plasma stabilizer as the plasma exits the electrode interior and enters the furnace environment. The collimator is both air and water cooled because of its close proximity to the plasma. In addition, it uses vortex stabilization to confine the plasma and to prevent it from contacting the collimator surface.

Magnetically confining a plasma requires that an external magnetic field be applied to the plasma at the lower end of the top electrode. The two types of magnetic confinements considered are solenoidal confinement and cusp confinement. With solenoidal confinement, the external magnet is a solenoid which focuses the plasma as it travels down the axis of the solenoid. Although this method is effective, it is not opti- 
mum because the solenoidal field tends to generate many extraneous field lines and the plasma is typically non-uniformly constricted.

The cusp confinement utilizes four bar magnets as shown in figure 8.2 (Arata). The plasma is centered on the cusp axis and the uniform elliptic constriction confines the plasma. Because there exist many fewer extraneous magnetic field lines, this type of magnetic confinement is favored (Arata, PEC).

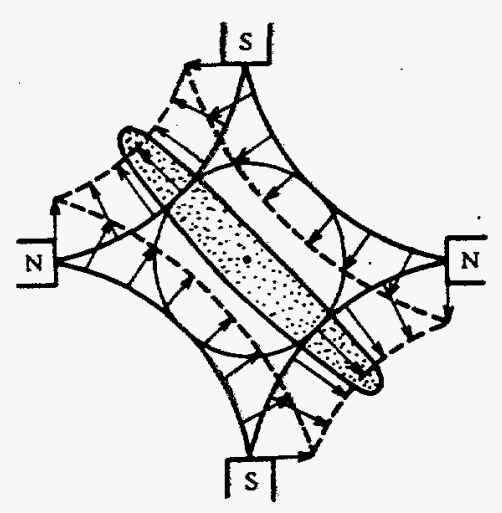

Figure 8.2. Axial View of Cusp Confinement of Plasma Discharge

\subsection{Heat Transfer:}

Four mechanisms of heat transfer exist within a waste destruction facility. These mechanisms are resistance heating, conduction, convection, and radiation. Resistance heating is a result of the current flowing through the plasma gas. Ohm's law relates the voltage, current, and resistance of a circuit in the following manner.

$$
\mathrm{V}=\mathrm{I} * \mathrm{R}
$$


where, $\quad \mathrm{V}=$ voltage in volts

$I=$ current in amperes

$\mathrm{R}=$ resistance in ohms

The total energy is expressed by the formula,

$$
E=I * V * t
$$

where, $\quad E=$ total energy

$t=$ time of current flow in seconds.

Combining these two equations gives the heat energy.

$$
\mathrm{H}=\mathrm{I}^{2} * \mathrm{R} * \mathrm{t} * \mathrm{~K}
$$

where, $\quad H=$ heat energy

$\mathrm{K}=$ heat losses

Conduction occurs through molecules traveling short distances before they transfer their heat to near molecules through collisions. This process occurs within the slag and between the slag and the crucible. Convection is a transfer of energy because of motion. Within the furnace environment, convection occurs between the hot gases and the waste stream. Radiation is similar to conduction in that it utilizes temperature gradients; however, the radiation process utilizes temperature gradients over long distances. For example, in a plasma waste treatment facility, the furnace gas and walls are heated through radiation. The equation describing the radiative heat flux is as follows:

$$
\mathrm{q}^{\prime \prime}=\sigma * \mathrm{~T}^{4}
$$

where, $\quad q^{\prime \prime}=$ radiative heat flux

$$
\begin{aligned}
& \sigma=\text { Stefon - Boltzman constant }=5.670 \mathrm{E}-8 \mathrm{~W} / \mathrm{m}^{2} / \mathrm{K}^{4} \\
& \mathrm{~T}=\text { temperature }
\end{aligned}
$$

Because the conduction contribution to the total amount of heat transfer is negligible, it will not be discussed further. 
Convection. is heat transfer between a surface and a moving fluid at a different temperature. Two types of convection exist and both play a role within a plasma incinerator. Natural, or free, convection is heat flow driven by a buoyancy force caused by density differences developed as a result of the transfer of heat. Natural convection is the swirling, turbulent fluid in the environment. Forced convection is used by the vortex stabilized arc.

Many different dimensionless variables may be used to characterize the specifics of the convection. A few are the Nussult number, the Grashoff number, the Prandlt number, and the Rayleigh number. The precise roles of each of these terms in modeling a plasma thermal destruction facility are still unknown. When the roles have been determined, the natural convection of the system may be modeled as a small cylindrical heat source, centered within a large cylindrical volume: This would be useful because it adequately approximates a plasma thermal destruction facility, and general correlations are already known for this geometry. The forced convection of the system can be modeled as single round nozzle, jet impingement heat transfer. Illustrations for the cylindrical and jet impingement convections are shown below (Guyer, Todreas). 


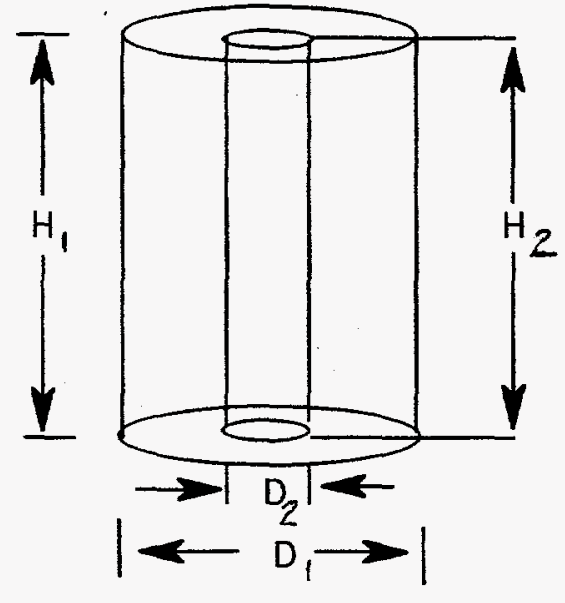

a)

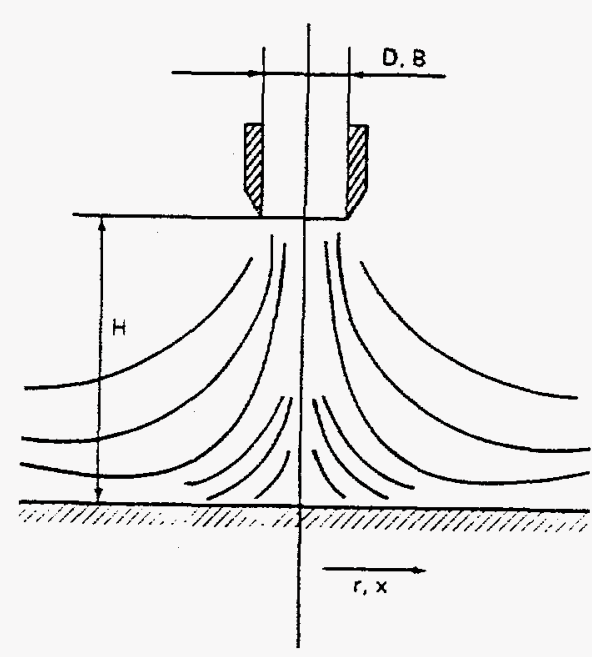

b)

Figure 8.3. a) Cylindrical Approximation; b) Jet Impingement Approximation.

\subsection{Plasma gases:}

The plasma gas serves a dual role. Its primary purpose is to serve as the ionizing medium that constitutes the plasma. The additional role of the of the plasma gas is to provide the gas vortex stabilization of the plasma, insulating it from the torch's internal and external components; thus, minimizing torch damage. The desirable qualities a plasma gas should demonstrate include: abundance, low cost, inertness to undesirable reactions, the capacity to enhance the waste destruction process, general safety, and functionability in a variety of conditions. No one gas has yet demonstrated all of the qualities but some have demonstrated a majority of them. These gases and corresponding desirable qualities will be described below. 
A variety of gases may perform suitably as plasma gases. Gases characteristic of those considered are argon, oxygen, and air.

Argon offers the benefit of inertness. Therefore, as the waste dissociates, no undesirable recombinations will occur between the waste products and the plasma gas. On the other hand, argon is very expensive so it must be used sparingly. This requirement limits the amount of gas that can be used to vortex stabilize the plasma, which in turn, limits the power that can be delivered through the torch to the plasma. If the torch power increases to a high value, then the low gas flow of the vortex stabilization will allow for insufficient insulation of the torch internal components from the plasma. Lastly, argon's inertness causes it not to enhance the waste destruction process.

Oxygen is one of the most favored plasma gases. It is cheap and abundant. Its high electronegativity causes it to bond well with almost any radical or compound in various conditions. This consistently enhances the waste destruction process. Oxygen is completely safe to use, and safe to breathe if it escapes into the atmosphere.

The main disadvantage with oxygen as a plasma gas is its excellent capacity to bond. This quality causes oxygen to bond with waste constituents that form harmful products in addition to the innoxious compounds desired. In an oxygen rich environment, harmful compounds such as $\mathrm{CO}$ and $\mathrm{NO}_{\mathrm{x}}$ may be generated.

Air is another favored plasma gas. Air is very abundant and cheap. It is composed of approximately 80 percent nitrogen and 20 percent oxygen which provides enough oxygen for suitable combustion to occur. Therefore, if a excess of air can be used as the ionizing medium and vortex stabilizer, then air will possess the same benefits as oxygen as a plasma gas. 
Likewise, the primary drawback of an air plasma is the possible formation of undesirable compounds. Of primary concern is $\mathrm{NO}_{\mathbf{x}}$ formation of because of the excess oxygen and nitrogen in the system.

This study specifically analyzes air plasmas. Thermal waste destruction in an oxygen rich environment is termed incineration. Incineration requires that enough oxygen be present to allow for sufficient combustion to occur. Waste destruction in an oxygen starved environment is termed pyolysis. Since air is composed of approximately 20 percent oxygen, air may or may not provide incineration characteristics, depending on the flow rate. This study assumes that a sufficient amount of air is used to provide for sufficient combustion (Dorin, PEC). 


\subsection{RESULTS AND DISCUSSION}

\subsection{Mass balance and heat balance:}

The purpose of of mass balance calculations is to quantify inputs and outputs of a system. This technique offers a way to determine items such as the amount of air required for a process and the amount of waste reduction. The mass balance calculations are applications of the first law of thermodynamics: in a steady state system the inputs into the system equal the outputs from the system, therefore, mass is conserved. Since the calculation is based on such a universal premise, it is true of other waste destruction systems as well. The system is defined to include the mass of the waste feed $\left(M_{f}\right)$, the cooling air $\left(M_{a}\right)$, the flue gas $\left(M_{g}\right)$, and the ash discharge $\left(M_{r}\right)$. They are related in the following manner.

$$
\mathbf{M}_{\mathrm{f}}+\mathrm{M}_{\mathrm{a}}-\mathrm{M}_{\mathrm{r}}-\mathrm{M}_{\mathrm{g}}=\mathbf{0}
$$

Assumptions can be made to expedite the calculation of waste destruction system parameters. Prominent assumptions are listed below.

- The waste undergoes complete combustion.

- All hydrogen within the system is converted to water vapor, $\mathrm{H}_{2} \mathrm{O}$, in the absence of chlorine.

- All chlorines are converted to hydrochloric acid, $\mathrm{HCl}$.

- All carbon is converted to carbon dioxide, $\mathrm{CO}_{2}$.

- All nitrogen from the waste or air will form diatomic nitrogen, $\mathrm{N}_{2}$.

- Each waste within a specific EPA classification contributes equally to the total mass of the classification.

- Sufficient air is provided to allow adequate combustion.

- Since air is 80 percent nitrogen and 20 percent oxygen, it can be approximated as 4 moles of $\mathrm{N}_{2}$ for every 1 mole of $\mathrm{O}_{2}$. 
- No $\mathrm{NO}_{\mathbf{x}}$ formation is considered even though its concentration is known to increase with temperature because only the combustion aspect of the chemical interactions is considered.

- The components within the classes of wastes can be evaluated as isolated quantities (Brunner).

\subsubsection{D002 analysis}

\subsubsection{Mass balance for $\mathrm{D} 002$}

As one example of mass balance calculations, a mass balance analysis will be performed on the D002 category of North Carolina's average hazardous waste. This waste is composed of acetic anhydride, $\mathrm{C}_{4} \mathrm{H}_{6} \mathrm{O}_{3}$, and trichlorobenzene, $\mathrm{C}_{6} \mathrm{H}_{3} \mathrm{Cl}_{3}$. The following are considered known quantities:

- $3.12 \mathrm{E} 6 \mathrm{~kg} / \mathrm{yr}$ D002 waste feed for the state of North Carolina

- all D002 waste exists in liquid form

- the combustion equations for the two organic wastes considered

- the ambient temperature outside the system, room temperature ( $298 \mathrm{~K}$ )

- the furnace temperature which $1873 \mathrm{~K}$. This temperature corresponds to $1600^{\circ} \mathrm{C}$ which is the highest temperature for which federal regulations exist. 
Table 9.1: Formula Weights of Compounds Studied in Mass and Energy Balances

\begin{tabular}{|l|l|l|}
\hline \multicolumn{1}{|c|}{$\begin{array}{c}\text { Compound } \\
\text { Name }\end{array}$} & $\begin{array}{c}\text { Chemical } \\
\text { Formula }\end{array}$ & \multicolumn{1}{|c|}{$\begin{array}{c}\text { Formula } \\
\text { Weight }\end{array}$} \\
\hline Acetic Anhydride & $\mathrm{C}_{4} \mathrm{H}_{6} \mathrm{O}_{3}$ & 102.0 \\
\hline Aniline & $\mathrm{C}_{6} \mathrm{H}_{7} \mathrm{~N}$ & 93.0 \\
\hline Carbon Dioxide & $\mathrm{CO}_{2}$ & 44.0 \\
\hline Hydrochloric Acid & $\mathrm{HCl}$ & 37.0 \\
\hline Nitrobenzene & $\mathrm{C}_{6} \mathrm{H}_{5} \mathrm{NO}_{2}$ & 123.0 \\
\hline Nitrogen & $\mathrm{N}_{2}$ & 28.0 \\
\hline Oxygen & $\mathrm{O}_{2}$ & 32.0 \\
\hline Trichlorobenzene & $\mathrm{C}_{6} \mathrm{H}_{3} \mathrm{Cl}_{3}$ & 183.0 \\
\hline Water & $\mathrm{H}_{2} \mathrm{O}$ & 18.0 \\
\hline & &
\end{tabular}

Combustion equation for acetic anhydride:

$$
1 \mathrm{C}_{4} \mathrm{H}_{6} \mathrm{O}_{3}+16 \mathrm{~N}_{2}+4 \mathrm{O}_{2}-\mathrm{CO}_{2}+3 \mathrm{H}_{2} \mathrm{O}+16 \mathrm{~N}_{2}
$$

Mass and moles of acetic anhydride:

$$
\begin{gathered}
\text { mass }=3.12 \mathrm{E} 6 \mathrm{~kg} \mathrm{D002} * 0.5 \mathrm{~kg} \mathrm{aa} / 1 \mathrm{~kg} \mathrm{D002}=1.56 \mathrm{E} 6 \mathrm{~kg} \mathrm{aa} \\
\text { moles }=1.56 \mathrm{E} 6 * 1000 \mathrm{~g} \mathrm{aa} / 1 \mathrm{~kg} \mathrm{aa} * 1 \mathrm{~mol} \mathrm{aa} / 102 \mathrm{~g} \mathrm{aa}= \\
=1.53 \mathrm{E} 6 \mathrm{~mol} \mathrm{aa}
\end{gathered}
$$

Masses of constituents of combustion equation 9.1.2:

nitrogen:

$1.53 \mathrm{E} 6 \mathrm{~mol} \mathrm{aa} * 16 \mathrm{~mol} \mathrm{~N}_{2} / 1 \mathrm{~mol} \mathrm{aa} * 28.0 \mathrm{~g} \mathrm{~N}_{2} / 1 \mathrm{~mol} \mathrm{~N}_{2}$ *

$$
\text { * } 1 \mathrm{~kg} \mathrm{~N}_{2} / 1000 \mathrm{~g} \mathrm{~N}_{2}=6.85 \mathrm{E} 6 \mathrm{~kg} \mathrm{~N}_{2}
$$

Remaining masses are found from equation 9.1.5 
oxygen: mass $\left(\mathrm{O}_{2}\right)=1.96 \mathrm{E} 6 \mathrm{~kg}$

carbon dioxide: mass $\left(\mathrm{CO}_{2}\right)=2.69 \mathrm{E} 6 \mathrm{~kg} \mathrm{CO}$

water: mass $\left(\mathrm{H}_{2} \mathrm{O}\right)=8.25 \mathrm{E} 5 \mathrm{~kg} \mathrm{H}_{2} \mathrm{O}$

nitrogen: $\operatorname{mass}\left(\mathrm{N}_{2}\right)=6.85 \mathrm{E} 6 \mathrm{~kg} \mathrm{~N}_{2}$

Input masses of acetic anhydride, nitrogen, and oxygen into system in $\mathrm{kg}: 1.04 \mathrm{E} 7 \mathrm{~kg}$

Output masses of carbondioxide, waste and nitrogen from system in $\mathrm{kg}: 1.04 \mathrm{E} 7 \mathrm{~kg}$

Although the masses of the input and output are the same, the amount of hazard has been eliminated.

Combustion equation for trichlorobenzene:

$$
1 \mathrm{C}_{6} \mathrm{H}_{3} \mathrm{Cl}_{3}+24 \mathrm{~N}_{2}+6 \mathrm{O}_{2} \cdots-\cdots \mathrm{CO}_{2}+3 \mathrm{HCl}+24 \mathrm{~N}_{2}
$$

Mass and moles of trichlorobenzene from equations 9.1.3 and 9.1.4 respectively:

mass tcb $=1.56 \mathrm{E} 6 \mathrm{~kg} \mathrm{tcb}$

moles of tcb $=8.53 \mathrm{E} 6$

Masses of constituents of equation 9.1.6 calculated from equation 9.1.5:

nitrogen: $\operatorname{mass}\left(\mathrm{N}_{2}\right)=5.28 \mathrm{E} 6 \mathrm{~kg}$

oxygen: $\operatorname{mass}\left(\mathrm{O}_{2}\right)=1.64 \mathrm{E} 6 \mathrm{~kg}$

carbon dioxide: mass $\left(\mathrm{CO}_{2}\right)=2.25 \mathrm{E} 6 \mathrm{~kg}$

hydrochloric acid: mass $(\mathrm{HCl})=9.46 \mathrm{E} 5 \mathrm{~kg}$

nitrogen: $\operatorname{mass}\left(\mathrm{N}_{2}\right)=5.56 \mathrm{E} 6 \mathrm{~kg}$ 
Input of reactants (trichlorobenzene, nitrogen, oxygen) into system in kg: $8.92 \mathrm{E} 6 \mathrm{~kg}$ Output (carbon dioxide, hydrochloric acid, nitrogen) from system in $\mathrm{kg}: 8.92 \mathrm{E} 6 \mathrm{~kg}$ The amount of trichlorobenzene has been reduced to zero and the initial amount of hazardous material has been reduced by approximately 50 percent. Also, the original substance, trichlorobenzene, has little industrial value relative to the resulting hazardous substance, hydrochloric acid, which is very marketable to industry (Brunner, Dorin, West).

\subsubsection{Heat balance for $\mathrm{D} 002$ :}

The generation, absorption, and flow of heat is also conserved. These parameters are all related by the following equation:

$$
Q_{\text {in }}+Q_{\text {gen }}-Q_{\text {abs }}-Q_{\text {out }}=0
$$

where, $\quad Q_{\text {in }}=$ heat input to the system

$$
\begin{aligned}
& Q_{\text {gen }}=\text { heat generated within the system } \\
& Q_{\text {abs }}=\text { heat absorbed within the system } \\
& Q_{\text {out }}=\text { heat output from the system }
\end{aligned}
$$

The heat input is calculated using the specific heat of the plasma gas, the mass of the plasma gas, and the temperature of the gas.

$$
\begin{aligned}
\mathrm{Q}_{\mathrm{in}}(\mathrm{kJ}) & =\mathrm{m}(\mathrm{kg}) * \mathrm{c}_{\mathrm{p}}(\mathrm{J} / \mathrm{mol} / \mathrm{K}) * \Delta \mathrm{T}(\mathrm{K}) * 1000 \mathrm{~g} / 1 \mathrm{~kg} * \\
& * 1 \mathrm{~mol} / \mathrm{FW}(\mathrm{g}) * 1 \mathrm{~kJ} / 1000 \mathrm{~J}
\end{aligned}
$$

where, $\quad \mathrm{m}=$ mass

$$
\begin{aligned}
& c_{p}=\text { specific heat } \\
& \Delta T=\text { change in temperature }=T_{\text {furnace }}(1873 \mathrm{~K})-T_{\text {ambient }}(298 \mathrm{~K})
\end{aligned}
$$




$$
\text { FW = formula weight }
$$

The variable $c_{p}$ is temperature dependent. Therefore, since both the ambient temperature and furnace temperature are known, an average $c_{p}$ was calculated from the $c_{p}$ of the ambient gas temperature and the $c_{p}$ of the destruction environment.

The heat generated is determined by the enthalpy $\left(\Delta_{\mathrm{f}} \mathrm{H}\right)$ of the wastes. The units of enthalpy are $\mathrm{kJ} / \mathrm{mol}$. The wastes release the amount of heat generated as they decompose through combustion. No heat is generated in $\mathrm{N}_{2}$ or $\mathrm{O}_{2}$ because these atoms are in their ground level energy states.

$$
\mathrm{Q}_{\text {gen }}(\mathrm{kJ})=-\Delta_{\mathrm{f}} \mathrm{H}(\mathrm{kJ} / \mathrm{mol}) * \text { moles of waste }
$$

$\Delta_{\mathrm{f}} \mathrm{H}$ is actually the amount of energy absorbed by the specific compound; thus, $-\Delta_{\mathrm{f}} \mathrm{H}$ is the amount of energy expelled from the compound. All of this emitted energy is assumed to be released into the waste destruction environment.

The heat absorbed is calculated similarly to the heat generation calculation using equation 9.1.10. This quantity represents the amount of energy used within the system to form the product of the reaction. Since a single waste often generates multiple products, this term is a summation of energies used in forming the various products.

The heat output is found using equation 9..1.8. Although multiple products are generated, the $\mathrm{N}_{2}$ value of the $\mathrm{c}_{\mathrm{p}}$ is used in this analysis because nitrogen dominates the weight of the output. From the heat output, the outlet gas temperature from the system can be determined

A table of constants related to energy balance is shown below. 
Table 9.2: Energy Balance Constants

\begin{tabular}{|l|l|l|l|l|}
\hline Compound Name & $\begin{array}{l}\text { Chemical } \\
\text { Formula }\end{array}$ & $\begin{array}{c}-\Delta_{\mathbf{f}} \mathbf{H} \\
(\mathbf{k J} / \mathbf{m o l})\end{array}$ & $\begin{array}{c}\mathbf{c}_{\mathbf{p}}\left(\mathbf{T}_{1}\right) \\
(\mathbf{J} / \mathbf{m o l} / \\
\mathbf{K})\end{array}$ & $\begin{array}{l}\mathbf{c}_{\mathbf{p}}\left(\mathbf{T}_{2}\right) \\
(\mathbf{J} / \mathbf{m o l} / \\
\mathbf{K})\end{array}$ \\
\hline Nitrogen (Air) & $\mathrm{N}_{2}$ & 0.0 & $\begin{array}{l}29.2 \\
(298 \mathrm{~K})\end{array}$ & $\begin{array}{l}35.7 \\
(1873 \mathrm{~K})\end{array}$ \\
\hline Oxygen & $\mathrm{O}_{2}$ & 0.0 & $\mathrm{n} / \mathrm{a}$ & $\mathrm{n} / \mathrm{a}$ \\
\hline Acetic Anhydride & $\mathrm{C}_{4} \mathrm{H}_{6} \mathrm{O}_{3}$ & 1807.1 & $\mathrm{n} / \mathrm{a}$ & $\mathrm{n} / \mathrm{a}$ \\
\hline Trichlorobenzene & $\mathrm{C}_{6} \mathrm{H}_{3} \mathrm{Cl}_{3}$ & 3267.6 & $\mathrm{n} / \mathrm{a}$ & $\mathrm{n} / \mathrm{a}$ \\
\hline Aniline & $\mathrm{C}_{6} \mathrm{H}_{7} \mathrm{~N}$ & 3392.8 & $\mathrm{n} / \mathrm{a}$ & $\mathrm{n} / \mathrm{a}$ \\
\hline Nitrobenzene & $\mathrm{C}_{6} \mathrm{H}_{5} \mathrm{NO}_{2}$ & 3088.1 & $\mathrm{n} / \mathrm{a}$ & $\mathrm{n} / \mathrm{a}$ \\
\hline Water & $\mathrm{H}_{2} \mathrm{O}$ & 241.8 & $\mathrm{n} / \mathrm{a}$ & $\mathrm{n} / \mathrm{a}$ \\
\hline Carbon Dioxide & $\mathrm{CO}_{2}$ & 393.7 & $\mathrm{n} / \mathrm{a}$ & $\mathrm{n} / \mathrm{a}$ \\
\hline Hydrochloric Acid & $\mathrm{HCl}$ & 92.3 & $\mathrm{n} / \mathrm{a}$ & $\mathrm{n} / \mathrm{a}$ \\
\hline
\end{tabular}

It is instructive to couple mass and energy balance calculations because they depend on similar information, and their coupled results provide a more comprehensive understanding of the system. Since the D002 mass balance has already been performed, a heat balance for the D002 category will be calculated.

acetic anhydride:

$Q_{\text {in }}:$

$$
\begin{aligned}
\text { daily mass per generator }= & \left(\text { mass of } \mathrm{N}_{2} \text { (initial) }+ \text { mass of } \mathrm{O}_{2}\right) / \\
& / 702 \text { generators } / 365 \mathrm{~d} / \mathrm{yr} \\
= & (6.85 \mathrm{E} 6 \mathrm{~kg}+1.96 \mathrm{E} 6 \mathrm{~kg}) / 2.56 \mathrm{E} 5 \\
\text { daily mass per generator }= & 34.4 \mathrm{~kg} \text { air }
\end{aligned}
$$

Note: 2.56 E 5 represents the conversion factor from state generation per year to individual generator per day 


$$
\begin{aligned}
c_{p} & =\left(c_{p}\left(T_{\text {inlet }}=298 \mathrm{~K}\right)+c_{p}\left(T_{\text {furnace }}=1873 \mathrm{~K}\right)\right) / 2 \\
& =29.2 \mathrm{~J} / \mathrm{mol} / \mathrm{K}+35.7 \mathrm{~J} / \mathrm{mol} / \mathrm{K} \\
c_{p} & =32.45 \mathrm{~J} / \mathrm{mol} / \mathrm{K}
\end{aligned}
$$

$Q_{\text {in }}$ from equation 9.1.8:

$$
\mathrm{Q}_{\text {in }}=1.22 \mathrm{E} 4 \mathrm{~kJ}
$$

$Q_{\text {gen }}$ from equation 9.1.10

$$
\mathrm{Q}_{\text {gen }}=1.08 \mathrm{E} 5 \mathrm{~kJ}
$$

Recall: Diatomic nitrogen and oxygen are not included.

Recall molar ratios in equation 9.1.2:

$$
\begin{aligned}
& \mathrm{Q}_{\mathrm{abs}}=\left(394 \mathrm{~kJ} / \mathrm{mol} \mathrm{CO}_{2} * 1.53 \mathrm{E} 6 \mathrm{~mol} \mathrm{aa} * 4 \mathrm{~mol} \mathrm{CO}_{2} / 1 \mathrm{~mol} \mathrm{aa}+\right. \\
&\left.+242 \mathrm{~kJ} / \mathrm{mol} \mathrm{H}_{2} \mathrm{O} * 1.53 \mathrm{E} 6 \mathrm{~mol} \mathrm{aa} * 3 \mathrm{~mol} \mathrm{H}_{2} \mathrm{O} / 1 \mathrm{~mol} \mathrm{aa}\right) / \\
& / 2.56 \mathrm{E} 5 \\
&=(2.40 \mathrm{E} 9 \mathrm{~kJ}+1.11 \mathrm{E} 9 \mathrm{~kJ}) / 2.57 \mathrm{E} 5 \\
& \mathrm{Q}_{\mathrm{abs}}= 1.23 \mathrm{E} 4 \mathrm{~kJ} \\
& \mathrm{Q}_{\text {out }}= \mathrm{Q}_{\mathrm{in}}+\mathrm{Q}_{\mathrm{gen}}-\mathrm{Q}_{\mathrm{abs}} \\
&= 1.22 \mathrm{E} 5 \mathrm{~kJ}+1.08 \mathrm{E} 5 \mathrm{~kJ}-1.23 \mathrm{E} 5 \mathrm{~kJ} \\
& \mathrm{Q}_{\text {out }}= 1.07 \mathrm{E} 5 \mathrm{~kJ} \\
& \mathrm{Q}_{\text {out }} \text { reflects the output energy from the system. The reason } \mathrm{Q}_{\text {out }} \text { is a full order of mag- } \\
& \text { nitude larger than } \mathrm{Q}_{\mathrm{in}} \text { is because exothermic reactions within the system occur. }
\end{aligned}
$$

trichlorobenzene: 
$\mathrm{Q}_{\text {in }}$ :

mass from equation 9.1.11:

$$
\operatorname{mass}(\text { air })=28.7 \mathrm{~kg}
$$

$c_{p}$ from equation 9.1.12:

$$
c_{p}=32.45 \mathrm{~J} / \mathrm{mol} / \mathrm{K}
$$

$Q_{\text {in }}$ from equation 9.1.8:

$$
Q_{\text {in }}=1.02 \mathrm{E} 4 \mathrm{~kJ}
$$

$Q_{\text {gen }}$ from equation 9.1 .10

$$
\mathrm{Q}_{\text {gen }}=1.09 \mathrm{E} 5 \mathrm{~kJ}
$$

Recall: Diatomic nitrogen and oxygen are not included.

Recall molar ratios in equation 9.1.6:

$\mathrm{Q}_{\mathrm{abs}}$ from equation 9.1.13:

$$
\mathrm{Q}_{\mathrm{abs}}=8.77 \mathrm{E} 4 \mathrm{~kJ}
$$

$Q_{\text {out }}$ from equation 9.1.7:

$$
=1.02 \mathrm{E} 4 \mathrm{~kJ}+1.09 \mathrm{E} 5 \mathrm{~kJ}-8.77 \mathrm{E} 4 \mathrm{~kJ}
$$

$Q_{\text {out }}=3.11 \mathrm{E} 4 \mathrm{~kJ}$

Again, exothermic reactions contribute to $Q_{\text {out }}$ being larger than $Q_{i n}$.

Output temperature of products:

Note that the wastes enter the furnace system at $1873 \mathrm{~K}$ ( see equation 9.1.9). It is understood that the products exiting the system will have a different temperature because 
of the heat added and removed while the wastes are converted into their products. The ambient temperature remains the same as in equation 9.1.9.

$$
\begin{aligned}
Q_{\text {out }} \text { D002 } & =10656.6 \mathrm{~kJ} \text { aa }+31074.8 \mathrm{~kJ} \mathrm{tcb} \\
& =41731.4 \mathrm{~kJ}
\end{aligned}
$$

$$
\begin{aligned}
& \begin{aligned}
\text { mass of output } & =\mathrm{m} \mathrm{N}_{2} \text { output }(\mathrm{aa})+\mathrm{m} \mathrm{H}_{2} \mathrm{O}(\mathrm{aa})+\mathrm{m} \mathrm{CO}_{2}(\mathrm{aa})+ \\
+ & \mathrm{m} \mathrm{N}_{2} \text { output }(\mathrm{tcb})+\mathrm{m} \mathrm{HCl}(\mathrm{tcb})+\mathrm{m} \mathrm{CO}_{2}(\mathrm{tcb}) \\
& =26.7 \mathrm{~kg}+3.2 \mathrm{~kg}+10.5 \mathrm{~kg}+87.8 \mathrm{~kg}+3.7 \mathrm{~kg}+21.7 \mathrm{~kg}
\end{aligned} \\
& \text { mass of output }=153.6 \mathrm{~kg}
\end{aligned}
$$$$
\text { mass total } \mathrm{N}_{2} / \text { mass total output }=114.5 \mathrm{~kg} / 153.6 \mathrm{~kg} \sim 70 \%
$$

Therefore, the $\mathrm{N}_{2}$ value of $c_{p}$ data will be used.

Substituting equation 9.1.7 into equation 9.1.8 generates equation 9.1.17.

$$
\begin{aligned}
\mathrm{Q}_{\text {out }}(\mathrm{kJ}) & =\mathrm{m}(\mathrm{kg}) * \mathrm{c}_{\mathrm{p}}(\mathrm{J} / \mathrm{mol} / \mathrm{K}) *\left[\mathrm{~T}_{\text {out }}-\mathrm{T}_{\text {ambient }}\right](\mathrm{K}) * \\
& * 1000 \mathrm{~g} / 1 \mathrm{~kg} * 1 \mathrm{~mol} / \mathrm{FW}(\mathrm{g}) * 1 \mathrm{~kJ} / 1000 \mathrm{~J}
\end{aligned}
$$

It is noted that two dependent unknowns exist: $c_{p}$ and the exit $T_{f u r n a c e}$. Although $c_{p}$ is a function of $\mathrm{T}_{\text {fumace}}$, since no functional correlation is known between the two, an iterative process is necessary to determine the unknowns.

After many iterations:

$\mathrm{T}_{\text {out }}=653 \mathrm{~K}$ and the corresponding $\mathrm{c}_{\mathrm{p}}$ is $30.7 \mathrm{~J} / \mathrm{mol} / \mathrm{K}$

(Brunner, Dean, Stephenson, White)

9.1.1.3. Practical applications of D002 findings 
D002 mass flow rate per generator:

mass flow $=3.12 \mathrm{E} 6 \mathrm{~kg} \mathrm{D002} / \mathrm{yr} / \mathrm{N} . \mathrm{C} . / 702$ generators $/ \mathrm{N} . \mathrm{C} . / 365 . \mathrm{d} / \mathrm{yr}$

$=12.4 \mathrm{~kg} /$ gen. $/ \mathrm{d}$

If a plasma destruction facility utilizes a standard $1 \mathrm{MW}$ torch, given the mass flow rate and destruction chamber temperature, the time to destroy the waste can be calculated.

moles of air $=239$ moles from aa +203 moles from tcb

moles of air $=443 \mathrm{~mol}$ air

$$
\begin{aligned}
& \text { mass of air }=443 \mathrm{~mol} * 144 \mathrm{~g} / 1 \mathrm{~mol} * 1 \mathrm{~kg} / 1000 \mathrm{~g} \\
& =63.7 \mathrm{~kg} \text { air } \\
& \begin{aligned}
\mathrm{Q}_{\text {in }} & =\mathrm{m}^{*} \mathrm{c}_{\mathrm{p}} * \Delta \mathrm{T} / \mathrm{FW} \\
& =63.7 \mathrm{~kg} * 32.45 \mathrm{~kJ} / \mathrm{mol} / \mathrm{K} * 1573 \mathrm{~K} * 1 \mathrm{~mol} / 144 \mathrm{~g} \\
& =2.26 \mathrm{E} 5 \mathrm{~kJ}
\end{aligned} \\
& \mathrm{Q}_{\text {torch }}=\mathrm{Q}_{\mathrm{in}}=22579.8 \\
& =2(\mathrm{~kW}) * \mathrm{t}(\mathrm{s}) \\
& \mathrm{t}=2.26 \mathrm{E} 5 \mathrm{~kJ} / 1000 \mathrm{~kW} \\
& =22.6 \mathrm{~s}
\end{aligned}
$$


An easier method may also be used to calculate the time to destroy the D002 waste. Using the values from equations

$$
\begin{aligned}
& \begin{array}{l}
\mathrm{Q}_{\text {torch }}=\mathrm{Q}_{\text {in }}(\mathrm{D} 002)=12193.8 \mathrm{~kJ} \text { aa } \\
\quad=22374.9 \mathrm{~kJ} \\
\mathrm{Q}_{\text {torch }}=\mathrm{P}(\mathrm{kW}) * \mathrm{t}(\mathrm{s}) \\
\mathrm{t}=22374.9 \mathrm{~kJ} / 1^{*} 10^{3} \mathrm{~kW} \\
=22.4 \mathrm{~s}
\end{array}
\end{aligned}
$$

Because this model is $0-D$, the mass of the wastes and the power required to destroy the wastes are directly related. Thus, an expression can be generated to correlate the torch power, the time, and the mass involved in the destruction process.

$$
\begin{aligned}
& \operatorname{mass} \alpha \mathrm{Q}_{\mathrm{in}}=\mathrm{P}_{\text {torch }} * \mathrm{t} \\
& 12.4 \mathrm{~kg} \propto 1 \mathrm{MW} * 22.8 \mathrm{~s}
\end{aligned}
$$

This expression provides any unknown value. Given any of the two values, the third value can be determined.

Given $1 \mathrm{~kg}$ of D002 wastes with the same $1 \mathrm{MW}$ torch, the time necessary to destroy the wastes is

$$
\begin{aligned}
& (12.4 \mathrm{~kg} / 12.4)=1 \mathrm{~kg} \alpha 1 \mathrm{MW} *(22.8 \mathrm{~s} / 12.4) \\
& \mathrm{t}=22.8 \mathrm{~s} / 12.4 \\
& =1.8 \mathrm{~s}
\end{aligned}
$$

If wastes are to be destroyed monthly ( 30 days ), and the torch is to be run for 5 minutes ( $600 \mathrm{~s}$ ) while destroying the wastes, the torch power rating will have to be 
$12.4 \mathrm{~kg} / \mathrm{d} * 30 \mathrm{~d} /$ month $\alpha(1 \mathrm{MW} * 30 / 600) *(22.8 \mathrm{~s} * 600 \mathrm{~s})$

$$
\begin{aligned}
\mathrm{P}_{\text {torch }} & =1 \mathrm{MW} * 30 / 600 \\
& =0.5 \mathrm{MW}
\end{aligned}
$$

\subsubsection{K083 analysis}

An additional mass and heat balance will be calculated on the $\mathrm{K} 083$ waste category.

9.1.2.1. Mass balance for K083

Combustion equation for aniline:

$4 \mathrm{C}_{6} \mathrm{H}_{7} \mathrm{~N}+124 \mathrm{~N}_{2}+31 \mathrm{O}_{2}-\cdots-24 \mathrm{CO}_{2}+14 \mathrm{H}_{2} \mathrm{O}+126 \mathrm{~N}_{2}$ (9.1.27)

Mass and moles of aniline from equations 9.1 .3 and 9.1 .4 respectively:

mass of aniline $=1.25 \mathrm{E} 6 \mathrm{~kg}$

moles of aniline $=1.31 \mathrm{E} 6 \mathrm{~mol} \mathrm{ani}$

Masses of constituents of aniline equation 9.1.27 calculated from equation 9.1.5:

nitrogen: $\operatorname{mass}\left(\mathrm{N}_{2}\right)=1.14 \mathrm{E} 7 \mathrm{~kg}$

oxygen: mass $\left(\mathrm{O}_{2}\right)=3.25 \mathrm{E} 6 \mathrm{~kg}$

carbon dioxide: mass $\left(\mathrm{CO}_{2}\right)=3.48 \mathrm{E} 6 \mathrm{~kg}$

water: mass $\left(\mathrm{H}_{2} \mathrm{O}\right)=8.29 \mathrm{E} 5 \mathrm{~kg}$

nitrogen: mass $\left(\mathrm{N}_{2}\right)=1.16 \mathrm{E} 5 \mathrm{~kg}$ 
Input of aniline reactants (aniline, nitrogen, and oxygen) into system in $\mathrm{kg}: 1.59 \mathrm{E} 7 \mathrm{~kg}$ Output (carbon dioxide, water, nitrogen) from system in $\mathrm{kg}: 1.59 \mathrm{E} 7 \mathrm{~kg}$ It must be noted that the volume of hazardous material has been totally eliminated during the mass conservation process.

Cornbustion equation for nitrobenzene:

$4 \mathrm{C}_{6} \mathrm{H}_{5} \mathrm{NO}_{2}+100 \mathrm{~N}_{2}+25 \mathrm{O}_{2} \longrightarrow 24 \mathrm{CO}_{2}+10 \mathrm{H}_{2} \mathrm{O}+102 \mathrm{~N}_{2}$

Mass and moles of nitrobenzene from equations 9.1 .3 and 9.1.4 respectively:

mass $\mathrm{nb}=1.22 \mathrm{E} 6 \mathrm{~kg}$

moles $\mathrm{nb}=9.96 \mathrm{E} 6 \mathrm{~mol} \mathrm{nb}$

Masses of constituents of nitrobenzene equation 9.1.28 calculated from 9.1.5:

nitrogen: mass $\left(\mathrm{N}_{2}\right)=6.97 \mathrm{E} 6 \mathrm{~kg}$

oxygen: mass $\left(\mathrm{O}_{2}\right)=1.99 \mathrm{E} 6 \mathrm{~kg}$

carbon dioxide: mass $\left(\mathrm{CO}_{2}\right)=2.63 \mathrm{E} 6 \mathrm{~kg}$

water: $\operatorname{mass}\left(\mathrm{H}_{2} \mathrm{O}\right)=4.48 \mathrm{E} 5 \mathrm{~kg}$

nitrogen: mass $\left(\mathrm{N}_{2}\right)=7.11 \mathrm{E} 6 \mathrm{~kg}$

Input of reactants (nitrobenzene, oxygen, and nitrogen) into system in $\mathrm{kg}: 1.02 \mathrm{E} 7 \mathrm{~kg}$ Output (carbon dioxide, water, nitrogen) from system in $\mathrm{kg}: 1.02 \mathrm{E} 7 \mathrm{~kg}$

The sum of hazardous material has been completely eliminated and only innocuous compounds remain (Brunner, Dorin, West).

\subsubsection{Heat balance for $\mathrm{K} 083$}


aniline:

$\mathrm{Q}_{\mathrm{in}}:$

daily mass per generator ( air ) $=57.3 \mathrm{~kg}$, from equation 9.1 .11

$\Delta \mathrm{T}=1575 \mathrm{~K}$, from equation 9.1 .9

$c_{\mathrm{p}}=32.45 \mathrm{~J} / \mathrm{mol} / \mathrm{K}$, from equation 9.1 .12

$Q_{\text {in }}=2.03 \mathrm{E} 4 \mathrm{~kJ}$, from 9.1 .8

$\mathrm{Q}_{\text {gen }}=1.74 \mathrm{E} 5 \mathrm{~kJ}$, from equation 9.1.10

$\mathrm{Q}_{\mathrm{abs}}=1.68 \mathrm{E} 5 \mathrm{~kJ}$, from 9.1 .13

$\mathrm{Q}_{\text {out }}=2.65 \mathrm{E} 4 \mathrm{~kJ}$, from equation 9.1 .7

Heat energy input $=$ Heat energy output

Therefore, heat energy is conserved.

nitrobenzene:

daily mass per generator ( air $)=35.0 \mathrm{~kg}$, from equation 9.1 .11

$\Delta \mathrm{T}=1575 \mathrm{~K}$, from equation 9.1.9

$c_{p}=32.45 \mathrm{~J} / \mathrm{mol} / \mathrm{K}$, from equation 9.1 .12

$\mathrm{Q}_{\text {in }}=1.24 \mathrm{E} 4 \mathrm{~kJ}$, from equation 9.1 .8

$Q_{\text {gen }}=1.26 \mathrm{E} 5 \mathrm{~kJ}$, from equation 9.1 .10

$\mathrm{Q}_{\mathrm{abs}}=1.15 \mathrm{E} 5 \mathrm{~kJ}$ from equation 9.1 .13

$\mathrm{Q}_{\text {out }}=2.41 \mathrm{E} 4 \mathrm{~kJ}$, from equation 9.1 .7

The exothermic reactions within the system cause the output energy to be greater than the input energy.

Output temperature of the products:

$\mathrm{Q}_{\text {out }} \mathrm{K} 083=50594.4 \mathrm{~kJ}$, from equation 9.1 .14 
mass of output $=103.0 \mathrm{~kg}$, from equation 9.1 .15

mass total $\mathrm{N}_{2} /$ mass total output $=114.5 \mathrm{~kg} / 103.0 \mathrm{~kg}-70 \%$, from equation 9.1 .16

Therefore, the $\mathrm{N}_{2} \mathrm{c}_{\mathrm{p}}$ data will be used.

After many iterations using equation 9.1.17

$T_{\text {out }}=1475 \mathrm{~K}$ and the corresponding $\mathrm{c}_{\mathrm{p}}$ is $34.3 \mathrm{~J} / \mathrm{mol} / \mathrm{K}$

(Brunner, Dean, Stephenson, White)

\subsubsection{Practical applications of K083 findings}

K083 mass flow rate per generator:

mass flow $=9.6 \mathrm{~kg} /$ gen. $/ \mathrm{d}$, from equation 9.1 .8

If a plasma destruction facility utilizes a standard $1 \mathrm{MW}$ torch, given the mass flow rate, the time of operation of the facility can be calculated.

Using the aniline and nitrobenzene $\mathrm{Q}_{\mathrm{in}}$ values $2.03 \mathrm{E} 4 \mathrm{~kJ}$ and $1.24 \mathrm{E} 4 \mathrm{~kJ}$, respectively $\mathrm{Q}_{\text {torch }}=3.27 \mathrm{E} 5 \mathrm{~kJ}$, from equation 9.1 .23

$\mathrm{Q}_{\text {torch }}=\mathrm{P}(\mathrm{kW}) * \mathrm{t}(\mathrm{s})$, from equation 9.1 .22

$t=32.7 \mathrm{~s}$

The correlation between mass, power, and time for this waste is as follows

$9.6 \mathrm{~kg} \propto 1 \mathrm{MW} * 32.7 \mathrm{~s}$

This expression provides any unknown value, given the other two values. 
9.2. Trends Observed Varying Temperature with Respect to Time:

For a set DRE, the temperature of the destruction environment and the amount of time the waste resides in the environment are related. Presumably, as the temperature increases, then the waste residence time decreases for a set DRE, and vice versa.

The temperature and time data used was obtained from a table in Calvin Brunner's Hazardous Waste Incineration, 2nd Edition. Brunner derived an equation to express the concentration of the waste as a function of time and temperature. He assumed an oxygen rich environment to provide for suitable combustion. In addition, he considered a constant DRE of $99.99 \%$ to remain consistent with federal regulatory requirements. Beginning with a differential equation relating the differential concentration and the differential time, Brunner derived an expression utilizing the Arrhenius form of the rate constant, the frequency factor, and the activation energy of each compound to relate the destruction efficiency, waste temperature, and residence time of the compounds. This derivation is shown below.

$$
\mathrm{dC} / \mathrm{dt}=-\mathrm{kC}
$$

where $\mathrm{C}=$ destruction concentration at time $\mathrm{t}$ in seconds

$$
k=\text { rate constant }
$$

Integration of this equation will generate

$$
t=(1 / k) * \ln \left(C_{0} / C\right)
$$

where $C_{0}=$ initial destruction $(0$ when $t=0)$

The Arrhenius form of the rate constant, $\mathrm{k}$, is

$$
k=V * \exp [-\mathrm{E} /(\mathrm{R} * \mathrm{~T})]
$$

where $\mathrm{V}=$ frequency factor in $1 /$ seconds

$$
\mathrm{E}=\text { activation energy in cal } / \mathrm{g}-\text { mole }
$$




$$
\begin{aligned}
& \mathrm{R}=\text { universal gas constant }, 1.987 \mathrm{~K}-\mathrm{cal} / \mathrm{g}-\text { mole } \\
& \mathrm{T}=\text { system temperature }
\end{aligned}
$$

Combining and manipulating equations 3 and 4 yields

$$
\mathrm{N}=1-\exp \left\{-\mathrm{V}^{*} \mathrm{t} * \exp \left[-\mathrm{E} /\left(\mathrm{R}^{*} \mathrm{~T}\right)\right]\right\}
$$

where $\mathbf{N}=$ destruction removal efficiency

Solving for the system temperature gives

$$
T=E /\left(R^{*}\{\ln (t)+\ln [-\ln (1-N)] / V\}\right)
$$

All of the values can be manipulated except for the activation energy and frequency factor, which are read from tables, and the gas constant, which is constant.

Software was used to fit a curve to his temperature versus time data for each compound. The curve fits provide a useful form of the data while maintaining accuracy. The function that consistently provided the most accurate fit was:

$$
\mathbf{y}=\mathbf{a} /[\ln (\mathrm{T})+\mathrm{b}]
$$

where $\mathrm{T}=$ temperature in degrees Celsius

$t=$ time in seconds

a (computer generated fitting constant) $=E / R$

$b($ computer generated fitting constant $)=\ln [-\ln (1-N)] / V$

This equation fit the data to an $\mathrm{r}^{2}$ accuracy ranging between 0.9998 and 0.99999999 . Thus, with such a simple and accurate logarithmic relationship between the temperature and time, the data can be manipulated more easily for future work.

The generated plots reveal that the temperature does vary smoothly with time. As expected, the higher the temperature, the lower the residence time required for destruction. The temperatures and times expressed in these results are on the same order 
of magnitude as the results generated from the heat balance calculations. The plots can be found in Appendix 3 (Jandel).

This result offers important implications towards the technology of hazardous waste destruction via plasma treatment because plasma destruction facilities are able to safely reach temperatures greatly exceeding conventional incinerators' maximum operating temperatures. This will provide for a greater throughput because of the brief amount of time required to destroy the wastes in the waste stream. Ultimately, this will lead to a greater efficiency: amount of waste destroyed for a given time duration of operation (Brunner, Jandel).

\subsection{Radicals Generated:}

Hazardous waste destruction occurs as a specified amount of heat energy is introduced to the hazardous waste stream. As the waste materials are heated, certain chemical bonds between atoms and molecules break creating radicals. Radicals are an important concern because their unstable condition causes them to react easily with many molecules and atoms. The reactions may be highly exothermic causing an explosion, may generate further hazardous wastes, or may inhibit desired reactions by reacting with a limiting reagent. Also, most radicals pose a health threat to humans if they escape into the atmosphere.

As the hazardous waste is cooled, the radicals recombine with other radicals to form the original compounds or new compounds. Hazardous waste must be cooled under specified conditions to govern the desired recombinations. If the recombinations can be controlled, innoxious compounds can be generated.

Although the consideration of radicals is important, there exists no way to accurately characterize them during the operation of a destruction system because of the 
complex dissociation and recombination possibilities, and because the system is closed and therefore unobservable. Attempts have been made to quantify the various radicals in waste destruction conditions. These attempts require an exceedingly controlled environment:

- exact measurements of the initial samples

- exact radical measurement devices that are accurate under wide temperature variations

- even and slowly varying temperature distributions

- accurate temperature measuring devices

- a crucible that is inert regarding the initial sample and the subsequent radicals.

A. L. Suris, a Russian scientist, has attempted to conduct such a test with various compounds. His results are used as the basis for the following analysis. His results considered individual compounds, both simple and complex. Specific compounds were considered because of the interest to the North Carolina hazardous waste destruction application.

Because of the nature of hazardous waste, these compounds were analyzed as a composite of compounds. Such a consideration employs the assumption that none of the radicals of differing compounds recombine prematurely. This assumption may not be valid at low temperatures but at higher temperatures, temperatures of interest, the heat energy introduced to the system is likely to be sufficient to prevent undesired recombination. Therefore, this assumption is valid at high temperatures. The temperatures considered in this analysis were $800{ }^{\circ} \mathrm{C}, 1200^{\circ} \mathrm{C}$, and $1600^{\circ} \mathrm{C}$; the plasma gas used was air. These temperature and gas selections are representative of those of interest for a plasma destruction facility.

At $800{ }^{\circ} \mathrm{C}$, the formation of radicals is minor. Nitrogen, oxygen, water, and carbon dioxide molecules are unaffected. Hydocarbons and chlorinated hydrocarbons 
are affected by the temperature although the effect is minimal. These dissociations release chlorine and hydrogen radicals to generate hydrochloric acid. Also the dissociated hydrogen and carbon radicals recombine to form many intermediate hydrocarbons. These hydrocarbons are only stable at high temperatures and will recombine to form stable hydrocarbons at lower temperatures. In addition, diatomic chlorine molecules are generated as a result of the dissociating chlorinated hydrocarbons.

When the temperature reaches $1200{ }^{\circ} \mathrm{C}$ more dissociation is evident. It is instructive to note that this is the regulatory standard temperature for hazardous waste thermal treatment facilities; this allows for an analysis of the dissociation required to meet federal regulations. The same molecules remain generally unaffected. While water and carbon dioxide remain completely inert, the nitrogen and oxygen molecules begin to dissociate a minor amount which initiates nitric oxide (NO) formation. At this temperature, some of the hydrocarbons and chlorinated hydrocarbons have been eliminated and no additional hydrocarbons nor chlorinated hydrocarbons have been generated. More hydrochloric acid is generated because of the furtherly dissociated hydrocarbons. New free radicals in the system are chlorine ions generated from dissociated diatomic chlorine molecules and hydrogen molecules resulting from the dissociated hydrocarbons.

The most abundant compound resulting from molecular dissociation is hydrochloric acid. Concerning the regulatory standards, it must be realized that the excess oxygen necessary for the combustion process would sufficiently minimize hydrochloric acid formation because the hydrogen would react with the excess oxygen generating water. The intermediate hydrocarbons and chlorinated hydrocarbons would also be minimized in the environment specified by regulations. This would occur because the carbon and hydrogen radicals would react with the excess oxygen. The resulting mole- 
cules would be water and carbon dioxide, respectively. Therefore the federal regulations concerning hazardous waste thermal destruction are reasonable.

Another notable issue concerns hydrochloric acid formation resulting from pyrolysis. Although pyrolysis will effectively destroy the original hazardous wastes, the formation of hydrochloric acid must be addressed. Once hydrochloric acid is generated, only very high temperatures will dissociate it. It is possible that the plasma treatment system be operated at sufficiently high temperatures to dissociate hydrochloric acid, but consistent operation to address the needs of a specific compound is unlikely.

Many differences in the existing radicals are apparent at $1600{ }^{\circ} \mathrm{C}$. Nitrogen, oxygen, water, and carbon dioxide are still abundant. However, each contributes to the generation of undesired radicals. Oxygen and nitrogen still form nitric oxide. Now carbon dioxide and water dissociate to form carbon monoxide and hydroxide, respectively. The remaining oxygen radicals recombine to generate diatomic oxygen molecules. No chlorinated hydrocarbons and few hydracarbons exist at this temperature. Although hydrochloric acid is being formed, it begins to dissociate at this temperature. This, along with the dissociating hydrocarbons, allows for diatomic hydrogen molecules to form. Also, chlorine oxide ( $\mathrm{ClO})$ is generated. This radical is hazardous but because it is very unstable at low temperatures, it is not of great concern. It will dissociate before escaping from the waste destruction system. Finally, more free chlorine radicals are generated from the dissociation of diatomic chlorine molecules.

Many conclusions may be drawn from this analysis. First, at temperatures near $800^{\circ} \mathrm{C}$, few hazardous compounds demonstrate an effect. Many radicals are generated as the hazardous waste is introduced to higher temperatures. Many of the radicals are dissociated more completely as the temperature increases further. 
Next, the federal regulations concerning hazardous waste thermal treatment appear to be acceptable considering the radicals existing at the prescribed temperatures and plasma gases within a plasma facility. Since air consists of twenty percent oxygen, then federal regulations could be met using air.

Thirdly, individual atomic radicals resulting from dissociation and are recombined with other single radicals to form radical molecules. This is the only way radical molecules are formed because radicals in molecular form are not dissociated from compounds. Therefore, in the right environment, the atomic radicals can be prompted to recombine to form innocuous compounds before the molecular radicals are formed. Since oxygen has a higher electronegativity than all other items found within hazardous waste, incorporating a surplus of oxygen in the environment will prevent many of the intermediate hydrocarbons formed as well as the hydrochloric acid formed because the radicals formed will be biased to recombine with the oxygen.

9.4 Comparison plasma destruction with conventional destruction:

9.4.1 Residence times and waste throughput:

Typical waste residence times for conventional incineration systems are on the order of seconds. This is primarily because of the RCRA statute requiring hazardous wastes to be thermally treated for at least two seconds at $1200{ }^{\circ} \mathrm{C}$ to guarantee four nines DRE. Secondly, this results from the desired minimization of the products of incomplete destruction.

Plasma thermal treatment of waste offers the possibility of shorter waste residence times which undoubtedly increases the hazardous waste throughput capacity. The lower residence times stem from the high temperature capacity of the plasma system. As the graphs in Appendix 3 show, at higher temperatures, less time is required to 
efficiently destroy the wastes. While the maximum safe operating temperature of a conventional system is stunted near $1000^{\circ} \mathrm{C}$, plasma destruction systems can safely operate with a system temperature greater than $1500^{\circ} \mathrm{C}$.

The plots indicate that if the plasma system were to operate at $1050^{\circ} \mathrm{C}$ with a waste residence time of one second with a typical North Carolina waste stream, the four nines DRE requirement would be met. This fact implies that the $1200{ }^{\circ} \mathrm{C}$ and two seconds federal requirement may be conservative. Operation in this mode would at least double the throughput capacity of conventional destruction technologies which have a minimum residence time of two seconds. Moreover, increasing the destruction temperature to $1150{ }^{\circ} \mathrm{C}$ would reduce the required residence times to less than one-half second. This quadruples the conventional throughput capacity. Therefore the residence times are notably shorter with the plasma destruction technology than with conventional technologies (Freeman, Hall, PEC).

\subsubsection{DRE:}

As Table 9.1 (Dellinger) shows, the DRE of hazardous waste increases with increasing temperature. Although the scanty information provided in the table prevents an accurate functional correlation, the trend is evident.

Again, plasma destruction offers a benefit over conventional destruction methods. Because of the elevated safe operating temperatures of plasma systems, they are able to more thoroughly destroy wastes to higher DREs than conventional systems within a given amount of time. No quantification of the increase shall be attempted.

Thus, plasma thermal destruction offers the advantages of a decreased time requirement; an increased efficiency; an increased DRE; and an increased throughput when compared to conventional thermal waste destruction technologies. These facts 
suggest that plasma hazardous waste destruction is superior to the conventional technologies (Dellinger, Lide). 
Table 9.3: Temperatures Required for Set DREs at Two seconds

\begin{tabular}{|c|c|c|c|c|}
\hline Compound Name & $\begin{array}{l}\text { Chemical } \\
\text { Formula }\end{array}$ & $\mathrm{T}_{\text {onset }}\left({ }^{0} \mathrm{C}\right)$ & $\begin{array}{c}\mathrm{T}_{99 \%}\left({ }^{0} \mathrm{C}\right) \\
2 \text { sec. }\end{array}$ & $\begin{array}{l}\mathrm{T}_{99.99 \%} \\
\left({ }^{\circ} \mathrm{C}\right), 2 \mathrm{sec} .\end{array}$ \\
\hline Acetonitrile & $\mathrm{C}_{2} \mathrm{H}_{3} \mathrm{~N}$ & 760 & 900 & 950 \\
\hline Tetrachloroethylene & $\mathrm{C}_{2} \mathrm{Cl}_{4}$ & 660 & 850 & 920 \\
\hline Acrylonitrile & $\mathrm{C}_{3} \mathrm{H}_{3} \mathrm{~N}$ & 650 & 830 & 860 \\
\hline Methane & $\mathrm{CH}_{4}$ & 660 & 830 & 870 \\
\hline Hexachlorobenzene & $\mathrm{C}_{6} \mathrm{Cl}_{6}$ & 650 & 820 & 880 \\
\hline Tetrachlorobenzene & $\mathrm{C}_{6} \mathrm{H}_{2} \mathrm{Cl}_{4}$ & 660 & 800 & 850 \\
\hline Pyridine & $\mathrm{C}_{5} \mathrm{H}_{5} \mathrm{~N}$ & 620 & 770 & 840 \\
\hline Dichloromethane & $\mathrm{CH}_{2} \mathrm{Cl}_{2}$ & 650 & 770 & 780 \\
\hline Carbon Tetrachloride & $\mathrm{CCl}_{4}$ & 600 & 750 & 820 \\
\hline Trichlorobenzene & $\mathrm{C}_{6} \mathrm{H}_{3} \mathrm{Cl}_{3}$ & 640 & 750 & 790 \\
\hline Dichlorobenzene & $\mathrm{C}_{6} \mathrm{H}_{4} \mathrm{Cl}_{2}$ & 630 & 740 & 780 \\
\hline Ethane & $\mathrm{C}_{2} \mathrm{H}_{6}$ & 500 & 735 & 785 \\
\hline Benzene & $\mathrm{C}_{6} \mathrm{H}_{6}$ & 630 & 730 & 760 \\
\hline Aniline & $\mathrm{C}_{6} \mathrm{H}_{7} \mathrm{~N}$ & 620 & 730 & 750 \\
\hline Monochlorobenzene & $\mathrm{C}_{6} \mathrm{H}_{5} \mathrm{Cl}$ & 540 & 710 & 780 \\
\hline Nitrobenzene & $\mathrm{C}_{6} \mathrm{H}_{5} \mathrm{NO}_{2}$ & 570 & 670 & 700 \\
\hline Chloroform & $\mathrm{CHCl}_{3}$ & 410 & 590 & 620 \\
\hline Trichloroethane & $\mathrm{C}_{2} \mathrm{H}_{3} \mathrm{Cl}_{3}$ & 390 & 570 & 600 \\
\hline
\end{tabular}

\subsubsection{Efficiencies:}

Plasma destruction facilities demonstrate unprecedented energy efficiencies. Conventional hazardous waste destruction facilities have energy efficiencies maximizing around 32 percent. Whereas, system efficiencies over 50 percent have been recorded in plasma facilities. Although such high effiencies are not yet common, the technology exists to commercially develop high efficiency plasma destruction facilities.

The dominant energy losses within a plasma treatment plant are: mechanical losses, torch losses, and atmospheric gas losses. Mechanical losses are minor and are 
generally unchangeable. The only way to alter these losses is to rearrange and replace the facility's machinery. The heating of the electrode also plays a minor role in reducing the overall efficiency. This can be adjusted using a different electrode design or different electrode materials. But since neither the mechanical nor torch losses greatly affect the efficiency, no adjustments are considered.

The most significant losses in a plasma waste destruction facility are losses to the destruction chamber gases. This is the result of the plasma's radiated heat as the plasma travels from the electrode to the slag. These losses can be adjusted in numerous ways. Altering the plasma power, changing the length of the plasma, and manipulating the vortex stabilization gas are possible adjustment mechanisms.

Studies have shown that optimizing the efficiency concerning atmospheric losses is a design endeavor rather than an engineering endeavor. The reduced scale model of plasma treatment plants often have very high efficiencies, while the full scale models have reduced efficiencies. This is because the model scale facilities maximize their waste throughput during testing, whereas the full scale modes often operate at much lower throughputs than their maximum. Therefore, if the full scale facilities are designed to operate at the feed rates at which they are expected to operate, less energy will influence the gaseous atmosphere and more would be imparted to the waste stream which will increase the efficiency of the system.

Consequently, plasma waste destruction systems have much higher efficiencies than conventional facilities. Moreover, the efficiencies of plasma facilities can be increased in numerous ways through adjusting either design or engineering parameters (PEC).

9.4.4. Maintenance: 
One exceptional benefit of a plasma destruction facility is its maintainability. Its non-operational times due to maintenance are far shorter than for conventional hazardous waste destruction facilities. This is primarily because of the simplicity of the overall plasma destruction concept.

A plasma destruction facility uses a hot gas to thermally treat hazardous wastes. Therefore, no moving parts are required. This reduces the likelihood of a mechanical failure because the variable of parts in motion are eliminated. Also, the lack of moving parts provides for a long life of the facility's components because there is no frictional wear on any of them. Finally, less work and time is required to repair stationary components than moving components because fewer tests are necessary to verify proper fitting and correct functioning of motionless components.

An additional benefit of the plasma facility concerning maintenance is that it operates at atmospheric pressure. Most conventional facilities operate at subatmospheric pressures for safety reasons. Because of this, if any internal component malfunctions, the system must cool, and the system pressure must be allowed to increase. After the maintenance operation, the system must be pumped down to its original pressure. This pumping process is very time consuming. In contrast, plasma treatment facilities only require that the system cool before maintenance. This abbreviates the amount of time before it can resume operation.

Another set of problems plasma destruction avoids by operating at atmospheric pressure is that of seals. A facility operating below atmospheric pressure needs seals to maintain the pressure differences inside and outside the facility. The seals are often a primary failure of conventional systems. When a seal is broken, time must be taken to replace the seal, and more time must be taken to pump the facility back down to 
the operating pressure. This long process is not a concern with plasma destruction facilities because they have no pressure seals since they operate at atmospheric pressure.

Lastly, plasma treatment facilities do not depend on any chemical reactions as the primary means of waste destruction. So when maintenance is necessary, it can occur immediately after the system cools and no special actions are necessary to address compounds existing within the facility to promote the waste decomposition. It would be time consuming and costly to remove chemical materials from a facility when maintenance is needed.

Therefore, the plasma destruction facility is superior to conventional hazardous waste destruction facilities in the area of maintenance. This results from the plasma facility's stationary components, atmospheric pressure operation, and no chemical materials within the facility's destruction chamber (Hall, Lee, PEC).

\subsubsection{Costs:}

The costs associated with plasma torch destruction facilities are lower than those associated with conventional facilities. The Kawisaki Steel Corporation in Kawisaki, Japan conducted a study comparing the capital costs, maintenance costs, and energy costs of a plasma and conventional facility. The Kawisaki Steel Corporation performs steel processing and waste ash processing. Albeit hazardous waste streams are not specifically processed, because the technologies are similar, Kawisaki's results are credible and applicable to the hazardous waste destruction analysis.

Capital costs for a conventional facility were found to be moderate whereas for a plasma facility, the capital costs were low. The difference between the two costs stems from the few and motionless parts necessary for a plasma facility. Both types of waste destruction facilities require construction, but the time of construction for a plasma 
facility is less than for a conventional facility. This decreases the relative costs of a plasma facility. Also, fewer tests need to be conducted to verify the suitable operation of a plasma facility because there are fewer items to test and the items tested can be done simply.

The only two expensive components for a plasma torch are the collimator and the electrode shroud. The collimator is expensive because it is heavily machined, and the shroud because it is constructed with a large quantity of material and contains precise welds. All other components are inexpensive.

The actual licensing costs of a plasma destruction facility and a conventional facility were found to be the same in the state of California. Each costs approximately $\$ 3$ million which is average for the state. There is no evidence to indicate that the similarity in licensing costs would be different if the facilities were to be licensed in any other state.

The low maintenance costs of a plasma waste destruction facility greatly contrast the high maintenance costs of a conventional facility. This is primarily due to the motionless components of the plasma treatment facility as well as the lack of seals required for a plasma treatment facility. Only after certain catastrophic failures would expensive components of a plasma destruction facility need replacing. Because catastrophic failures are infrequent, the overall maintenance costs for a plasma waste treatment system are minimal.

The energy costs of a plasma system are moderate, but higher that those for a conventional system. A plasma facility is powered with electricity, which is four times more expensive than most energy sources. Even so, because of the design and engineering of plasma facilities, the energy costs are moderate. The high efficiencies, no fuels requirement, and effective heat transfer of the system are the dominant factors lowering 
the energy costs. To contrast, conventional facilities are powered by fuel which incur only minimal costs. As the effiencies of plasma systems increase, less energy will be lost and more waste will be processed with a given amount of energy. These factors will reduce the energy costs of plasma facilities making them more comparable to the energy costs of conventional facilities. Thus, energy costs for a plasma waste destruction system are higher than for a conventional facility, but very reasonable. In addition, the hopes of decreasing energy costs for the plasma system are promising.

Clearly, plasma waste destruction facilities are more outstanding than conventional facilities in the area of cost. While the technology approaches the low energy costs of conventional systems, it maintains a notable advantage in the areas of capital and maintenance costs (Guyer, PEC).

\subsubsection{Safety:}

Many safety factors are associated with plasma hazardous waste destruction facilities. Because of the great differences between the plasma technology and the conventional technology, certain plasma facility safety concerns are different from those realized in a conventional facility.

One general safety concern is the high operating temperature of the system. The high temperature mandates that no persons reside in areas near the system while it is in operation so that burns are prevented. Also the temperature and the heat source must remain under control at all times to prevent high heat damage to the interior of the facility. Another general concern is that the system operates at atmospheric pressure. Therefore, if a catastrophic failure occurred, then the products of incomplete destruction would be free to escape into the atmosphere. 
Areas of safety specific to plasma destruction facilities are radiated ultraviolet rays, electrical fires, hearing damage to persons, and certain high temperature reactions. The operation of the plasma torch may not be viewed because of the harmful ultraviolet rays emitted from the plasma. Electrical fires are a concern because of the high voltage and high current of the plasma. If the torch operates in an open area, then its sound will be loud and may cause hearing damage if no hearing protection is used. Certain volatile reactions are specific to plasma hazardous waste systems. One example is aluminum and water vapor. When these two components come in contact with one another at high temperatures, they react violently. Thus plasma waste destruction facilities have many safety concerns specific to them. Each one is typically addressed such that there is no threat to human life nor machinery while the facilities are operational.

Certain safety concerns typically realized in conventional waste destruction methods are eliminated through the use of plasma destruction of waste. First, the heat source is easily controlled by manipulating the power of the plasma. Next, the heat source is on top of the waste, making it easily identifiable and monitorable. Also, the plasma torch and other aspects of the facility are completely composed of non-hazardous materials. For example, neither cadmium nor beryllium are used. Therefore, no Materials Safety Data Sheets (MSDS) are necessary. Additionally, the wastes generated are effectively destroyed and there are fewer hazardous atmospheric emissions than from a conventional facility. Finally, the plasma torch is a predictable and reliable heat source. Hence, plasma hazardous waste destruction facilities present some safety concerns and addresses others. All of the safety concerns presented with this technology are maintainable and monitorable, making it safe for operation (Freeman, Hall, Lee, Dellinger).

\subsection{Regulations met:}


Plasma thermal destruction meets all of the federal regulations established by RCRA and TSCA. The regulations are specific so that safe and effective destruction of the waste is guaranteed. The plasma has the ability to meet all of the intermediate regulations which govern the temperature and the time of destruction. Also the technology allows for safe, effective hazardous waste destruction which surpasses the regulatory standards using shorter times than required. This may cause the federal regulations to adjust to account for the effectiveness of this technology.

Plasma waste destruction consistently attains the four nines DRE for hazardous waste required by RCRA. In addition, it regularly meets the six nines DRE TSCA mandates for PCBs. Finally, the level of PIDs are maintained at a safe level. Thus, this technology satisfies all of the federal regulations established for hazardous waste destruction facilities (Briggum, PEC, Wagner). 


\subsection{ADDITIONAL CONSIDERATIONS}

10.1. Future considerations

\subsubsection{Medical Waste}

EPA's research data and industry's operating experience indicate that thermal treatment is possibly one of the best available technologies for disposing of various waste streams. Thermal treatment is currently the most widely used medical waste disposal technology. The major advantage of thermal treatment is that it significantly reduces the volume of material, can destroy biological wastes (pathogens), and can destroy hazardous organic wastes. Plasma thermal treatment offers benefits beyond those offered by conventional thermal treatment facilities.

The definition of regulated medical waste is rather ambiguous. It can be summarized as any waste generated during the research, diagnosis, treatment, or immunization of humans or animals. The definition is said to include certain hazardous and radioactive materials, and pathogens. Medical wastes which do not fall into any of the listed categories are considered general refuse and is regulated as general household waste.

The main differences between the thermal treatment of medical waste and other waste streams include the following:

- Unique components exist within medical waste.

- The batch to batch variations of medical waste differ greatly.

- Medical waste thermal treatment facilities need to be small sized for on site thermal treatment applications.

These differences cause several additional problems and considerations with the design and operation of conventional medical waste thermal treatment facilities. 
Plasma thermal treatment addresses each of these areas in an effective manner. The unique constituents will be addresses by the high temperatures within the plasma thermal treatment facilities. Independent of the specific components, the excessively high temperature capabilities of plasma thermal treatment facilities will sufficiently destroy the waste.

The adjustable environment within plasma thermal treatment facilities' destruction chambers will provide the necessary flexibility for the various streams of medical waste. Plasma thermal treatment facilities can alter their temperatures of destruction in addition to the plasma gases to promote the most efficient and effective destruction for the specific batches of wastes. Contrarily, for conventional thermal treatment facilities, the wide batch to batch variations of medical waste coupled with the relatively small equipment sizes causes swings in operation characteristics to be much wider than desired. Because of the inherent adjustability of plasma thermal treatment facilities, this concern is not a problem.

Finally, the small size needs can be easily met with plasma thermal treatment facilities. Plasma thermal treatment facilities can be built in various sizes, from very large to very small, while maintaining their destruction effectivenesses. The MARC-I, constructed at the Massachusetts Institute of Technology, has a destruction chamber diameter of one foot. On the other hand, the Plasma Centrifugal Furnace, developed by Retech, Incorporated, employs a crucible diameter of six feet. Both systems have been proven effective.

The most notable advantage of plasma thermal treatment as compared to conventional thermal treatment technology concerns emissions. Generally speaking, the small size requirements of conventional thermal treatment facilities results in incomplete destruction of certain waste materials. The incomplete combustion may result in the 
same PCDDs and PCDFs resulting from incomplete hazardous waste destruction. The small thermal treatment facility sizes preclude the use of air pollution control mechanisms. Thus, the PIDs are released into the atmosphere. Plasma thermal treatment facilities, on the other hand, have been verified to destroy wastes down to $10^{-9}$ of their original volume (one part per billion), compared to $10^{-4}$ of the original volume for conventional thermal treatment facilities. This leads to two conclusions. First, for such an effective volume reduction by the plasma thermal treatment facilities, complete destruction can be expected, eliminating PID concerns. Also if any PIDs were to result form plasma thermal treatment, their concentrations would be $10^{-5}$ of the concentration emitted by conventional thermal treatment making pollution control devices much less of a concern.

Pathogen emissions are also a concern to conventional thermal treatment facilities. Recent studies indicate that conventional thermal treatment facilities emit only minimal pathogens. Even so, because pathogens possess the capacity to cause disease, the pathogen emissions must be completely eliminated. This can be accomplished by operating plasma thermal treatment facilities at the upper end of their temperature capacities. Above certain temperatures all living organisms cease to exist. Therefore, utilizing plasma thermal treatment to reach these temperatures all pathogens can be eliminated.

Other strengths of plasma thermal treatment are the under developed medical waste regulations. There are currently no comprehensive federal medical waste management regulations. Each state independently regulates its own medical waste management. Therefore, the medical waste regulations vary greatly from state to state. Some states have adopted regulations so strict that 90 percent of all operating incinerators are expected to be shut down. Other states have adopted the congressional statute which di- 
rects that all medical waste thermal treatment products are no longer tracked as medical waste. North Carolina has enacted stringent yet attainable medical waste thermal treatment regulations. Plasma incineration offers the alternative of effective destruction that will allow for many regulations to be met that are not currently being met by conventional thermal destruction facilities. This consistent effectiveness will promote universal federal regulations according to the standards set by plasma thermal destruction facilities.

The chief disadvantage of plasma thermal treatment is the cost. The power consumption costs of a plasma thermal treatment is four times greater than the cost of operating a conventional thermal treatment facility. This is a direct result of the electrical needs of the plasma arc. Yet it is the electric power of plasma thermal treatment that provides the versatility and overall benefit of the system. The power consumption costs are balanced by the facility's high efficiency as they are with hazardous waste treatment. Therefore, the cost increase is necessary but is outweighed by the technology's benefits.

Plasma thermal treatment is the most suitable response to the needs of medical waste disposal. Its high temperature capacity, variable operating conditions, and variable sizes makes it a considerable option for all medical waste streams generated. The plasma thermal treatment facility's reduced emissions of PIDs and pathogens when compared with conventional thermal treatment facilities increases the technology's attractiveness. Thus, plasma thermal treatment is the most effective medical waste destruction technology available (Lee, Palmark, Sears, DOE).

\subsubsection{Mixed Waste}

\subsubsection{General Considerations}


Mixed wastes are those which are both hazardous and radioactive. These wastes are difficult to treat primarily because they are heavily regulated. One example of a mixed waste is radioactive lead. This waste must be regulated as both a hazardous waste and a radioactive waste. Even if the radiation associated with the lead were minimized, it would still be regulated as a hazardous waste. Conversely, if the hazards of the lead were minimized, it would still be regulated as radioactive material. Plasma treatment of mixed wastes appears to be a reasonable solution to the problems of mixed waste destruction.

Mixed waste streams in the state of North Carolina are poorly characterized as a result of the conditions under which the waste streams were generated. Detailed characterization of these wastes would require significant costs; therefore, technologies are needed that can treat wastes, meet permit requirements, and satisfy process monitoring needs, with minimal waste stream characterization and segregation requirements. In addition, treatment technologies are needed that dramatically reduce waste volumes and that produce final waste forms that are disposable. The plasma destruction technology provides a relatively near-term solution to these technology needs. For many years, plasma arc technology has been in industrial use for metal cutting and welding, and metal ore smelting. Plasma arc thermal treatment units are commercially available for treating both hazardous wastes and radioactive wastes.

Under plasma arc technology development and application projects, representative surrogate waste streams will be treated in a plasma destruction facility to determine the applicability of the technology and any specialized process requirements. Initially, the surrogates will not contain any radioactive components. Partitioning of radionuclide surrogates will be determined, and a design for a second generation plasma destruction facility will be developed and tested. This facility will safely treat mixed 
wastes with a low level radioactive component. Waste stream characteristics which are required for processing will be determined, and the project staff will work with the regulatory agencies to determine the minimal characterization parameters required to meet regulatory requirements while ensuring process safety and effectiveness. Representative final vitrified waste forms produced by the process will be evaluated for their performance with respect to leachability, integrity, mechanical strength and other parameters which will be determined under the project.

Thus far, proof of concept test burns have been performed for materials in drums characteristic of North Carolina's waste streams but with no radioactive component. Wastes were effectively destroyed in the process and produced a final waste form that was vitrified with a high integrity. The plasma torch mixed waste destruction concept represents a relatively low-risk modification and application of a proven technology to North Carolina's unique low level radiological and hazardous waste stream processing requirements (DOE).

\subsubsection{Uranium Hexaflouride Considerations}

One possible application of the plasma waste thermal treatment technology is in the area of uranium hexaflouride $\left(\mathrm{UF}_{6}\right)$ management. Currently, this highly radioactive and toxic waste is strictly regulated because of its potential hazards to humans and the environment. In addition, its treatment and disposal are very expensive. Because this costly waste is treated per unit volume, it is desirable to do two things. First, a volume reduction decreases the amount of waste to be managed, thus lowering its cost of management. Also, a separation of the mixed waste into its hazardous and radioactive constituents reduces the amount of regulatory requirements the total quantity of waste 
has to meet. This, too, lowers the cost of management. The plasma thermal treatment technology adequately addresses both issues.

This technology can be used to dissociate $\mathrm{UF}_{6}$ into $\mathrm{UF}_{4}$ and HF through the following reaction:

$$
\mathrm{UF}_{6}+2 \mathrm{H}+\text { (heat) -----> } \mathrm{UF}_{4}+2 \mathrm{HF}
$$

The two hydrogen atoms necessary for the reaction to proceed may be supplied by the plasma gas if a hydrogen mixture is used; or, by the dissociation of a hydrogen rich compound. Either method of hydrogen production may be accomplished with existing plasma torch technology.

The benefit of such a separation is that the amount of mixed waste to be managed is reduced because of the separation of a portion of the hazardous component. Further, $U_{4}$ has a density of $6.70 \mathrm{~g} / \mathrm{cm}^{3}$, which is 43 percent greater than the density of $\mathrm{UF}_{6}\left(4.68 \mathrm{~g} / \mathrm{cm}^{3}\right)$. This also indicates a lower volume of mixed waste and cost of management.

The plasma thermal treatment technology is one of the few known mechanisms available to address the needs of $\mathrm{UF}_{6}$ disposal. The cost of disposal is significantly reduced by treating the waste with the plasma technology. This technology is considered to be a beneficial and cost saving mechanism in the management of $\mathrm{UF}_{6}$ (Lide).

\subsection{Needs}

Because of the novelty of this waste destruction technology many needs exist, that if addressed, will significantly improve the effectiveness and applicability of the technology. Some needs may be easily addressed while others are very detailed and complex. 
First, further study is needed on this subject. Studies need to to be conducted that are broader and more in depth. There exists virtually no benchmarked information regarding the plasma waste destruction technology. This information will improve the quality of research on the subject and more consistently identify trends.

Next, many needs are related to the chemistry of reactions within the destruction chamber. Much more high temperature chemistry and high temperature thermochemictry data is needed. This information includes specific heats, specific enthalpies, etc.. Also, chemistry information is needed to address chemical kinetics at high temperatures and during strong temperature gradients. This information will assist in determining how the radicals and other waste products react with one another in a cooperate environment.

Concerning the waste destruction facility, data is needed as well. More detailed models of the plasma torch and of temperature distributions within the facility must be generated. A thorough study on plasma torch gases mixtures and their effect on the torch, system, and waste destruction would be useful also.

This technology needs to be more specifically applied to the various existing waste destruction needs. For example, research can be conducted to determine how this technology may be specifically applied to mixed waste and medical waste treatment needs.

Finally, a detailed economic assessment of this technology is necessary. This assessment should include a detailed analysis of capital, operational, and economic costs, and the effects of inflation over time. Moreover, this assessment should offer a short term and long term economic comparison with the rotary kiln and other technologies considered for hazardous waste disposal. 


\subsection{CONCLUSIONS}

Plasma thermal destruction is superior to rotary kiln incineration and all other thermal treatment technologies considered to address North Carolina's waste disposal needs. A primary reason for this technology's marked advantage is the high operating temperature it utilizes. The high temperature of operation facilitates effective heat transfer, mandates shorter waste residence times, provides for higher throughputs, and maximizes DREs when compared to alternative waste destruction technologies.

Another benefit of this technology is its few moving parts. The rotary kiln technology uses many mobile components for its operation. Because the plasma thermal treatment technology employs few moving parts, it is considerably more simple to use and maintainable. Its maintainability causes it to have a fewer number of down times because of malfunction. Moreover, the simplicity of the technology's concept provides for shorter down times when it does malfunction.

The plasma waste destruction technology operates using electrical power. Therefore, its heat source is far more controllable than other waste destruction technologies. The furnace temperatures within a plasma treatment facility may be varied by adjusting the power output of the plasma torch; while, other technologies have no variation in their operating temperatures. The electrical power of the plasma destruction facility make its heat source safer and more monitorable than alternative waste treatment technologies. Also, the electrical powered heat source of the plasma technology is cleaner than the liquid fuel of the rotary kiln, and heat sources of other technologies.

Because the plasma treatment technology utilizes a gas as the heat transfer mechanism, it is more flexible and adaptable than alternative waste treatment technologies. It is flexible in that the gas can be adjusted to most effectively destroy all phases of wastes including solids, sludges, liquids, and gases. It is adaptable because the gas can 
be manipulated to effectively destroy a specific waste stream that may be difficult or impossible to destroy with other technologies. Lastly, the most commonly used and effective plasma gases, air and oxygen, are very cheap.

The high temperatures, effective DREs, and high throughputs, coupled with the low power consumption required to achieve them defines the plasma thermal treatment system as very efficient. Recorded efficiencies using the plasma technology are over 50 percent compared to the 32 percent upper level efficiencies of all other waste destruction technologies. Additionally, it is likely that the efficiencies of the plasma system will increase as heat transfer within the system is maximized.

The plasma treatment technology is also considered a viable alternative in many waste destruction arenas in which no other technologies are available. For medical wastes, the technology offers consistently effective destruction in addition to all of the other benefits noted. No conventional technology nor innovative technology offers the same effective destruction. For mixed wastes, plasma destruction shows itself to be very effective, both separating the wastes and densifying the mixed wastes. No conventional technologies have shown any promise of consistent, effective destruction. The ultimate disposal costs of the products of plasma treatment are significantly lower than the costs of disposal with no treatment because a lower mixed waste volume exists after plasma treatment.

Therefore the plasma thermal treatment technology is an excellent alternative in addressing the hazardous waste destruction needs of North Carolina. The technology offers many benefits which ultimately make it cheap and effective, surpassing all federal regulations. Plasma thermal treatment is the pre-eminent waste destruction technology presently available. 


\section{APPENDIX 1: CHEMICAL CONSTITUENT SELECTION FOR ANALYSIS}

Approximately one hundred chemicals are known to exist in notable quantities within North Carolina's waste; and potentially thousands exist in less abundant amounts. Therefore, simplifications are necessary to provide for real time analyses.

The first simplification was that all of the hazardous wastes analyzed in this study were composed of twenty-seven chemicals which have been heavily studied and whose chemical properties are well known in a variety of conditions. The chemicals investigated are listed in Table A-1.1. This simplification was useful because it allowed for a more focused approach to the study. It greatly increased the likelihood of necessary data existing in abundance. Having an abundance of information to cross reference promoted more consistent data that was to be studied. Studying only well known chemicals also decreased the evaluation time. From the perspective of time, it was impractical to consider the effects on all of the specific chemicals involved because too many existed in such varying quantities. Finally, this simplification was purely realistic. The averages addressed in this study considered four years of operation of all North Carolina's waste generation and disposal sites. Yet no one site generated nor managed the full variety of wastes considered. Each site generated and managed wastes according to the needs of the specific industry. Thus a pure average would not adequately consider the interests of the industries generating the wastes; whereas, addressing a fewer number of wastes in greater abundance models industry more closely.

In certain cases, approximations of chemicals were necessary. For example, consider EPA code number U061. The specified chemical for this code number is 1-1(2,2,2-Trichloroethylidine)bis[4-chlorobenzene], also known as DDT. The EPA code recognizes only this chemical within the U061 listing. However, this chemical has not been thoroughly studied which would have made its evaluation very difficult. Since no 
other chemicals are categorized within the U061 heading, no alternative chemicals were available to study within this category. Therefore, an approximation of DDT with a similar chemical composition was formulated from well-studied chemicals. This approximation allowed for the U061 category to remain in the study. All approximated chemicals are identified in Table A-1.1 with a star. Following the approximate chemical is the actual EPA recorded chemical in parentheses.

The final simplification made concerns metals. Generally, only heavy metals are identified as hazardous. These metals are easily separated from the bulk of the hazardous waste generated and are not incinerated for disposal. If these materials are incinerated with other hazardous wastes they may vaporize or chemically combine with other waste that is being incinerated. The more desirable method to address hazardous metals involves treating the metal wastes and recycling them. This practice is commonly performed within the hazardous waste management industry. So in this study no metals were considered as waste. This simplification most significantly affects the EPA D classification of wastes. .An effect is also noticeable within the $F$ and the $\mathrm{K}$ classifications. All of the eliminated metals are listed in table A-1.2.

Although the variety of wastes is lessened because of this simplification, the effect on this study is minimal for two reasons. First, the metals are dense. This mandates only a modest affect on the overall volume which is one of the study's areas of interest. Next, recall that many chemical are not considered because of the lack of necessary information concerning them. Therefore, eliminating the consideration of metals remains consistent with the first simplification addressed.

Thus, three notable simplifications were made in the selection of chemicals addressed within this study.

1. Only twenty-seven chemicals were considered. 
2. Chemical approximations were used when absolutely necessary.

3. No metals were considered.

These simplifications increased the realistic quality of this study for industry and significantly reduced the amount of computation time necessary for a thorough evaluation (Baker Brothers, Lancy, Lide, MRT, Snyder).

\section{Table A-1.1: Chemicals Investigated}

1. Acetic Anhydride

2. Acetonitrile

3. Acrylonitrile

4. Aniline

5. Benzene

6. Butane* (Butanone)**

7. Carbon Tetrachloride

8. Chloroform

9. Dichlorobenzene

10. Dichloromethane

11. Ethane* (DDD)

12. Ethyl Nitrite

13. Ethylidene Dichloride
14. Hexachlorobenzene

15. Methane

16. Methyl Iodide* (Methylene Chloride)

17. Monochlorobenzene

18. Nitrobenzene

19. Pentachlorobyphenal* (DDD)***

20. Propylene Oxide

21. Pyridine

22. Tetrachlorobenzene

23. Tetrachloroethylene

24. Toluene

25. Trichlorobenzene

26. Trichloroethane* (DDT)

27. Vinyl Chloride

**both butane and butene demonstrated similar qualities as butanone; therefore both were used to approximate butanone

***because of the similarity of properties between pentachlorobiphenyl and chlorobiphenyl, these two compounds were used interchangeably according to which properties were more clearly defined concerning the specific area 


\section{A-1.2: Metals Eliminated from Study}

\section{Metal Not Considered}

Arsenic

Barium

Cadmium

Chromium

Lead

Nickel
EPA Group Description Containing Metal

D004 - Arsenic

D005 - Barium

D006 - Cadmium

F006 - Electroplating Sludge

K061 - Dust and Sludge from Steel Production

K088 - Spent Potliners

D007 - Chromium

F006 - Electroplating Sludge

K061 - Dust and Sludge from Steel Production

K088 - Spent Potliners

D008 - Lead

K061 - Dust and Sludge from Steel Production

F006 - Electroplating Sludge 


\section{APPENDIX 2: VOLUME CALCULATIONS}

The North Carolina Hazardous Waste Annual Reports, the source of the quantities evaluated, reports waste quantities in units of weight. For this study, volumetric units are more suitable so a unit conversion is necessary. The following offers a detailed analysis of how the North Carolina hazardous waste volumes were calculated.

A list of the hazardous wastes generated in North Carolina averaged over four years (1989 - 1992) and their quantities by weight is presented in Table A-2.1. The table identifies the EPA code number, the type of hazardous wastes, and the amounts of wastes generated.

The specific wastes composing each of the EPA code groups were then identified. From these lists, wastes were selected that are well studied. Table A-2.2 identifies the specific wastes selected to study within each EPA code group. Certain group codes are not presented because either they offered a negligible contribution to the total quantity of North Carolina waste, or they contained solely heavy metals.

Next, physical properties were noted and listed in Table A-2.3. The values listed for each waste include the chemical formula, the boiling point, the melting point, and the density.

Each waste from Table A-2.2 was assumed to contribute an equal weight to the EPA code group. To calculate the volume of each waste within the respective code groups, the fractional weight contributed by each chemical was divided by its density, thus quantifying the fractional volume of each waste within each EPA code group. The fractional volumes only considered the code groups studied so these volumes had to be adjusted to acknowledge that not all code groups were studied within each EPA letter classification. This process is demonstrated in example EA2.1. All of the fractional vol- 
umes were added within each EPA code group to generate the total volume of waste within each code group.

To calculate the total volume of waste within an EPA letter classification of waste (i.e. D, F, etc.) it was assumed that the heavy metals and inorganics had a much greater density than the compounds considered. This assumption is valid because organics typically are less dense than water while heavy metals and inorganics are generally much more dense than water. Therefore, the total volume of waste within specific letter classifications was determined by summing the volumes of the code groups considered within the classifications. Thus, heavy metals nor organics were considered in the overall volume determination; but given the density assumption, this effect is negligible on the overall volume.

By summing the letter classification volumes calculated, a total average volume for North Carolina's hazardous waste was calculated. The calculated volumes are listed in Table 4.1. An itemized list of the fractional volumes within each EPA code group is shown in Table A-2.4 (Cobey, Howes, Lide, West). 


\section{Example EA2.1}

Note: mass values were originally recorded in lbs

$$
\begin{aligned}
\mathbf{k} & =\text { unit conversion constant } \\
& =0.45335993 \mathrm{~kg} / \mathrm{lb} * 1000 \mathrm{~g} / \mathrm{kg} * 1 \mathrm{~m}^{3} /(100 \mathrm{~cm})^{3} \\
\mathbf{k} & =4.536 * 10^{-4} \mathrm{~g}^{*} \mathrm{~m}^{3} / \mathrm{lb}^{*} \mathrm{~cm}^{3}
\end{aligned}
$$

D002 wastes:

fractional volume of acetic anhydride (50\% of D002 mass):

$6877381.25 \mathrm{lb} \mathrm{D002} * 0.5 \mathrm{lb}$ aa $/ 1 \mathrm{lb} \mathrm{D002/1.082}\left(\mathrm{g} / \mathrm{cm}^{3}\right) *$

$$
\text { * } 4.536 * 10^{-4} \mathrm{~g} * \mathrm{~m}^{3} / \mathrm{lb}^{*} \mathrm{~cm}^{3}=1441.7 \mathrm{~m}^{3}
$$

fractional volume of trichlorobenzene (50\% of D002 mass):

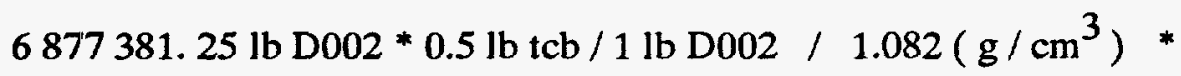

$$
\text { * } 4.536 * 10^{-4} \mathrm{~g} * \mathrm{~m}^{3} / \mathrm{lb}^{*} \mathrm{~cm}^{3}=1072.6 \mathrm{~m}^{3}
$$

Total volume of D002 wastes in $\mathrm{m}^{3}$ :

$$
\begin{array}{ll}
\text { acetic anhydride: } & 1441.6 \\
\text { trichlorobenzene: } & 1072.6 \\
\hline \text { Total D002: } & 2514.2
\end{array}
$$


Table A-2.1: Average Masses of North Carolina Wastes (1989-1992)

EPACode Description

$\begin{array}{ll}\text { D001 } & \text { Ignitable } \\ \text { D002 } & \text { Corrosive } \\ \text { D003 } & \text { Reactive } \\ \text { D004 } & \text { Arsenic } \\ \text { D005 } & \text { Barium } \\ \text { D006 } & \text { Cadmium } \\ \text { D007 } & \text { Chromium } \\ \text { D008 } & \text { Lead } \\ \text { D018 } & \text { Benzene }\end{array}$

Other D Wastes

TOTAL D

F001 Spent Halogenated Degreasing Solvents

F002 Halogenated Solvents

F003 Spent Halogenated and Toxic Solvents

F005 Spent Non-halogenated Solvents

F006
Avg. Amt. Gen. (kg)

$14 \quad 487$ 880. 00

3119580.20

462854.80

517 152. 50

442 539. 10

1474 272. 60

1883758.20

3567 245. 00

1515 244. 60

552 401. 60

$\begin{array}{llll}28 & 022 & 928 . \quad 60\end{array}$

1934739.20

1827 225. 80

6704 102. 80

$\begin{array}{llll}7 & 919 & 557 . & 10\end{array}$

2353 135. 10

864 177. 30

Other F Wastes

Sludges

TOTAL F

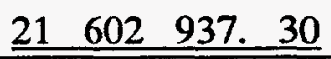


Table A-2.1: Continued

EPA Code Description

K001 Wastewater Treatment Sludge from Wood Preserving Processes

Avg.Amt. Gen. (kg)

9307060.10

K061 Emission Control Dust and Sludge from Steel Production

2486 035. 30

K083 Distillation Bottoms from Aniline

Production

2449586.20

K088 Spent Potliners from Primary Aluminum Reduction

$3 \quad 160 \quad 699.10$

551 878. 50

Other $\mathbf{K}$ Wastes

$17 \quad 955 \quad 259.00$

TOTAL K

72517.50

U060 DDD

724 211. 00

U061

DDT

663 185. 90

U159

Butanone

577 539. 80

Other $\mathrm{U}$ and Lab Pack Wastes

1410 565. 40

TOTAL $P, U, L A B$ PACK

$3448 \quad 019 . \quad 20$

TOTAL WASTE

\begin{tabular}{l}
$71 \quad 029 \quad 141.80$ \\
\hline
\end{tabular} 
Table A-2.2: Compounds within EPA Code Groups Analyzed in Study

D001:

Acetonitrile

Acrylinotrile

Ethyl Nitrite

Ethylidene Dichloride

Hexachlorobenzene

Methane

Propylene Oxide

Tetrachlorobenzene

Trichlorobenzene

Vinyl Chloride

D002:

Acetic Anhydride

Trichlorobenzene

D003:

Acetonitrile

Acrylonitrile

Butene

Chloroform

Toluene

D018:

Benzene

F001:

Carbon Tetrachloride

Dichloromethane

Methyl Iodide

Teterchloroethylene

Trichloroethane

F002:

Dichlorobenzene

Dichloromethane

Methyl Iodide

Monochlorobenzene

Tetrachloroethylene

F003:

Carbon Tetrachloride

Dichloromethane

Monochlorobenzene

Nitrobenzene

Tetrachloroethylene

Toluene 
F005:

Aniline

Benzene

Butene

Pyridine

Toluene

K001:

Pentachlorobiphenyl

K083:

Aniline

Nitrobenzene

U060:

Ethane

Pentachlorobiphenyl

U061:

Trichloroethane

U159:

Butene 
Table A-2.3: Physical Properties of Compounds Considered

\begin{tabular}{|c|c|c|c|c|}
\hline Compound Name & Formula & $\mathbf{B P}(\mathbf{C})$ & $\mathbf{M P}(\mathbf{C})$ & $\begin{array}{l}\text { Density } \\
\left(\mathrm{g} / \mathrm{cm}^{3}\right)\end{array}$ \\
\hline Acetic Anhydride & $\mathrm{C}_{4} \mathrm{H}_{6} \mathrm{O}_{3}$ & 140.0 & -73.1 & 1.082 \\
\hline Acetonitrile & $\mathrm{C}_{2} \mathrm{H}_{3} \mathrm{~N}$ & 81.6 & -45.7 & 0.7857 \\
\hline Acrylonitrile & $\mathrm{C}_{3} \mathrm{H}_{3} \mathrm{~N}$ & 77.5 & $\mathrm{n} / \mathbf{a}$ & 0.8060 \\
\hline Aniline & $\mathrm{C}_{6} \mathrm{H}_{7} \mathrm{~N}$ & 184 & -6.3 & 1.02173 \\
\hline Benzene & $\mathrm{C}_{6} \mathrm{H}_{6}$ & 80.1 & 5.5 & 0.8765 \\
\hline Butane & C4H10 & -0.5 & -138.4 & 0.6012 \\
\hline Carbon Tetrachloride & $\mathrm{CCl}_{4}$ & 76.5 & -23 & 1.5940 \\
\hline Chloroform & $\mathrm{CHCl}_{3}$ & 61.7 & -63.6 & 1.4985 \\
\hline Dichlorobenzene & $\mathrm{C}_{6} \mathrm{H}_{4} \mathrm{Cl}_{2}$ & 180.5 & -17 & 1.3048 \\
\hline Dichloromethane & $\mathrm{CH}_{2} \mathrm{Cl}_{2}$ & 40 & -95.1 & 1.3266 \\
\hline Ethane & $\mathrm{C}_{2} \mathrm{H}_{6}$ & -88.6 & -183.3 & 0.572 \\
\hline Ethyl Nitrile & $\mathrm{C}_{2} \mathrm{H}_{5} \mathrm{NO}_{2}$ & 16 & $\mathrm{n} / \mathrm{a}$ & 0.90 \\
\hline Ethylidene Dichloride & $\mathrm{C}_{2} \mathrm{H}_{4} \mathrm{Cl}_{2}$ & 57.3 & -97.0 & 1.1757 \\
\hline Hexachlorobenzene & $\mathrm{C}_{6} \mathrm{Cl}_{6}$ & 322 (sub) & 230 & 1.5691 \\
\hline Methane & $\mathrm{CH}_{4}$ & -164 & -182 & 0.5547 \\
\hline Methyl Iodide & $\mathrm{CH}_{3} \mathrm{I}$ & 42.4 & -66.5 & 2.2789 \\
\hline Monochlorobenzene & $\mathrm{C}_{6} \mathrm{H}_{5} \mathrm{Cl}$ & 132 & -45.6 & 1.1058 \\
\hline Nitrobenzene & $\mathrm{C}_{6} \mathrm{H}_{5} \mathrm{NO}_{2}$ & 210.8 & 5.7 & 1.2037 \\
\hline Pentachlorobiphenyl & $\mathrm{C}_{12} \mathrm{H}_{5} \mathrm{Cl}_{5}$ & 284 & 16 & 1.1579 \\
\hline Propylene Oxide & $\mathrm{C}_{3} \mathrm{H}_{6} \mathrm{O}$ & 37 & -112.1 & 0.8287 \\
\hline Pyridine & $\mathrm{C}_{5} \mathrm{H}_{5} \mathrm{~N}$ & 115.5 & -42 & 0.9819 \\
\hline Tetrachlorobenzene & $\mathrm{C}_{6} \mathrm{H}_{2} \mathrm{Cl}_{4}$ & 240 & 138 & 1.858 \\
\hline Tetrachloroethylene & $\mathrm{C}_{2} \mathrm{Cl}_{4}$ & 121 & -19 & 1.6227 \\
\hline Toluene & $\mathrm{C}_{7} \mathrm{H}_{8}$ & 110.6 & -95 & 0.8669 \\
\hline Trichlorobenzene & $\mathrm{C}_{6} \mathrm{H}_{3} \mathrm{Cl}_{3}$ & 213.5 & 17 & 1.4542 \\
\hline Trichloroethane & $\mathrm{C}_{2} \mathrm{H}_{3} \mathrm{Cl}_{3}$ & 74.1 & -30.4 & 1.3390 \\
\hline Vinyl Chloride & $\mathrm{C}_{3} \mathrm{H}_{3} \mathrm{Cl}$ & -13.4 & -153.8 & 0.9106 \\
\hline
\end{tabular}


Table A-2.4: Itemized List of Fractional Volumes within Each EPA Code Group

\begin{tabular}{|c|c|c|c|}
\hline $\begin{array}{c}\text { EPA Group } \\
\text { Code }\end{array}$ & Waste Materials & $\begin{array}{l}\text { Percent } \\
\text { Volume }\end{array}$ & $\begin{array}{c}\text { Volume } \\
\left(\mathrm{m}^{3}\right)\end{array}$ \\
\hline \multirow[t]{11}{*}{ D001 } & Acetonitrile & 12.18 & 1843.32 \\
\hline & Acrylonitrile & 11.88 & 1797.91 \\
\hline & Ethyl Nitrite & 10.64 & 1610.25 \\
\hline & Ethylidene Dichloride & 8.14 & 1231.90 \\
\hline & Hexachlorobenzene & 6.10 & 923.17 \\
\hline & Methane & 17.26 & 2612.12 \\
\hline & Propylene Oxide & 11.55 & 1747.97 \\
\hline & Tetrachlorobenzene & 5.15 & 779.40 \\
\hline & Trichlorobenzene & 6.58 & 995.81 \\
\hline & Vinyl Chloride & 10.51 & 1590.58 \\
\hline & TOTAL & 100.00 & 15133.96 \\
\hline \multirow[t]{3}{*}{ D002 } & Acetic Anhydride & 57.34 & 1441.68 \\
\hline & Trichlorobenzene & 42.66 & 1072.55 \\
\hline & TOTAL & 100.00 & 2514.19 \\
\hline \multirow[t]{6}{*}{ D003 } & Acetonitrile & 21.22 & 366.84 \\
\hline & Acrylonitrile & 20.69 & 357.68 \\
\hline & Butene & 27.73 & 479.38 \\
\hline & Chloroform & 11.13 & 192.41 \\
\hline & Toluene & 19.23 & 332.44 \\
\hline & TOTAL & 100.00 & 1728.74 \\
\hline \multirow[t]{2}{*}{ D018 } & Benzene & 100.00 & 555.21 \\
\hline & TOTAL & 100.00 & 555.21 \\
\hline $\begin{array}{l}\text { TOTAL D } \\
\text { WASTE }\end{array}$ & & & 19932.10 \\
\hline
\end{tabular}


TableA-2.4: Continued

\begin{tabular}{|c|c|c|c|}
\hline $\begin{array}{c}\text { EPA Group } \\
\text { Code }\end{array}$ & Waste Materials & $\begin{array}{l}\text { Percent } \\
\text { Volume }\end{array}$ & $\begin{array}{c}\text { Volume } \\
\left(\mathrm{m}^{3}\right)\end{array}$ \\
\hline \multirow[t]{6}{*}{ F001 } & Carbon Tetrachloride & 19.71 & 224.76 \\
\hline & Dichloromethane & 23.68 & 291.66 \\
\hline & Methyl Iodide & 13.79 & 169.85 \\
\hline & Tetrachloroethylene & 19.36 & 238.45 \\
\hline & Trichloroethane & 23.46 & 288.95 \\
\hline & TOTAL & 100.00 & 1231.67 \\
\hline \multirow[t]{6}{*}{ F002 } & Dichlorobenzene & 22.03 & 280.13 \\
\hline & Dichloromethane & 21.66 & 275.43 \\
\hline & Methyl Iodide & 12.61 & 160.35 \\
\hline & Monochlorobenzene & 25.99 & 330.49 \\
\hline & Tetrachloroethylene & 17.71 & 225.20 \\
\hline & TOTAL & 100.00 & 11271.60 \\
\hline \multirow[t]{7}{*}{ F003 } & Carbon Tetrachloride & 12.84 & 700.99 \\
\hline & Dichloromethane & 15.43 & 842.39 \\
\hline & Monochlorobenzene & 18.51 & 1010.54 \\
\hline & Nitrobenzene & 17.00 & 928.10 \\
\hline & Tetrachloroethylene & 12.62 & 688.98 \\
\hline & Toluene & 23.61 & 1288.97 \\
\hline & TOTAL & 100.00 & 5459.42 \\
\hline \multirow[t]{6}{*}{ F005 } & Aniline & 16.44 & 1550.64 \\
\hline & Benzene & 19.16 & 1807.19 \\
\hline & Butene & 27.93 & 2634.38 \\
\hline & Pyridine & 17.10 & 1612.89 \\
\hline & Toluene & 19.37 & 1827.00 \\
\hline & TOTAL & 100.00 & 9432.09 \\
\hline $\begin{array}{l}\text { TOTAL F } \\
\text { WASTE }\end{array}$ & & & 17394.78 \\
\hline
\end{tabular}


Table A-2.4: Continued

\begin{tabular}{|l|l|l|l|}
\hline EPA Group Code & Waste Materials & \multicolumn{1}{|c|}{$\begin{array}{c}\text { Percent } \\
\text { Volume }\end{array}$} & \multicolumn{1}{|c|}{$\begin{array}{c}\text { Volume } \\
\left(\mathbf{m}^{3}\right)\end{array}$} \\
\hline K001 & Pentachlorobiphenyl & 100.00 & 8037.87 \\
\hline & TOTAL & 100.00 & 8037.87 \\
\hline K083 & Aniline & 54.09 & 1198.78 \\
\hline & Nitrobenzene & 45.91 & 1017.48 \\
\hline TOTAL K WASTE & TOTAL & 100.00 & 2216.26 \\
\hline \hline U060 & Ethane & & 10254.13 \\
\hline & Pentachlorobiphenyl & 33.07 & 312.77 \\
\hline & TOTAL & 100.00 & 945.79 \\
\hline U061 & Trichloroethane & 100.00 & 495.28 \\
\hline & TOTAL & 100.00 & 495.28 \\
\hline U159 & Butene & 100.00 & 960.64 \\
\hline & TOTAL & 100.00 & 960.64 \\
\hline $\begin{array}{l}\text { TOTAL P, U, LAB } \\
\text { PACK WASTE }\end{array}$ & & & 2401.71 \\
\hline \hline
\end{tabular}


APPENDIX 3: PLOTS OF TEMPERATURE VS. TIME IN AN OXYGEN RICH ENVIRONMENT FOR 99.99\% DRE 


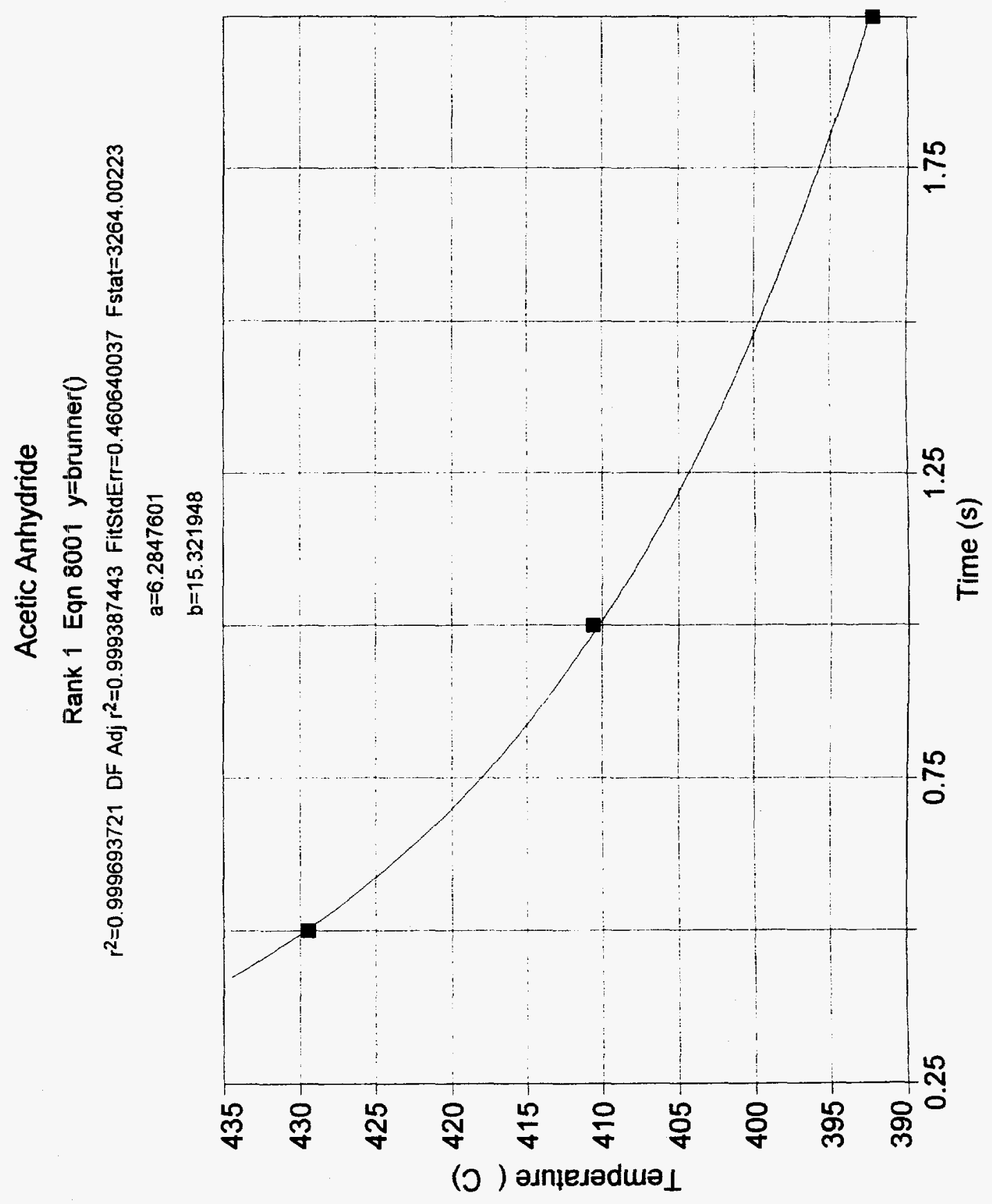




\section{Acetonitrile}

Rank 1 Eqn 8001 y=brunner()

$r^{2}=0.999934365$ DF Adj $r^{2}=0.99986873$ FitStdErr $=0.671730151$ Fstat=15234.7389

$$
a=12.593752
$$

$b=12.226838$

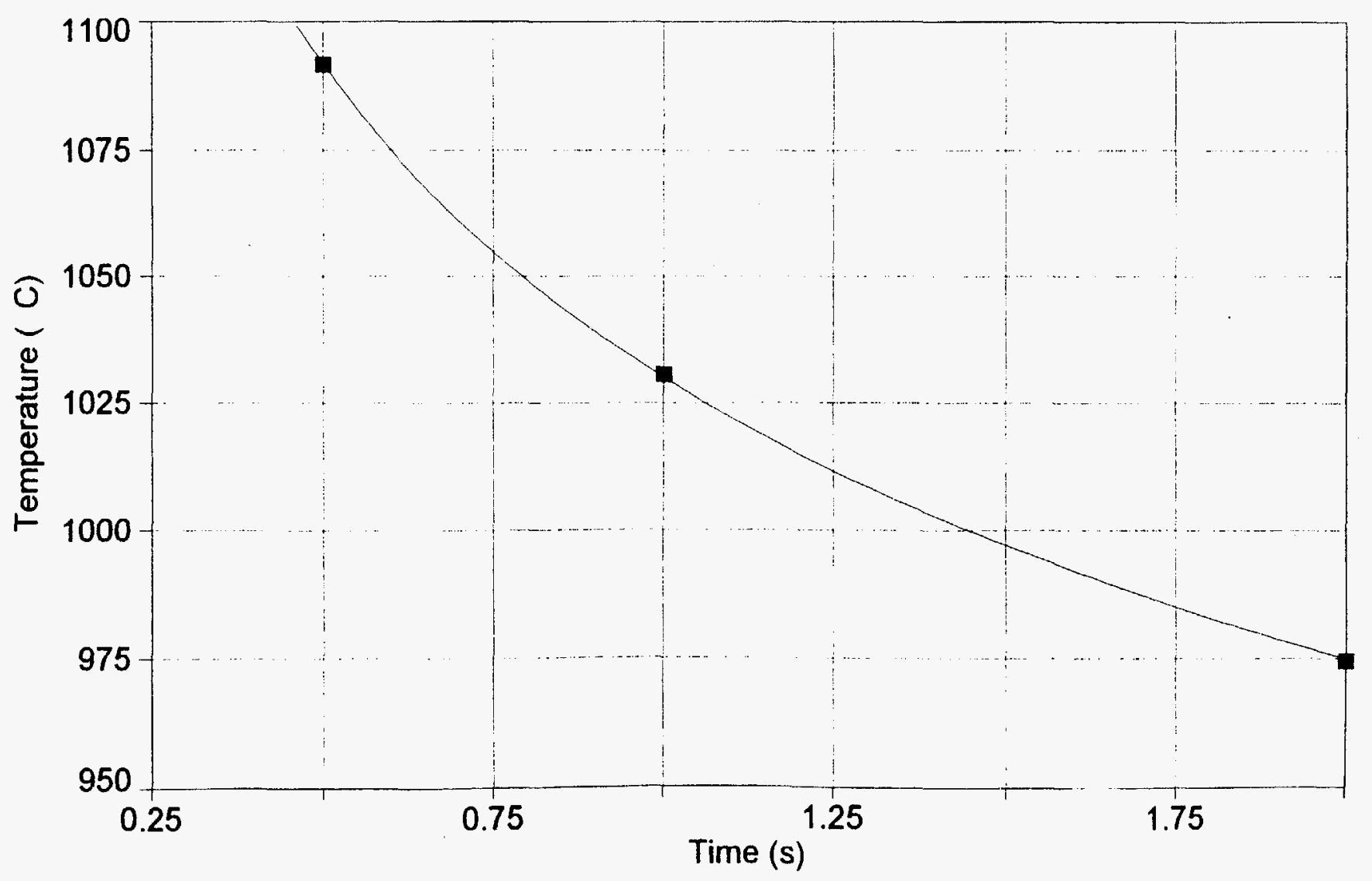




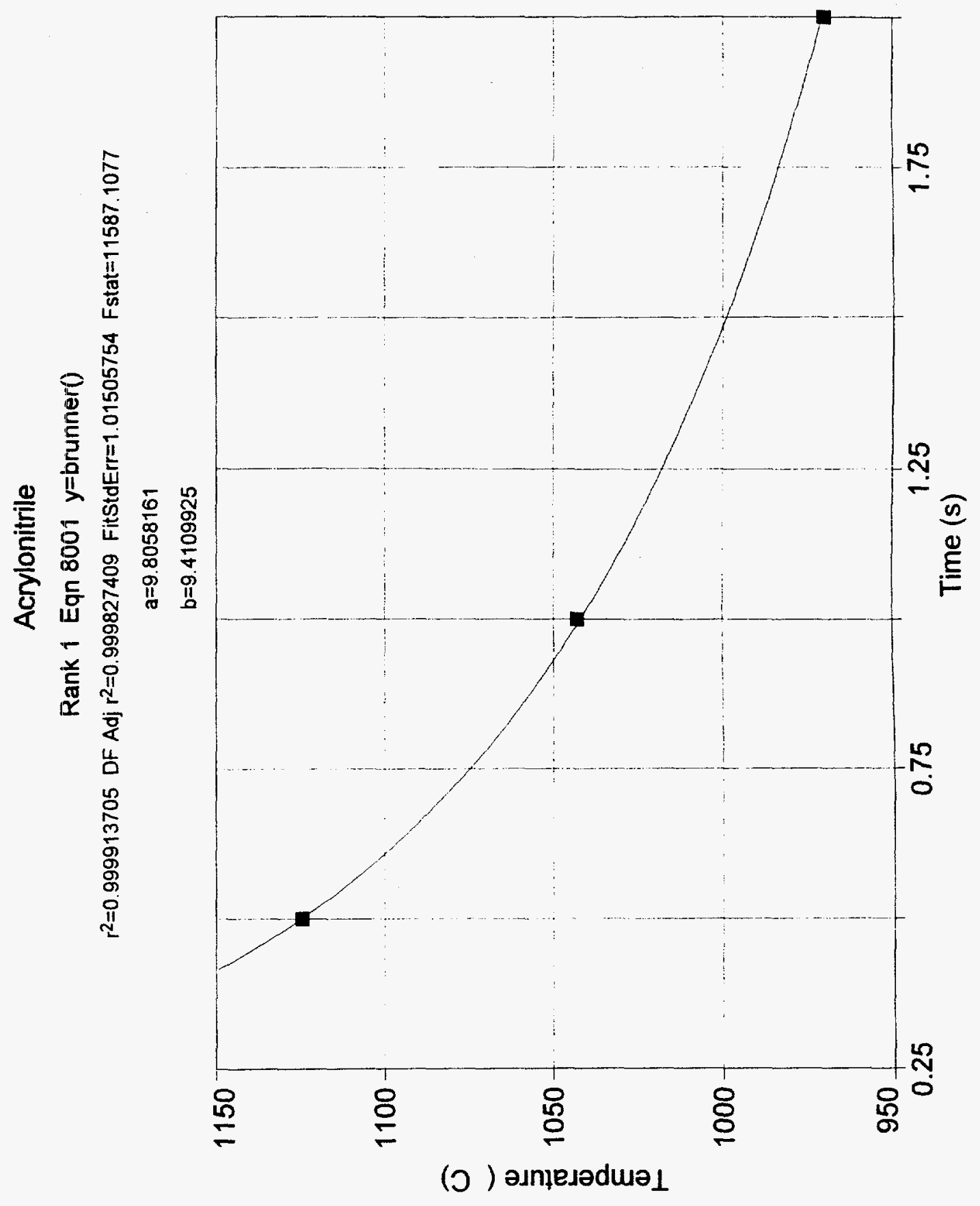




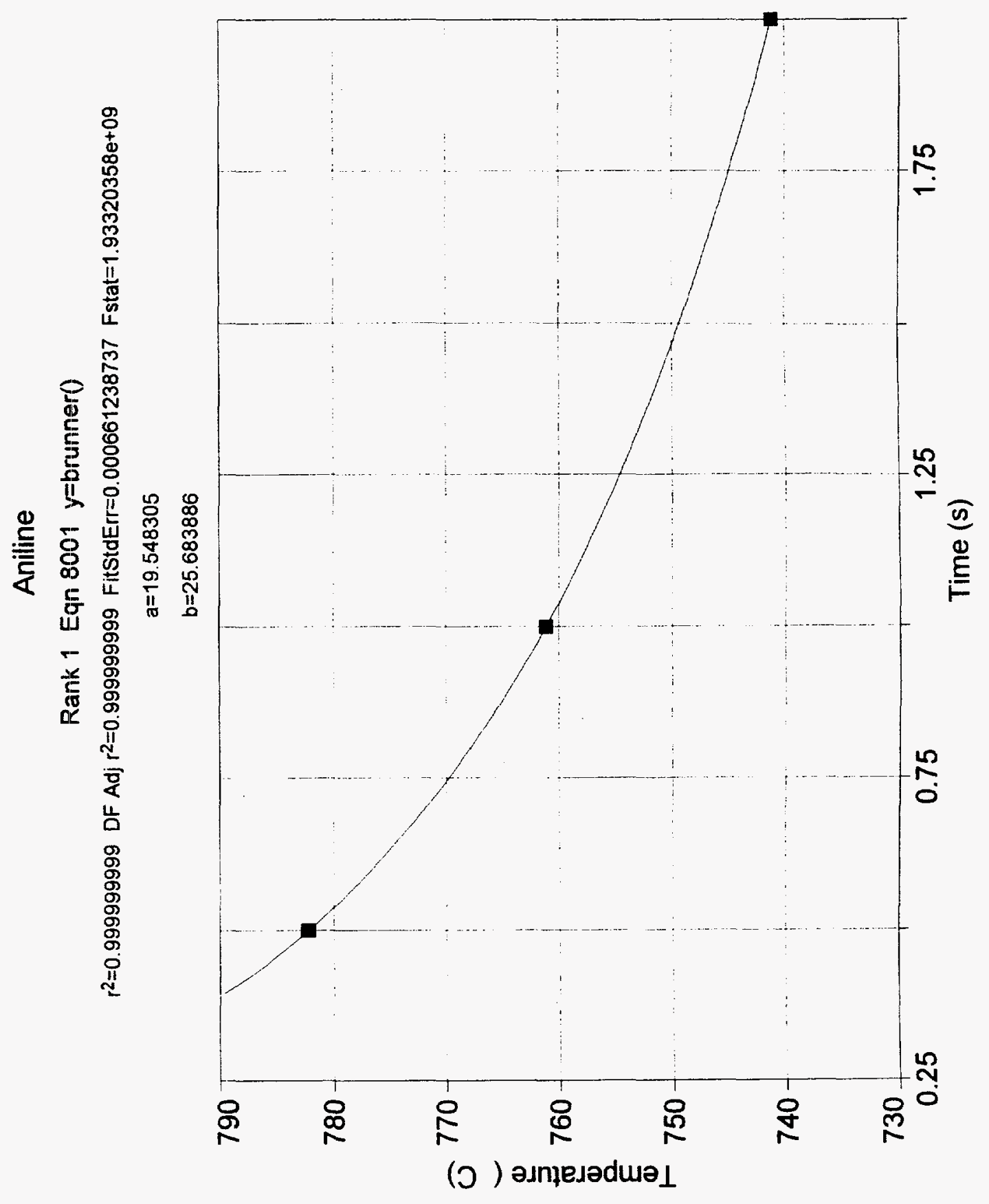




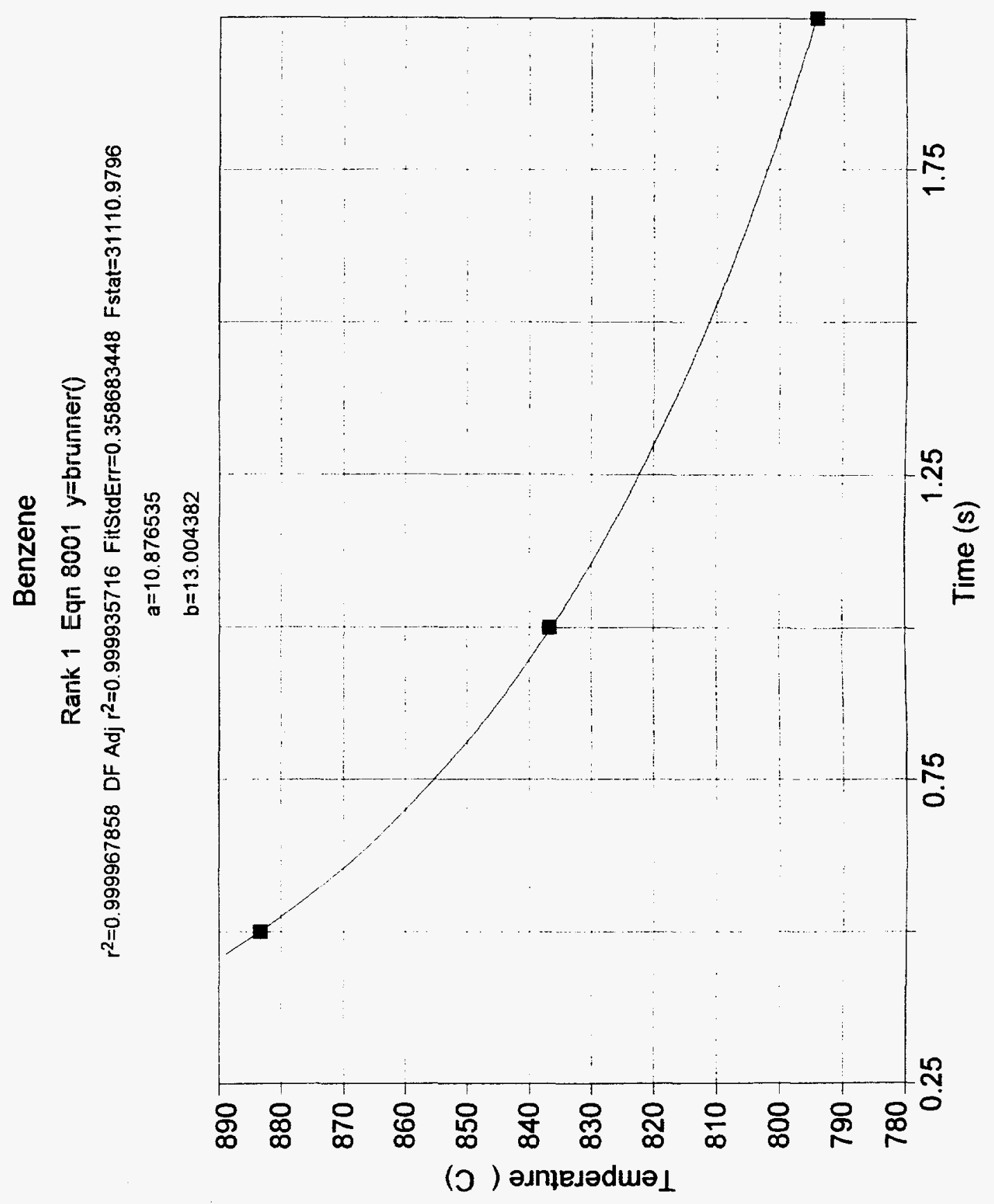




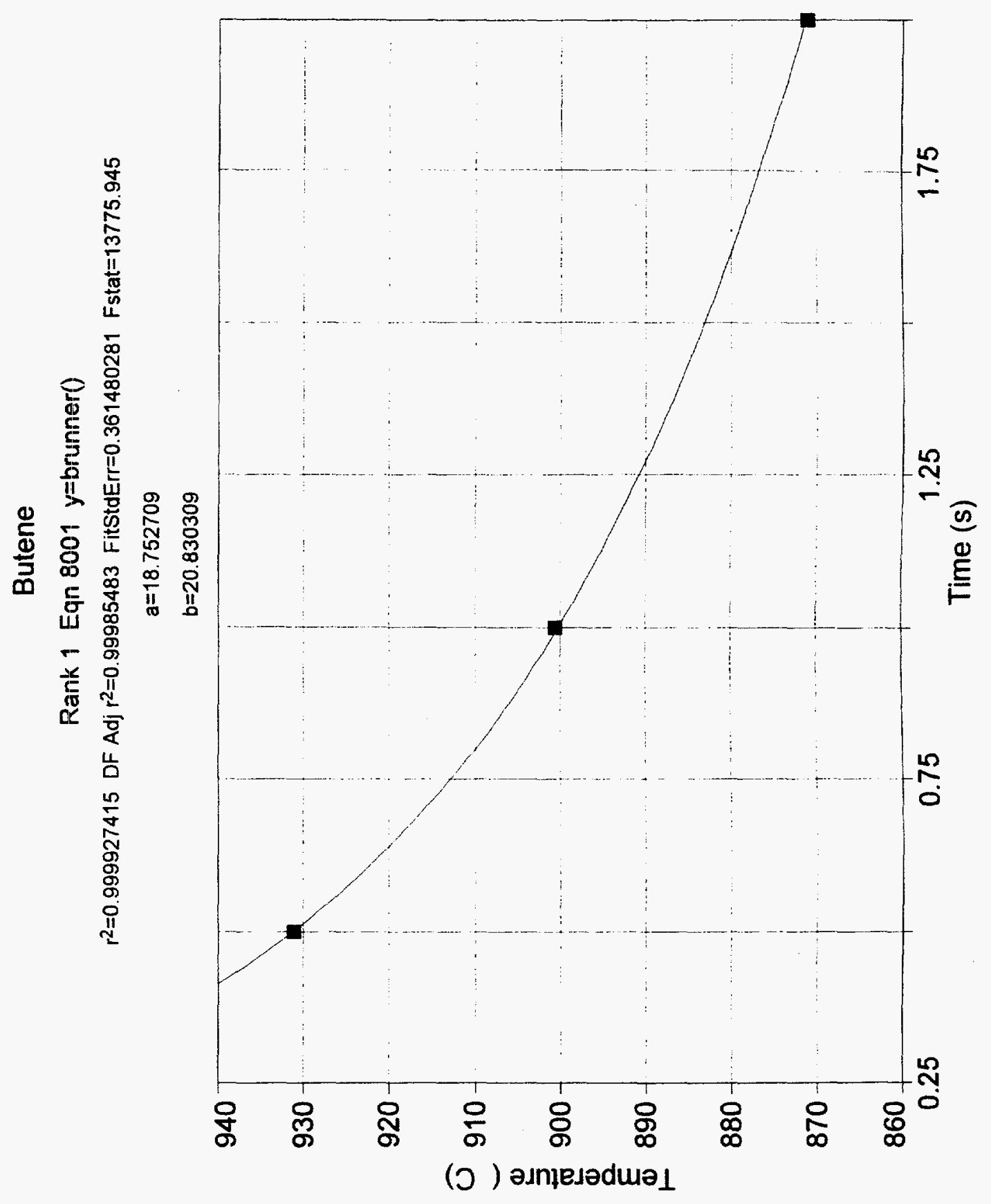




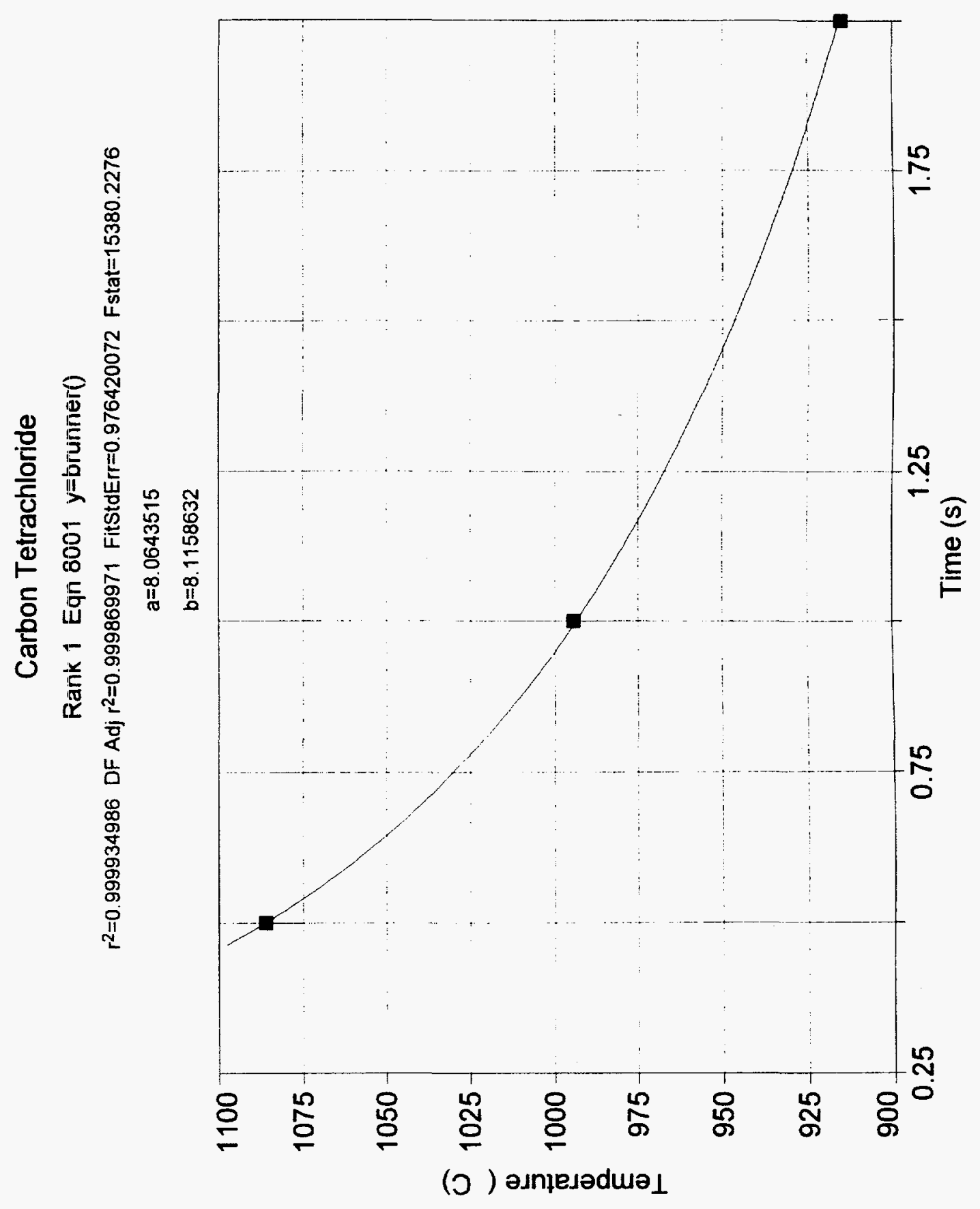




\section{Chloroform}

Rank 1 Equn 8001 y=brunner()

$r^{2}=0.999931347$ DF Adj $r^{2}=0.999862694$ FitStdE $r=0.286458485$ Fstat=14565.0477

$$
a=12.302126
$$

$b=18.693406$

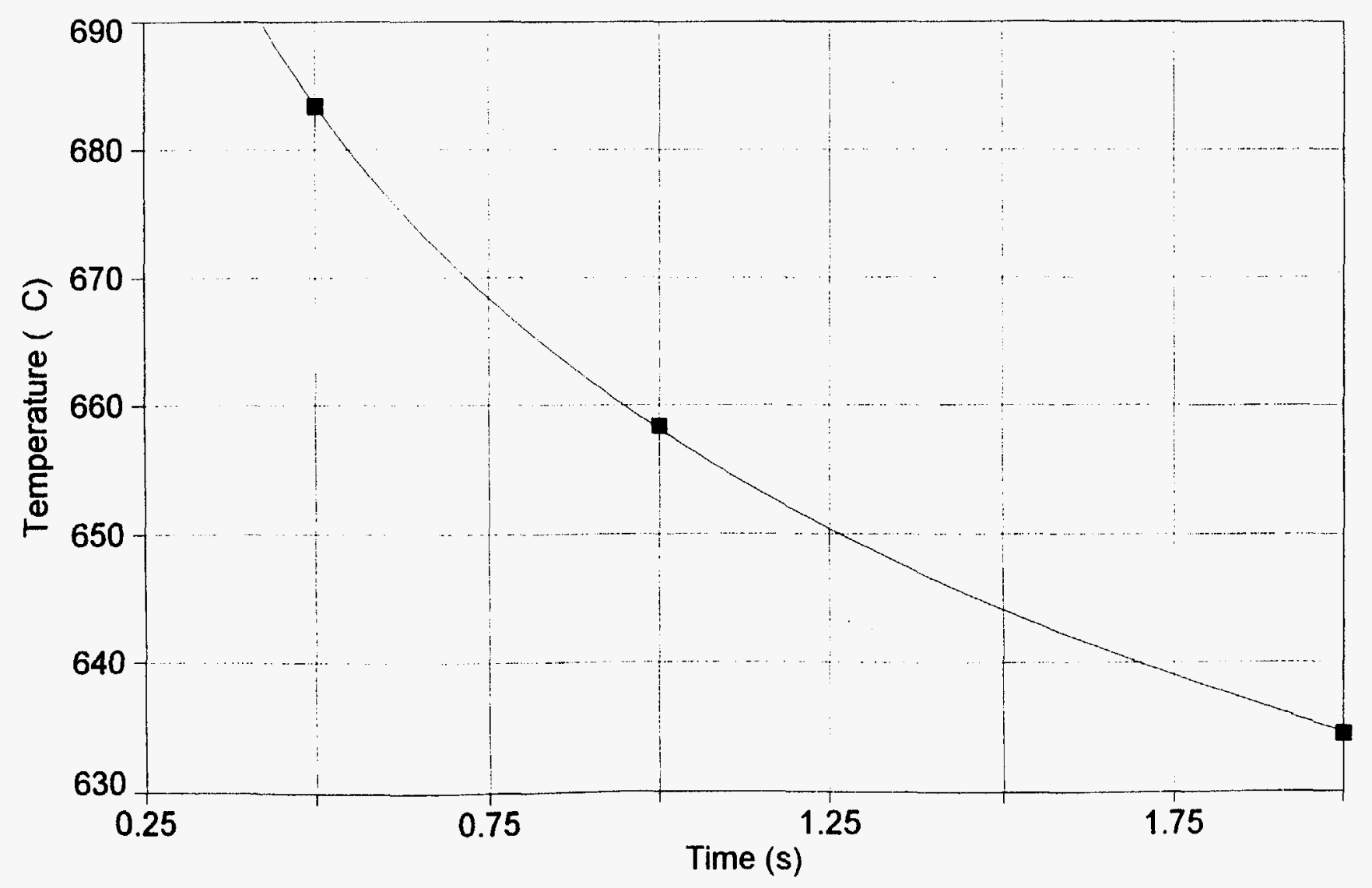




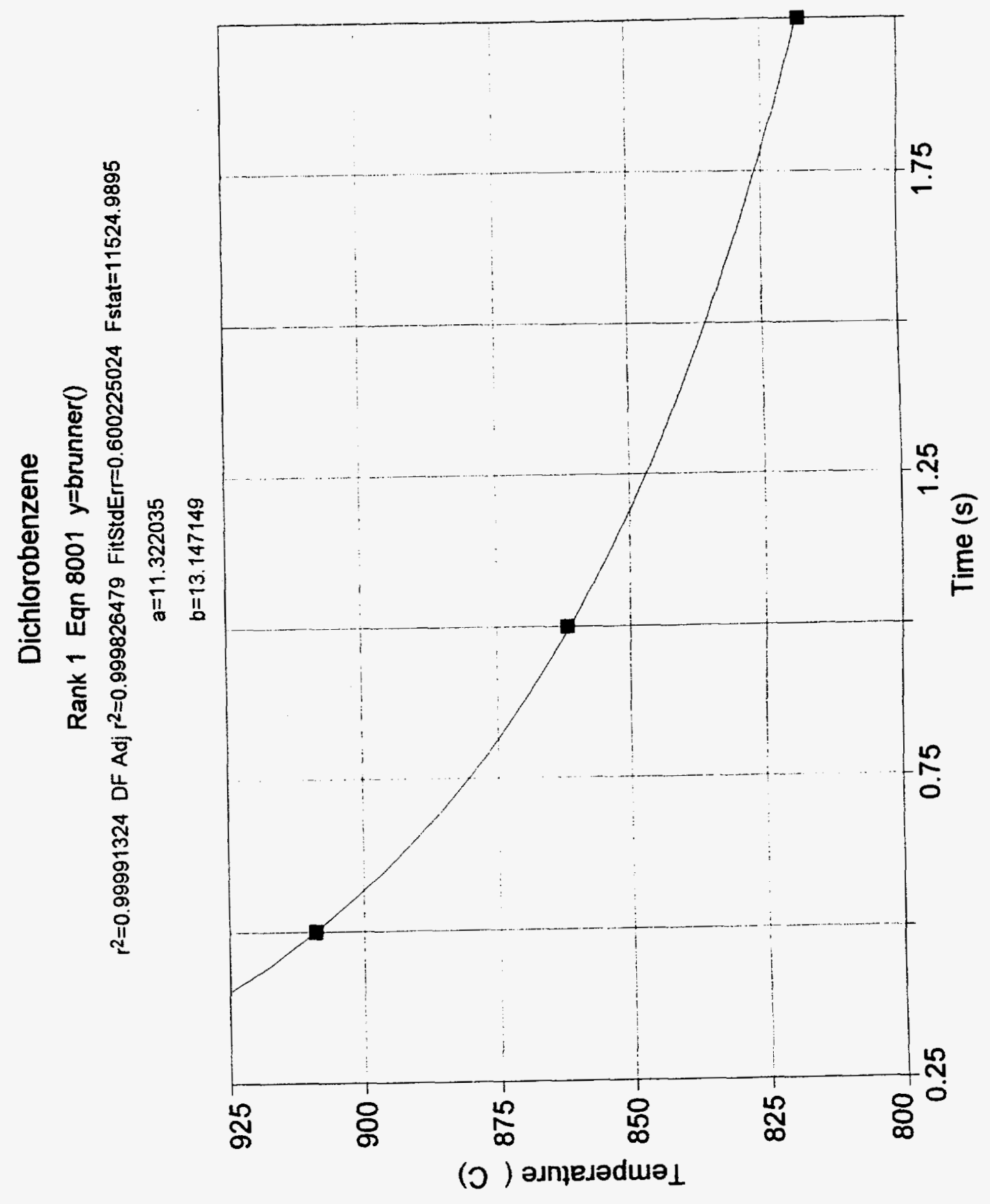




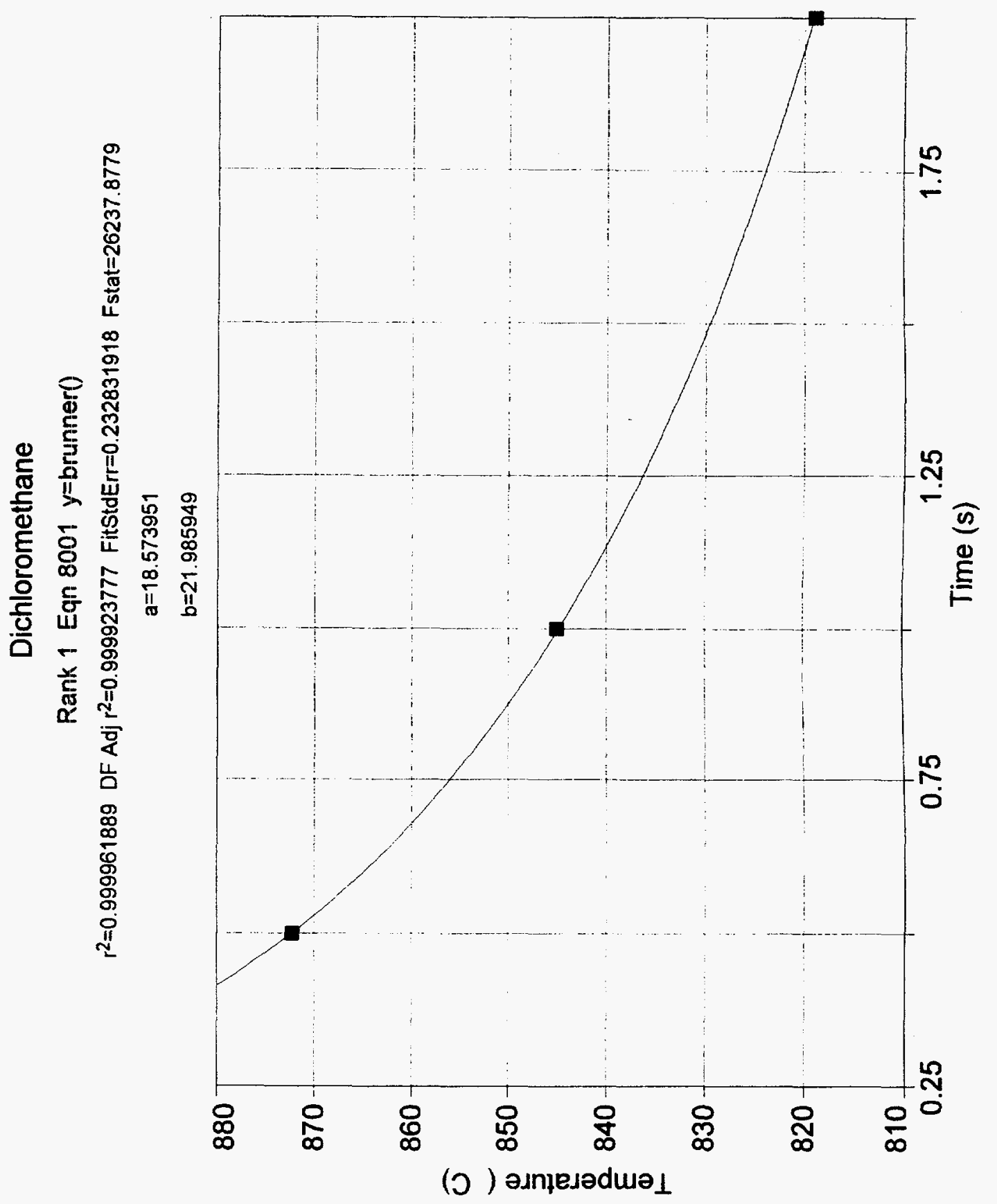




\section{Ethane}

Rank 1 Eqn 8001 y=brunner()

$r^{2}=0.999867315$ DF Adj $r^{2}=0.999734631$ FitStdErr $=1.50362294$ Fstat $=7535.66334$ $a=7.4371856$

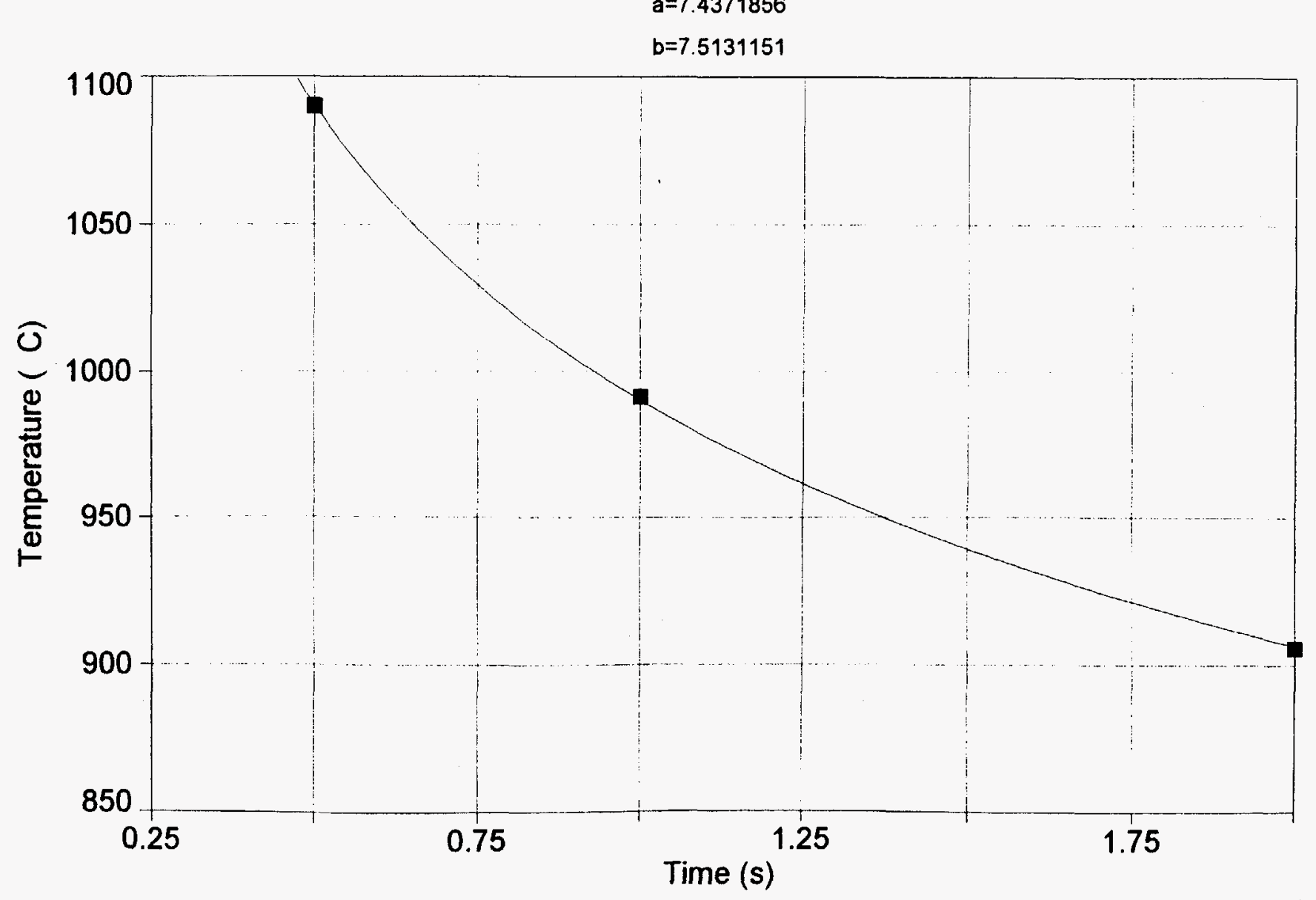




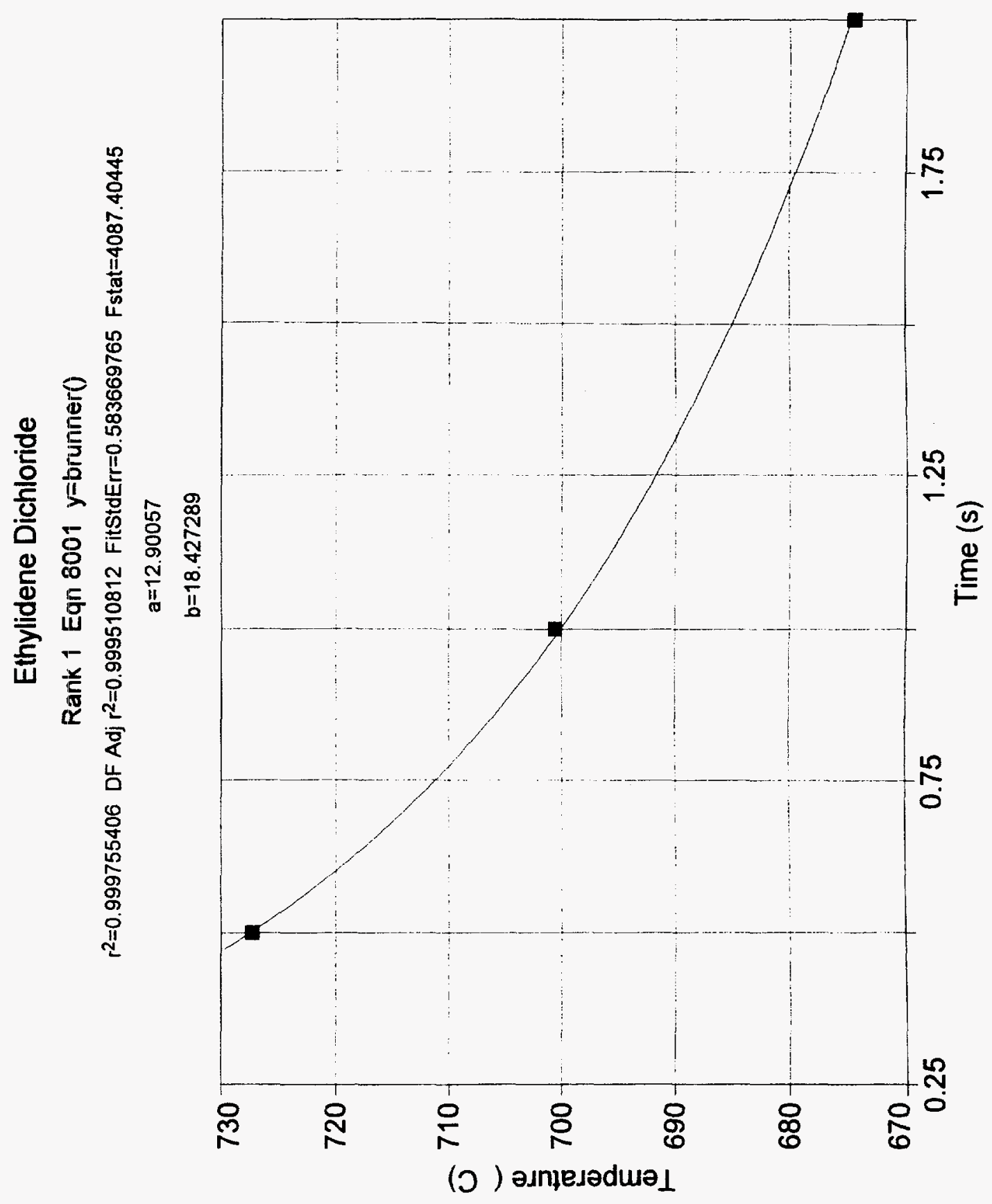




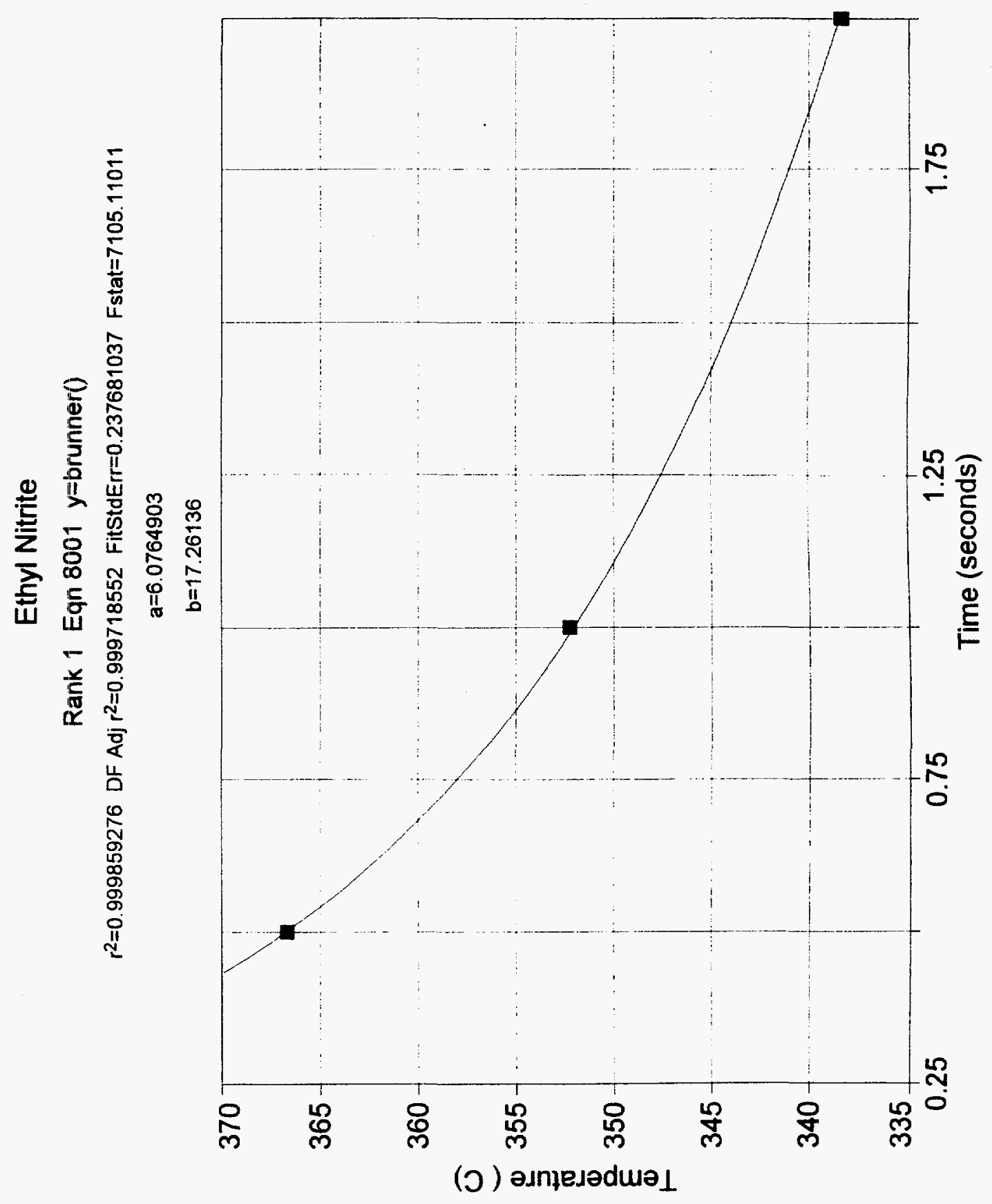




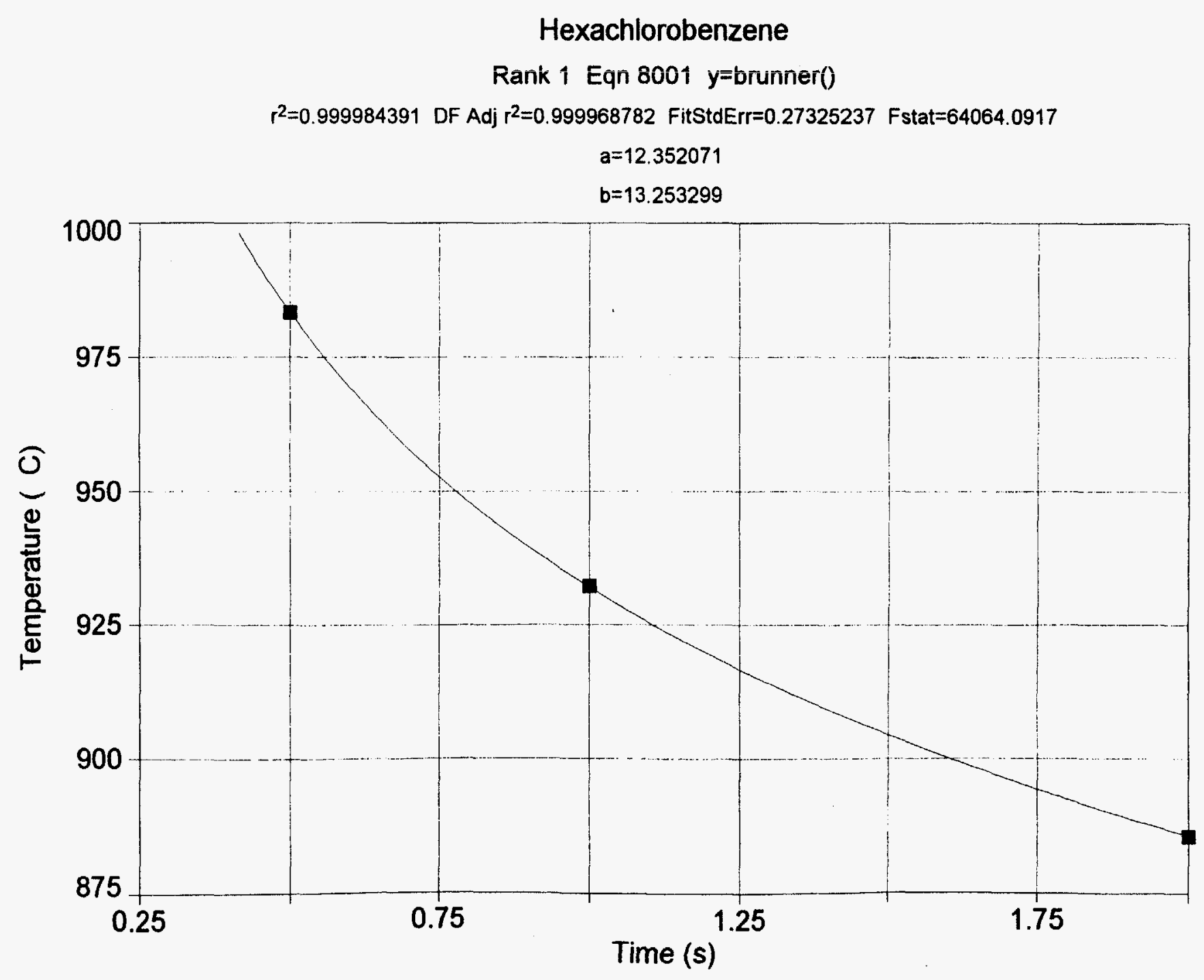




\section{Methane}

Rank 1 Eqn 8001 y=brunner()

$r^{2}=0.999943938$ DF Adj $r^{2}=0.999887876$ FitStdE $r r=0.455987522$ Fstat $=17836.4631$

$a=14.553336$

$b=15.325295$

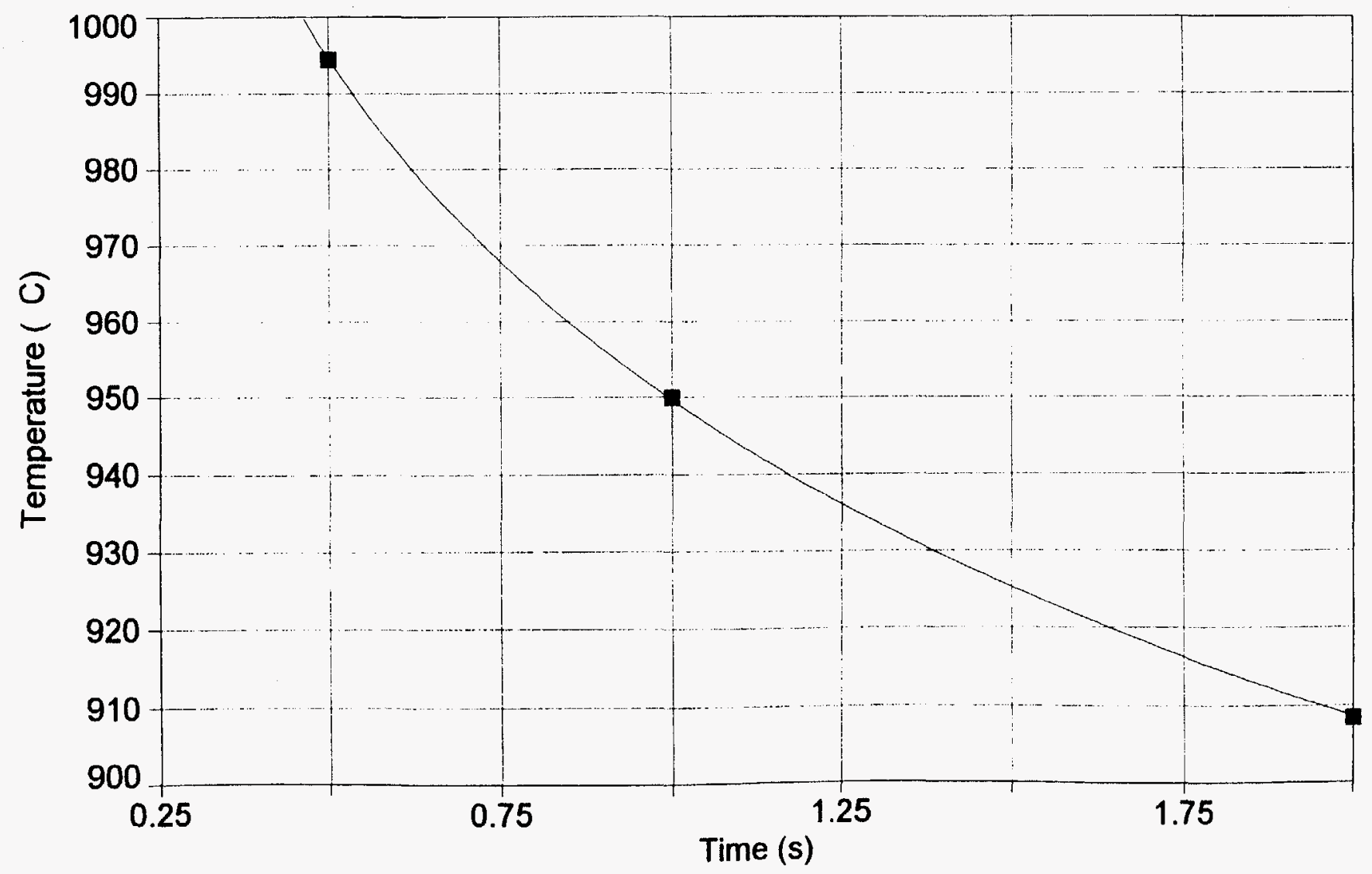




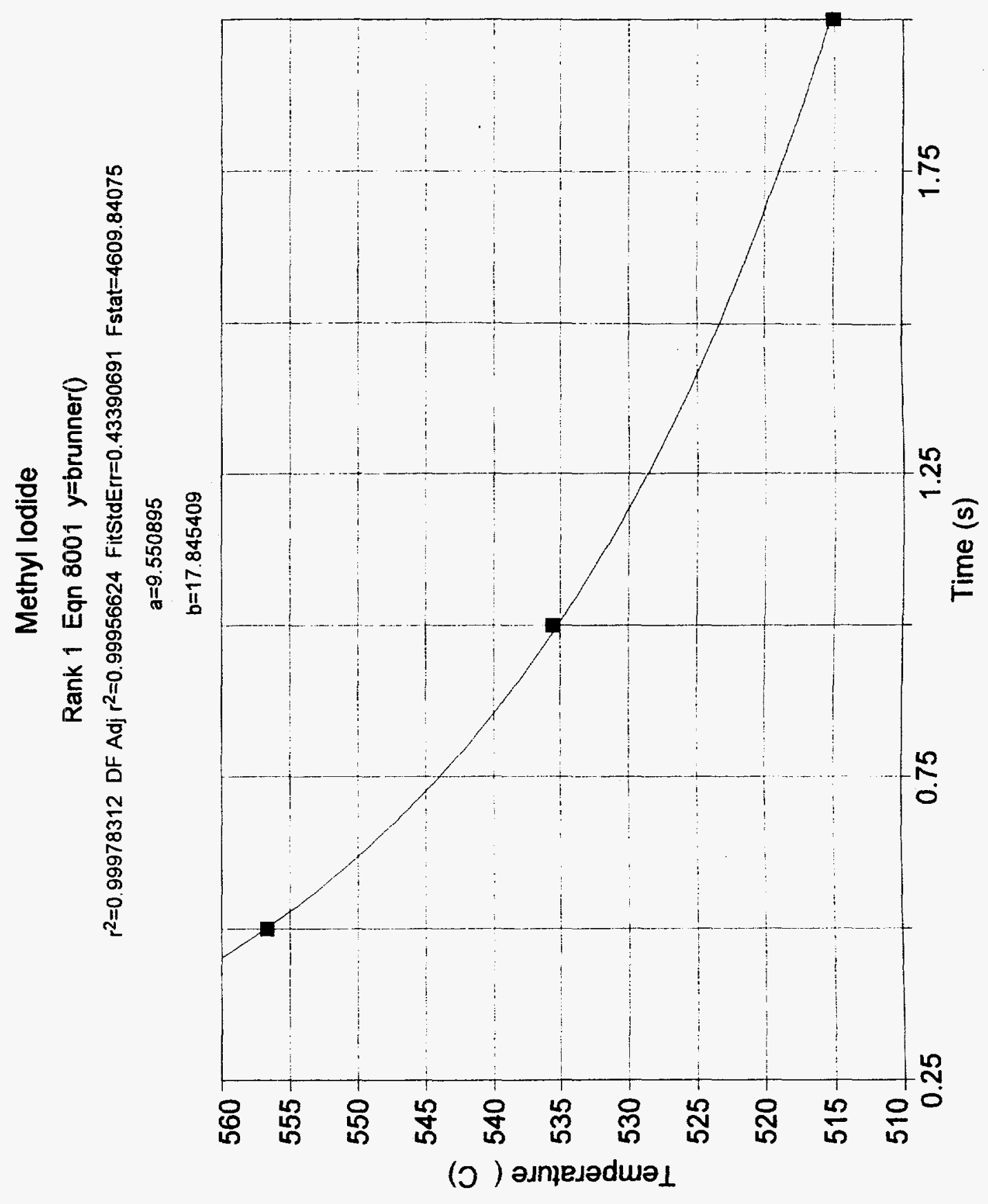




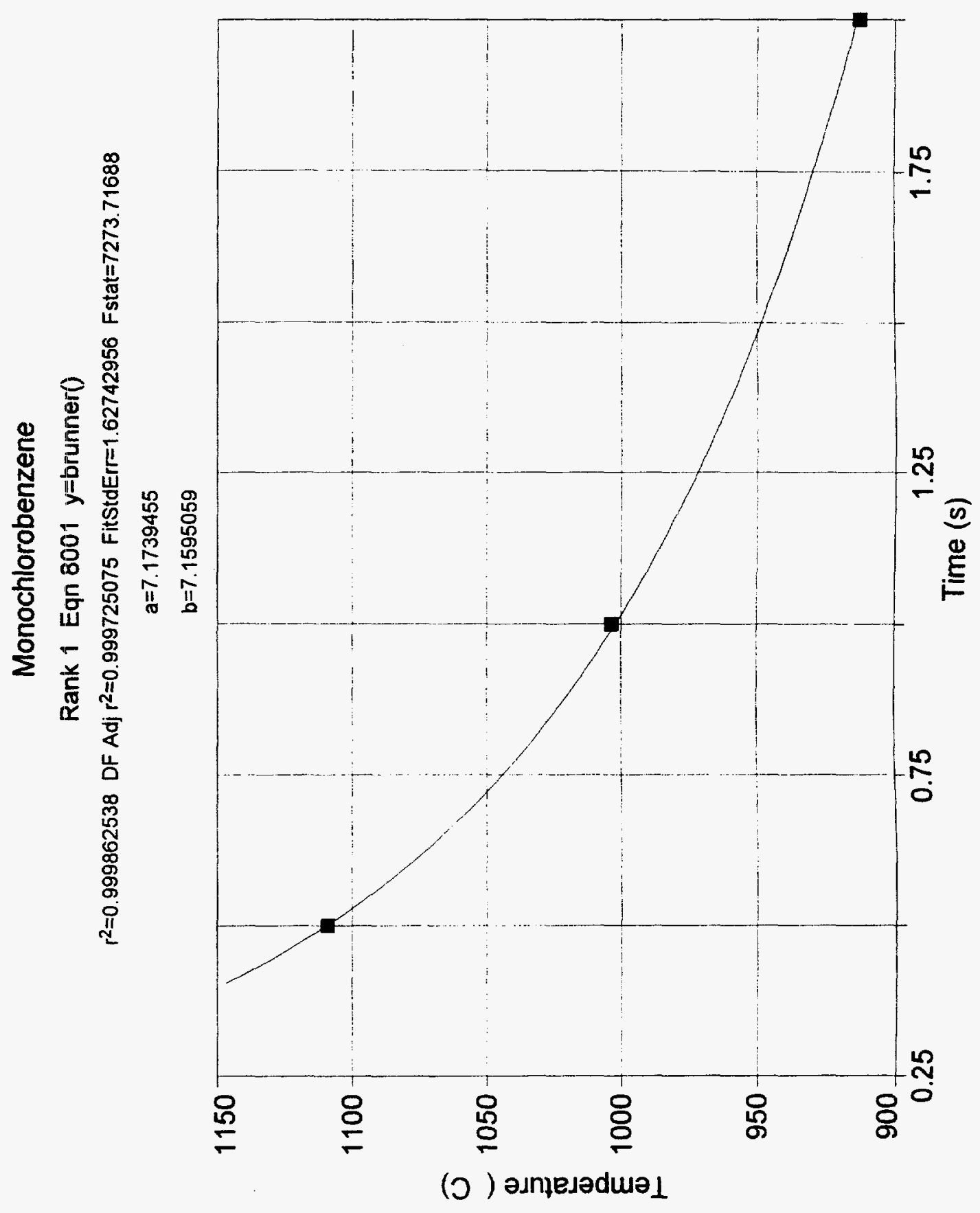




\section{Nitrobenzene}

Rank 1 Eqn 8001 y=brunner()

$r^{2}=0.999996473$ DF Adj $r^{2}=0.999992945$ FitStdE $r=0.0560784993$ Fstat $=283503.302$ $a=16.720583$

$b=23.441573$

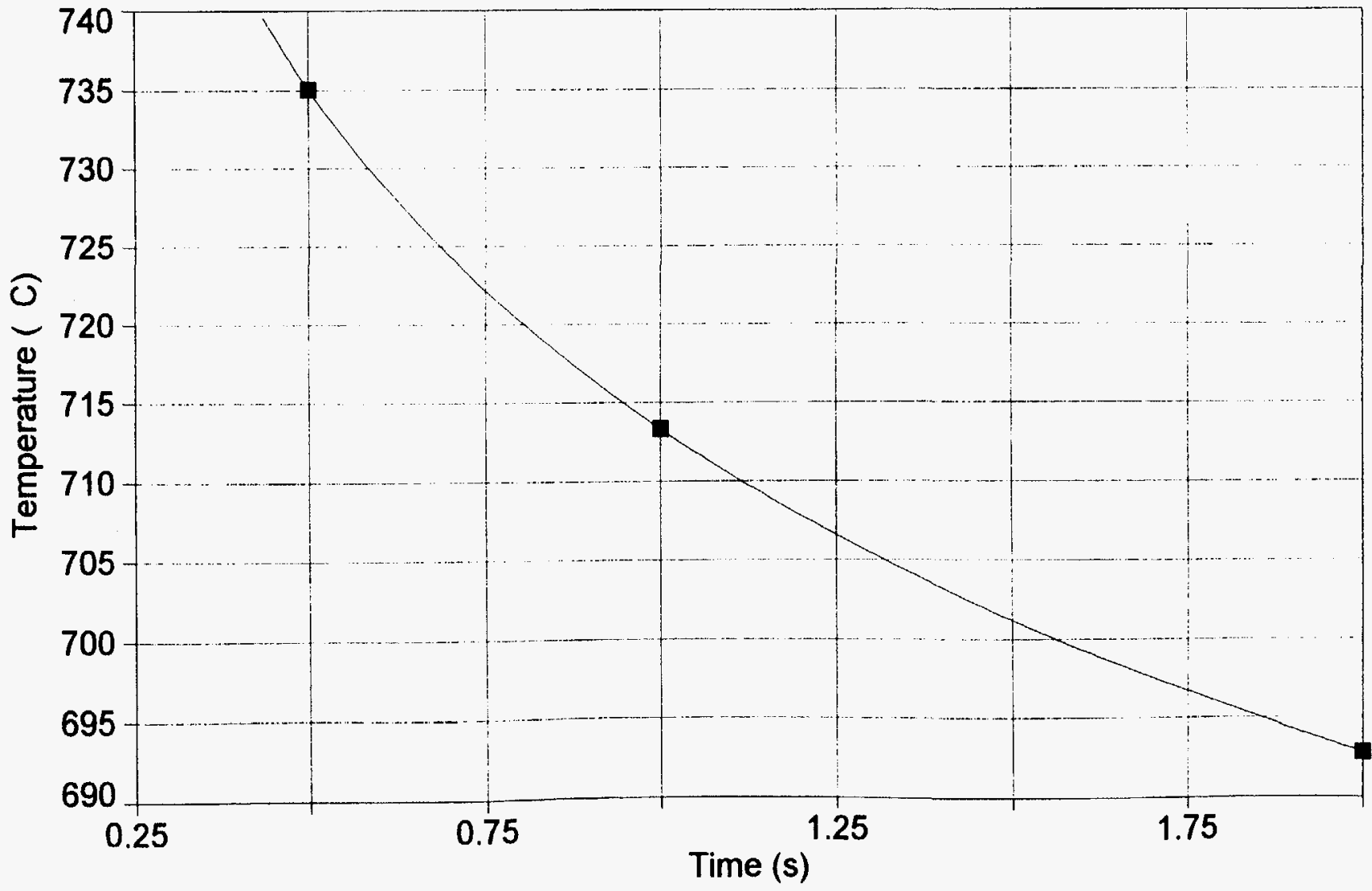




\section{Pentachlorobiphenyl}

Rank 1 Eqn 8001 y=brunner()

$r^{2}=0.999938153$ DF Adj $r^{2}=0.999876306$ FitStdErr $=0.225532368$ Fstat $=16167.8868$

$a=18.812177$

$b=25.371028$

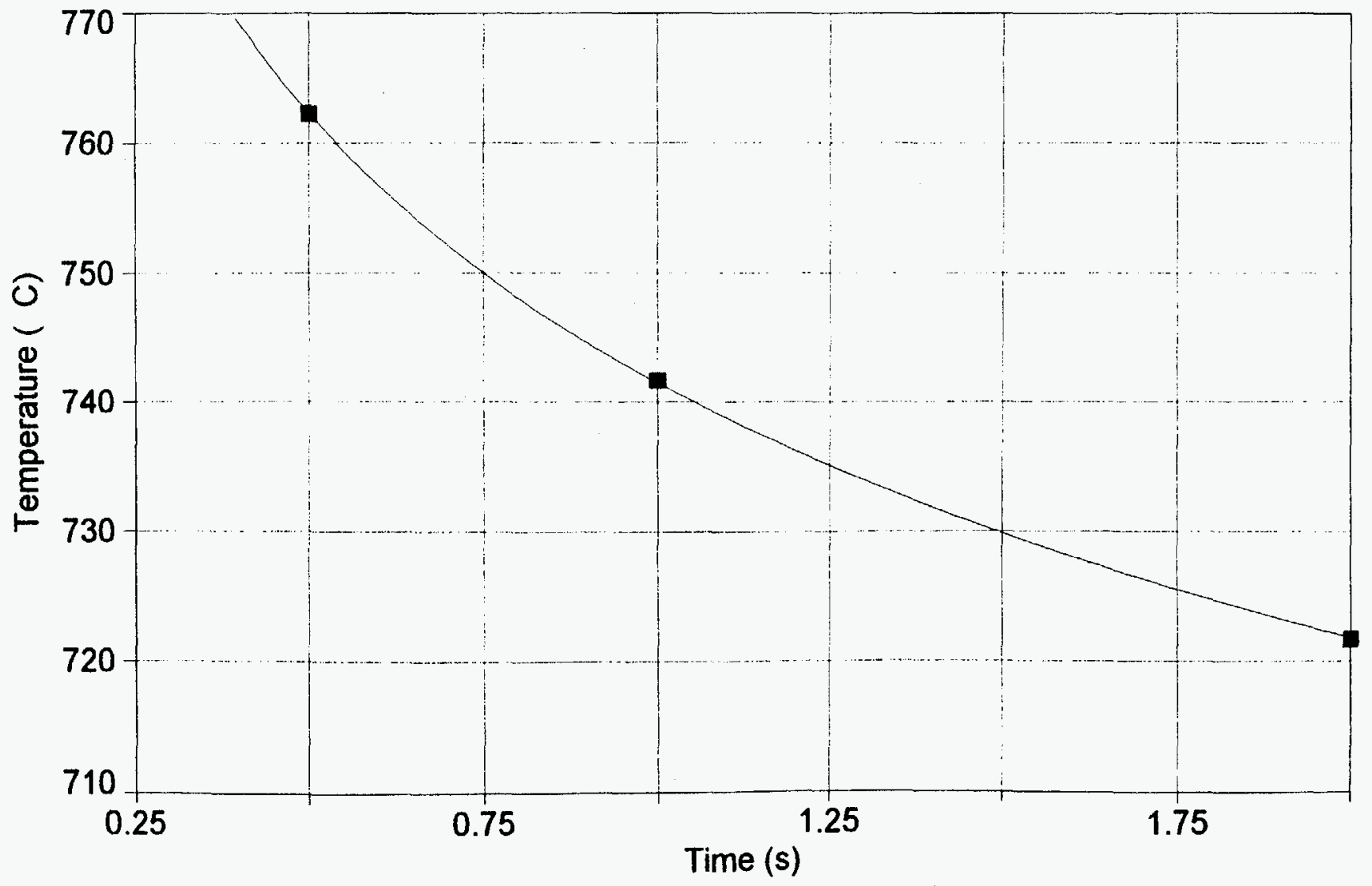




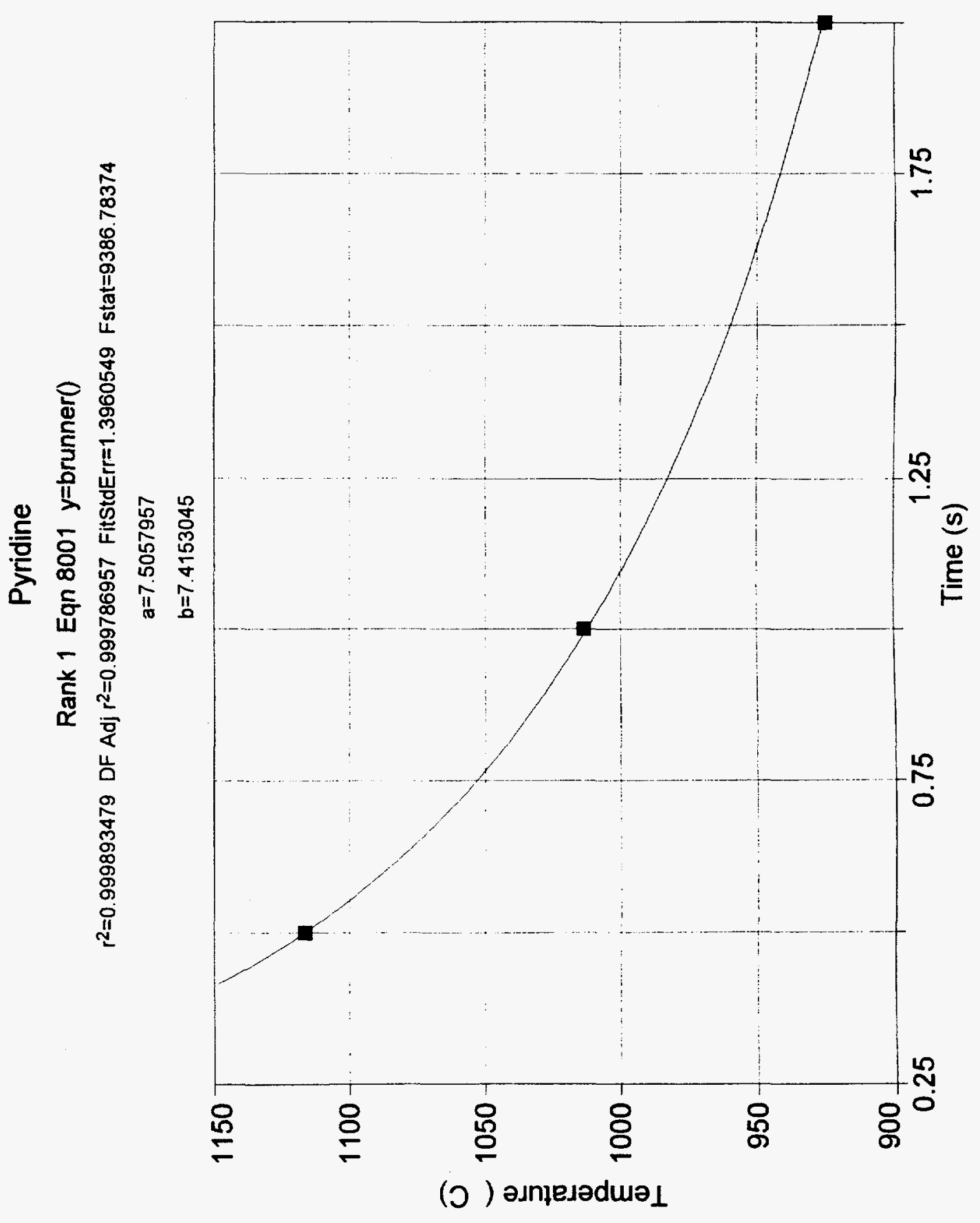




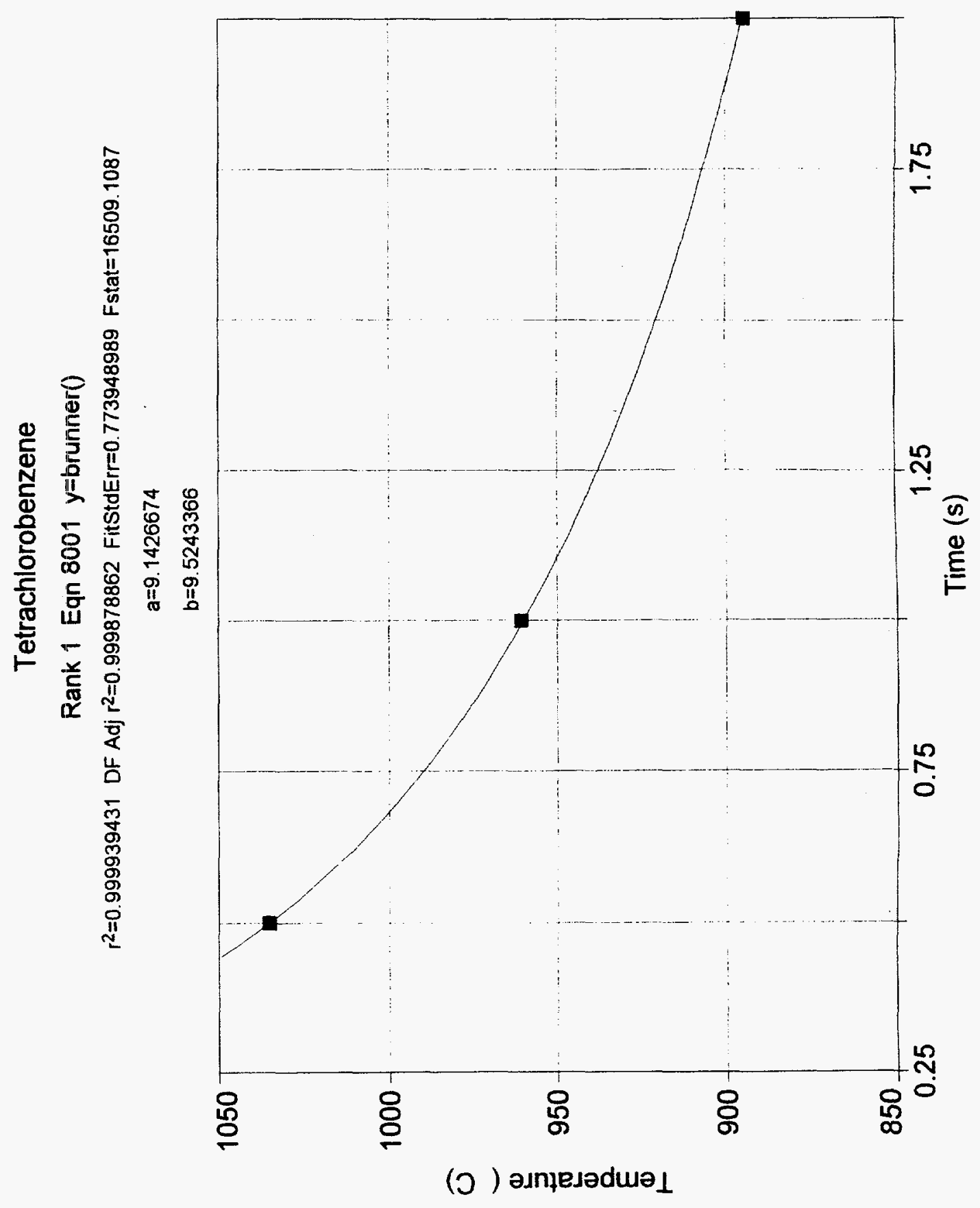




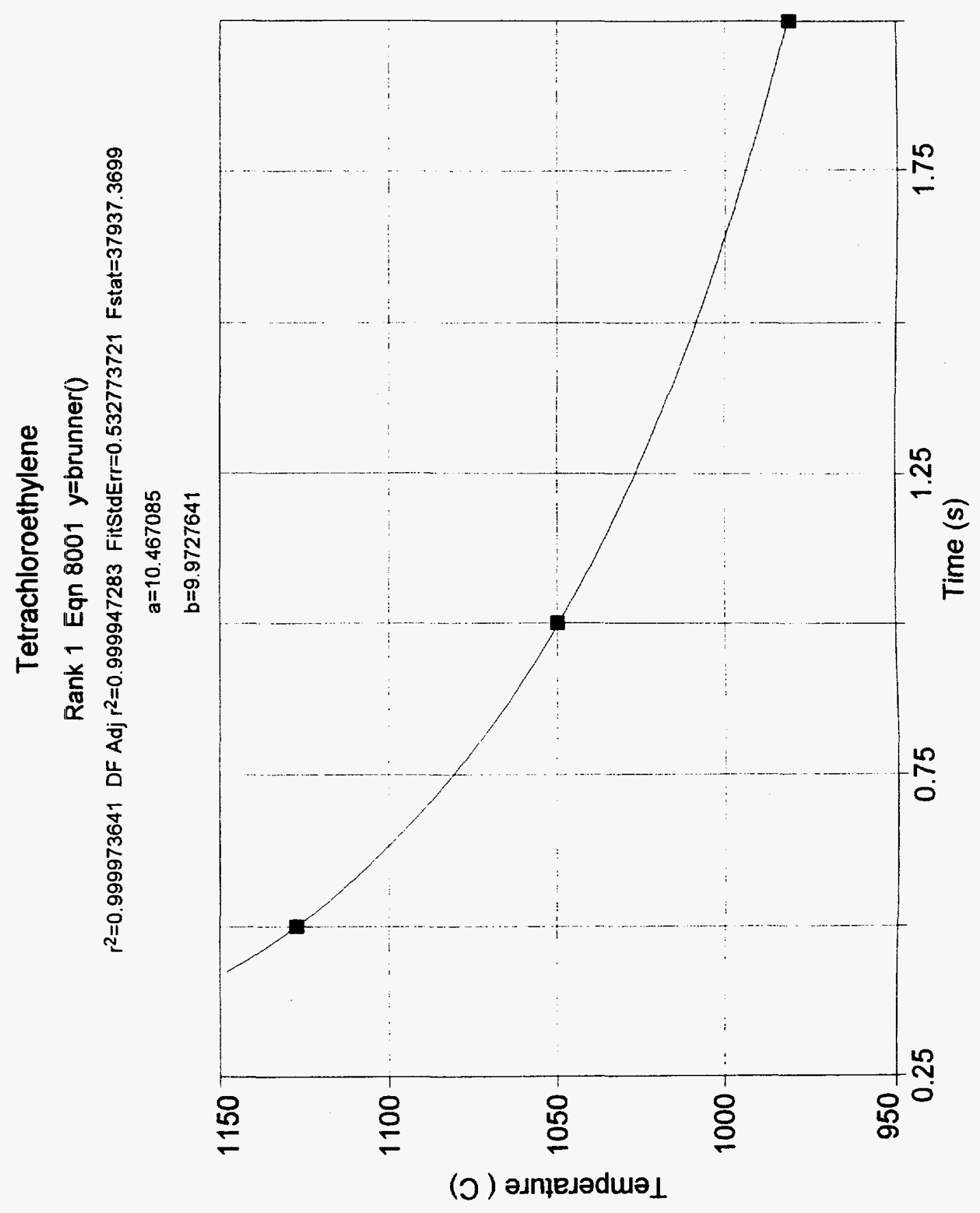




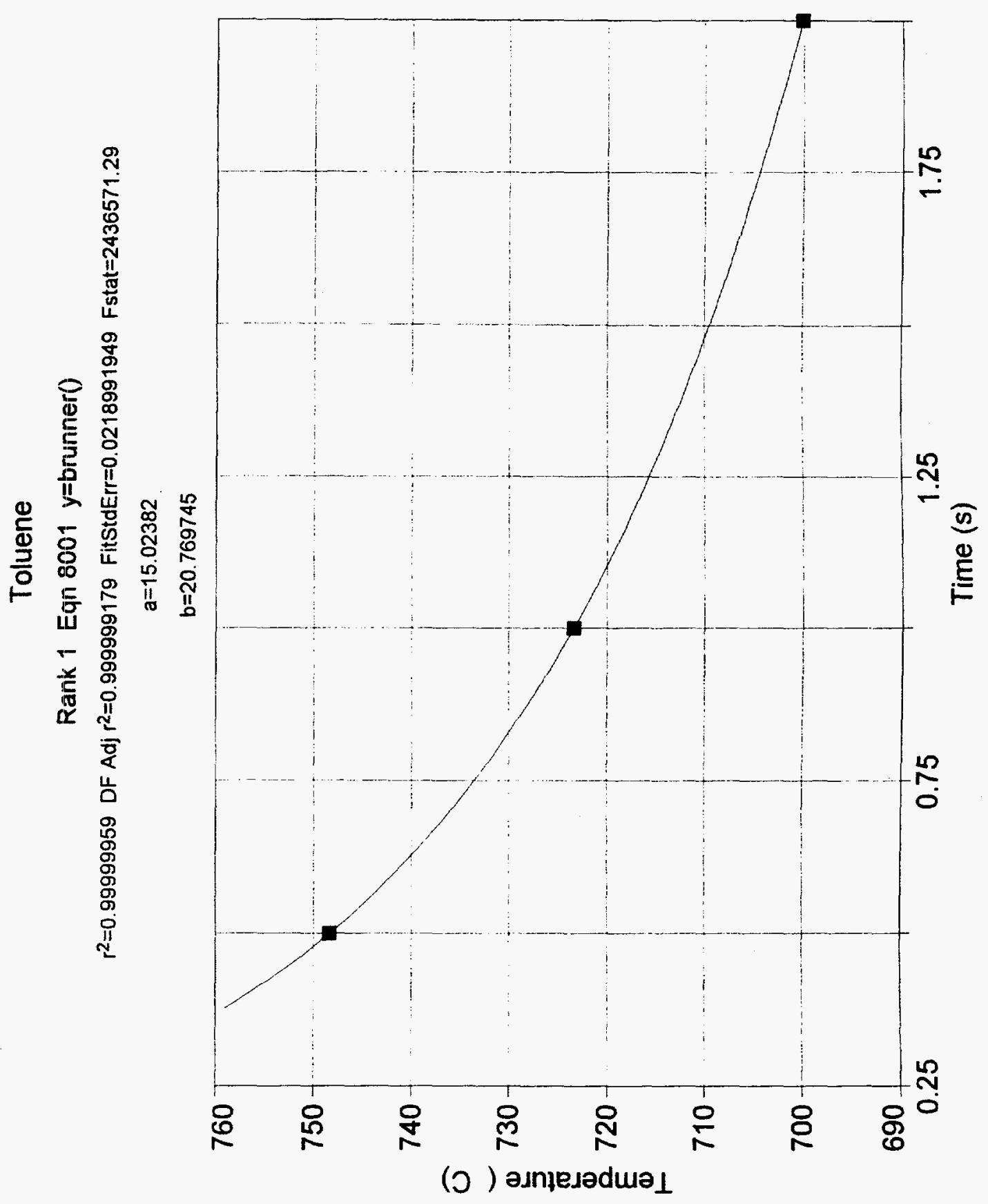




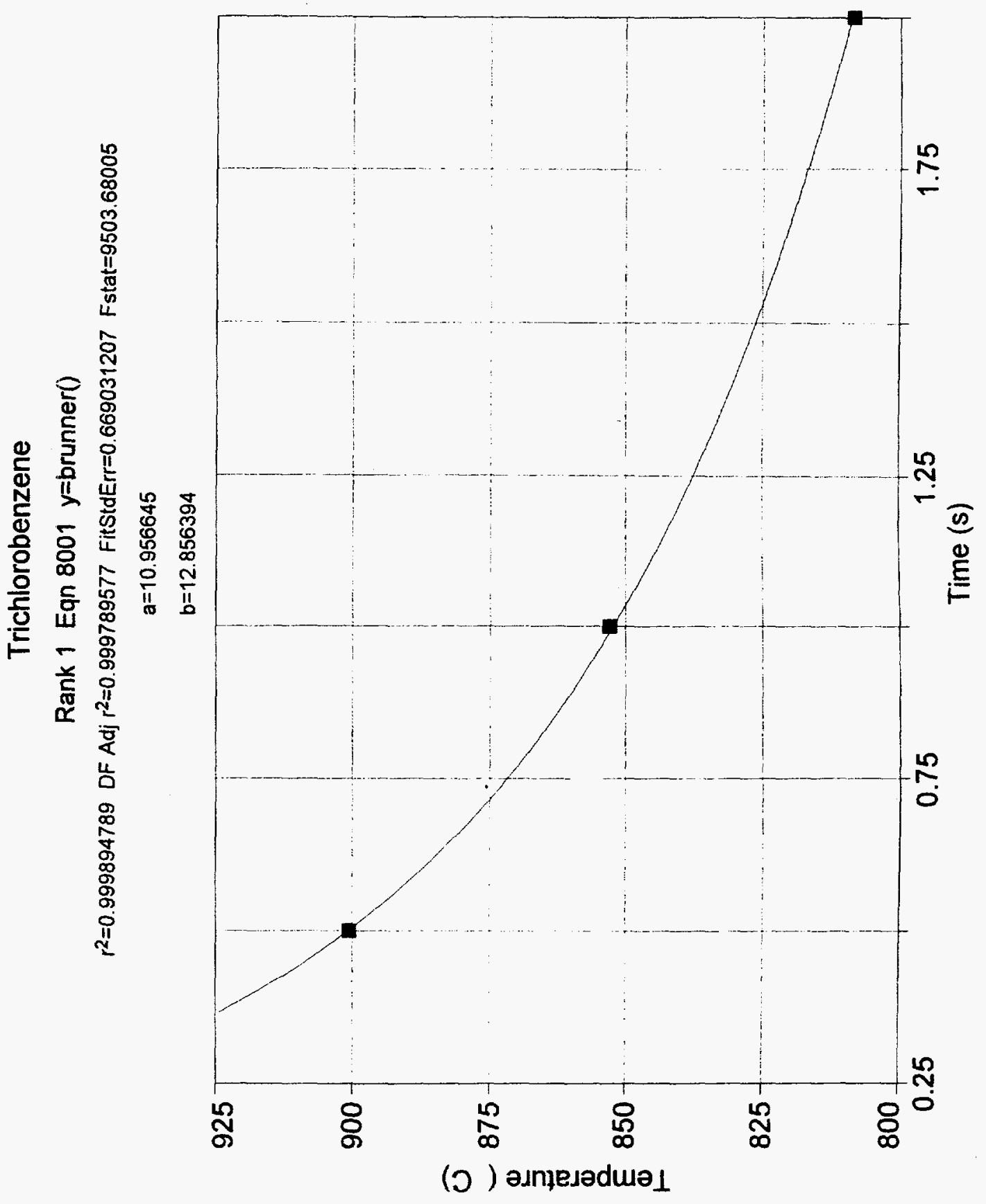




\section{Trichloroethane}

Rank 1 Eqn $8001 y=$ =brunner()

$r^{2}=0.99992223$ DF Adj $r^{2}=0.99984446$ FitStdE $r=0.492080871$ Fstat $=12857.4049$ $a=8.2279056$

$b=12.047898$

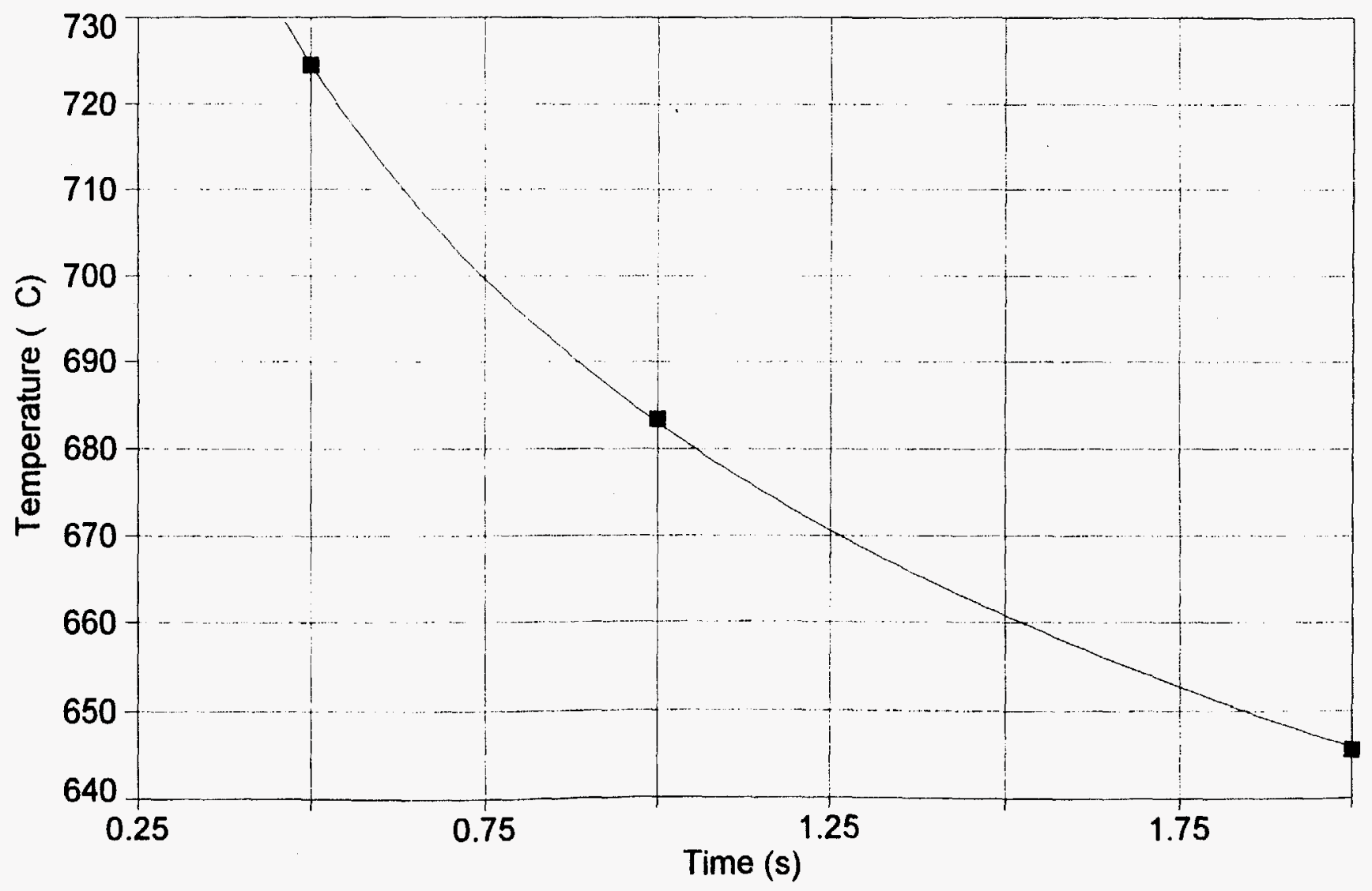




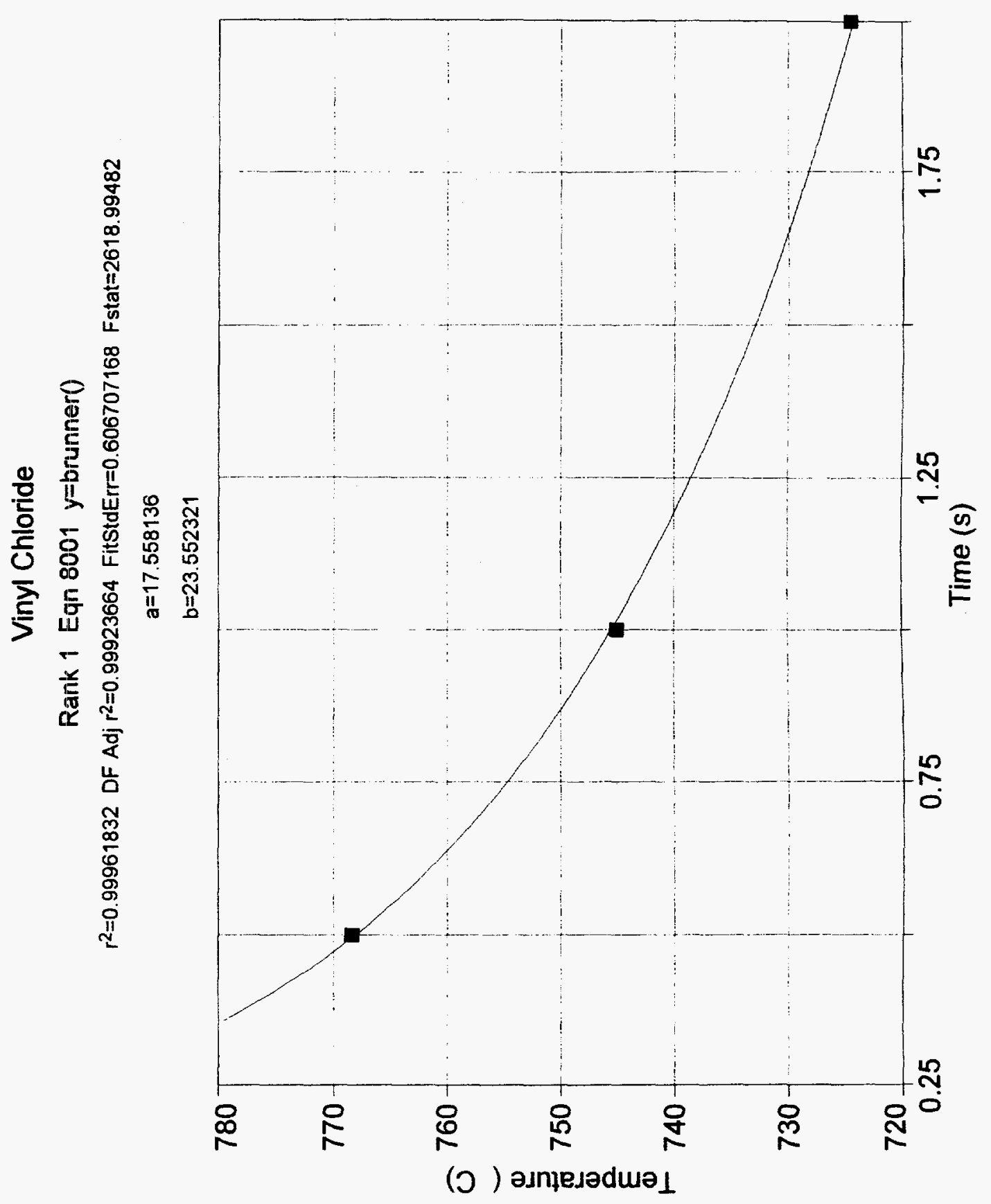




\section{REFERENCES}

Arata, Yoshiaki. (1986). Plasma, Electron, and Laser Beam Technology; Development and Use in Materials Processing. Metals Park OH: American Society for Metals.

Baker Brothers. Electrodialysis for Plating Metal Recovery (Brochure). Stoughton, MA: Systems Engineering and Manufacturing Corporation.

Briggum, Sue M., et. al. (1985). Hazardous Waste Regulations Handbook: A Practical Guide to RCRA and Superfund, Revised Edition. New York: Executive Enterprises Publications Company, Inc.

Brunner, Calvin R. (1993). Hazardous Waste Incineration, 2nd Edition. New York: McGraw - Hill.

Chen, Francis (1984). Introduction to Plasma Physics and Controlled Fusion, Second Edition; Volume 1: Plasma Physics. New York: Plenum.

Cobey, William W., Jr. (1989). 1989 Annual Report on the Generation, Storage, Treatment and Disposal of Hazardous Waste in North Carolina. Raleigh, NC: Department of Environment, Health and Natural Resources.

Cobey, William W., Jr.(1990). 1990 Annual Report on the Generation, Storage, Treatment and Disposal of Hazardous Waste in North Carolina. Raleigh, NC: Department of Environment, Health and Natural Resources.

Dellinger, Barry, et. al. (1984). Determination of the Thermal Decomposition Properties of 20 Selected Hazardous Organic Materials (EPA Report). Jefforson, AR: EPA.

Dorin, Henry. (1987). Chemistry: The Study of Matter. Newton MA: Allyn and Bacon, Inc.

Freeman, H. M., et. al. (1987). Thermal Destruction of Hazardous Waste -- a State-ofthe-Art Review (Journal Article). Cincinnati: EPA.

Guyer, Eric C. (1989). Handbook of Applied Thermal Design. New York: McGraw Hill.

Hall, R. E. , et. al. (1991). Ongoing Fundamental Hazardous Waste Incineration Research at EPA/RTP Facility (EPA Report). Research Triangle Park, NC: EPA.

Hazardous Materials Information Center. (1986). Federal Hazardous Waste Regulations - A User Friendly Text. Middletown, CT: Inter/Face Associates, Inc. 
Howes, Jonathan B. (1991). 1991 Annual Report on the Generation, Storage, Treatment and Disposal of Hazardous Waste in North Carolina. Raleigh, NC: Department of Environment, Health and Natural Resources.

Howes, Jonathan B. (1992). 1992 Annual Report on the Generation. Storage, Treatment and Disposal of Hazardous Waste in North Carolina. Raleigh, NC: Department of Environment, Health and Natural Resources.

Jandel Scientific. (1992). Table Curve Automated Curve Fitting Software. San Rafael, CA: AISN Software.

Lancy Systems. Recovery by Electrodialysis (Brochure). Zelienople, PA: Lancy International, Inc.

Dean, John A., (1985). Lange's Handbook of Chemistry, 13th Edition. New York: McGraw - Hill.

Lee, C. C., and Huffman, George (1989). Environmental Laws Relating to Medical Waste Disposal (EPA Report). Cincinnati: EPA.

Lee, C. C., and Huffman, George (1991). Review of Federal/State Medical Waste Management (EPA Report). Cincinnati: EPA.

Lee, C. C., et. al. (1991). Innovative Thermal Destruction Technologies (EPA Report). Cincinnati: EPA.

Lide, David R. (1990). CRC Handbook of Chemistry and Physics: 71st Edition, 19901991. Boston: CRC Press.

Metal Recovery Technology. Automatic, Electrolytic Metal Recovery from Drag-out or Rinse Solution: MRT 10 and 20 Series (Brochure). Albion, RI: Metal Recovery Technology, Inc.

Palmark, Mogens. (1985). Future Options for Disposal of Hazardous Wastes (Journal Article). Copenhagen V, Denmark: Chemcontrol A/S.

Plasma Energy Corporation (1994). Brochure. Raleigh, NC

Plasma Energy Corporation (1994). Verbal Communication. Raleigh, NC.

Reynolds, W. N. (1968). Physical Properties of Graphite. New York: Elsevier Publishing Co.

Sears, J. W., et. al. (1990). The Plasma Centrifugal Furnace: A Method for Stabilization and Decomposition of Toxic and Radioactive Wastes (Journal Article). Ukiah, CA: Retech, Inc. 
Snyder, R. (1987). Ethel Browning's Toxicity and Metabolism of Industrial Solvents, Second Edition: Volume 1 - Hydrocarbons. New York: Elsevier.

Stephenson, Richard M., and Malanowski. (1987). Handbook of the Thermodynamics of Organic Compounds. New York: Elsevier.

Todreas, Neil E., and Kazimi, Mujid (1990). Nuclear Systems I. New York: Hemisphere.

United States Department of Energy. (1994). Mixed Waste Integrated Program - Technology Summary. Oak Ridge, TN: Office of Scientific and Technical Information.

Wagner, Travis P. (1991) The Complete Guide to Hazardous Waste Regulation, Second Edition. New York: Van Nostrand Reinhold.

West, Robert C., and Astle, Melvin J. (1985). Handbook of Data on Organic Compounds. Boca Raton, FL: CRC Press.

White, Frank M. (1986). Fluid Mechanics, 2nd Edition. New York: McGraw - Hill. 